Distribution Category:

Coal Conversion and Utilization-Coal Science and Analysis (UC-90a)

ANL/FE-83-19

ANL/FE- -83-19

DE84 002682

ARGONNE NATIONAL LABORATORY

9700 South Cass Avenue

Argonne, Illinois 60439

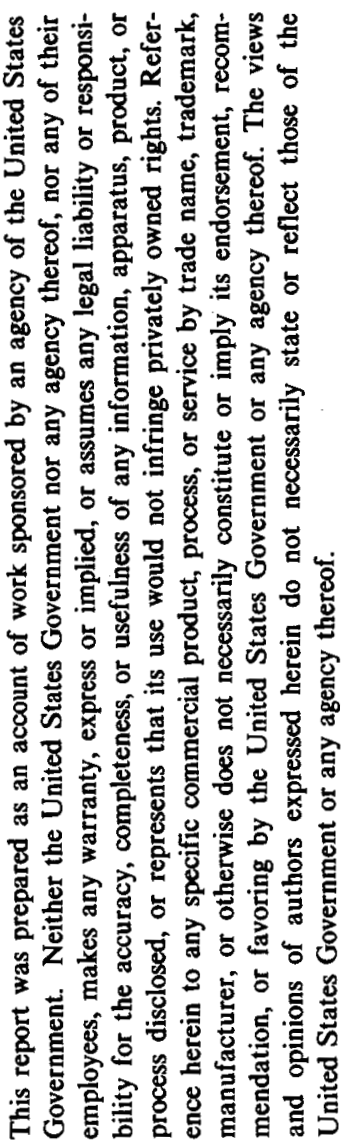

COMPUTER-ASSISTED ANALYSES OF THE THERMODYNAMIC

PROPERTIES OF SLAGS IN COAL-COMBUSTION SYSTEMS

by

Milton Blander and Arthur D. Pelton*

Chemical Technology Division

September 1983

HOTICE

PORTIONS OF THIS REPORT ARE ILLEGIBLE.

It has been reproduced from the best available copy to permit the broadest possible availability.

Department of Metallurgical Engineering, Ecole Polytechnique, University of Montreal, Montreal, Quebec, Canada H3C 3A7 


\section{DISCLAIMER}

This report was prepared as an account of work sponsored by an agency of the United States Government. Neither the United States Government nor any agency Thereof, nor any of their employees, makes any warranty, express or implied, or assumes any legal liability or responsibility for the accuracy, completeness, or usefulness of any information, apparatus, product, or process disclosed, or represents that its use would not infringe privately owned rights. Reference herein to any specific commercial product, process, or service by trade name, trademark, manufacturer, or otherwise does not necessarily constitute or imply its endorsement, recommendation, or favoring by the United States Government or any agency thereof. The views and opinions of authors expressed herein do not necessarily state or reflect those of the United States Government or any agency thereof. 


\section{DISCLAIMER}

Portions of this document may be illegible in electronic image products. Images are produced from the best available original document. 
ABSTRACT ............................ 1

SUMMARY . . . . . . . . . . . . . . . . . . . . . . 1

I. INTRODUCTION ....................... 3

I I. THEORETICAL BACKGROUND . . . . . . . . . . . . . . . . . 4

III. METHODS FOR THE ANALYSIS OF SILICATE SYSTEMS . . . . . . . . . . 11

IV. CALCULATIONS FOR THE BINARY AND TERNARY SYSTEMS

CONTAINING $\mathrm{Na}_{2} \mathrm{O}, \mathrm{CaO}, \mathrm{Al}_{2} \mathrm{O}_{3}$, and $\mathrm{SiO}_{2}$. . . . . . . . . . 21

A. $\mathrm{CaO}_{-} \mathrm{SiO}_{2}$. . . . . . . . . . . . . . . . . . . . 22

1. Data Considered .................. 22

2. Results ....................... 27

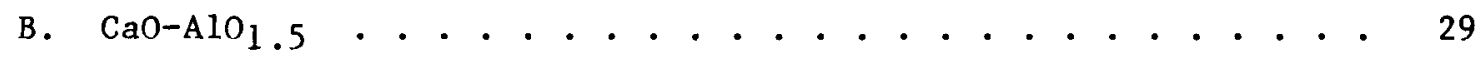

1. Data Considered . . . . . . . . . . . . . . 29

2. Results..................... 32

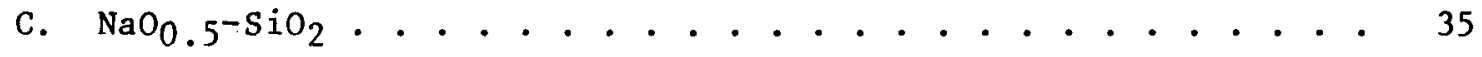

1. Data Considered . . . . . . . . . . . . . 35

2. Results.................. 39

D. $\mathrm{NaO}_{0.5}-\mathrm{AlO}_{1.5}$. . . . . . . . . . . . . . . . 40

1. Data Considered . . . . . . . . . . . . 40

2. Results..................... . 44

E. $\mathrm{AlO}_{1.5} \mathrm{SiO}_{2}$. . . . . . . . . . . . . . . . . 44

1. Data Considered . . . . . . . . . . . . . . . 44

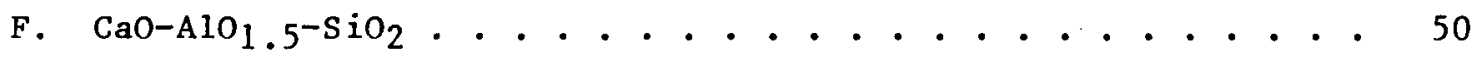

1. Activities .................... 50

2. Free Energy of Formation of Ternary Compounds ...... 51

3. Results... . . . . . . . . . . . . . . 52

G. $\mathrm{NaO}_{0} \mathrm{5}^{-\mathrm{CaO}-\mathrm{SiO}_{2}}$. . . . . . . . . . . . . . . 56

H. $\mathrm{NaO}_{0.5}-\mathrm{AlO}_{1.5} \mathrm{SiO}_{2}$. . . . . . . . . . . . . . 58

V. THE QUATERNARY SYSTEM $\left(\mathrm{Na}_{2} \mathrm{O}-\mathrm{CaO}-\mathrm{Al}_{2} \mathrm{O}_{3}-\mathrm{SiO}_{2}\right) . . . . . . . . . .63$

VI. DISCUSSION AND CONCLUSIONS . . . . . . . . . . . . . . 66

ACKNOWLEDGMENTS . . . . . . . . . . . . . . . . . . 67

REFERENCES . . . . . . . . . . . . . . . . . . . . . 68 


\section{LIST OF FIGURES}

No.

$\underline{\text { Title }}$

1. Experimental Molar Enthalpies of Mixing in the LiF-BeF 2 and $\mathrm{KF}-\mathrm{BeF}_{2}$ Systems Compared with Values Calculated Assuming Complete Bridge-Breaking

2. Experimental Molar Enthalpies of Mixing in the LiCl- $\mathrm{ZnCl}_{2}$ and $\mathrm{CsCl}_{-2 n C l}$ Systems Compared with Values Calculated As suming Complete Bridge-Breaking . . . . . . . . . . . . 8

3. Experimental Molar Enthalpies of Mixing in the $\mathrm{PbO}^{-\mathrm{SiO}_{2}}$ System Compared with Calculations Based on the Lin-Pelton Mode 1

4. Entropy of Mixing for $\mathrm{MO}^{-\mathrm{SiO}_{2}}$ Systems (where MO $=\mathrm{FeO}$, $\mathrm{MgO}$, or $\mathrm{CaO}$ ) Compared with Those Calculated from the Lin-Pelton Model and from Complete Bridge-Breaking .

5. Partial Molar Entropies of Mixing of $\mathrm{KF}$ in the $\mathrm{KF}-\mathrm{BeF}_{2}$ System and of $\mathrm{CsCl}$ in the $\mathrm{CsCl}^{-\mathrm{ZnCl}_{2}}$ System Compared with Those for Ideal Solutions and for the Case of Complete Bridge-Breaking

6. Measured Phase Diagram in the $\mathrm{CaO}-\mathrm{SiO}_{2}$ System from Phillips and Muan22.....................

7. Measured Phase Diagram in the $\mathrm{CaO}-\mathrm{SiO}_{2}$ System from Revised Version in Gutt 23

8. Measured Phase Diagram in the $\mathrm{CaO}-\mathrm{SiO}_{2}$ System, with Miscibility Gap Measured by 01 'shanskii24 . . . . . . . . . . . 24

9. Miscibility Gap for ${\mathrm{CaO}-\mathrm{SiO}_{2}}_{2}$. . . . . . . . . . . . . . . 24

10. Measured Activities of CaO, Relative to Solid as Standard State, in the $\mathrm{CaO}-\mathrm{SiO}_{2}$ System at 1500 and $1550^{\circ} \mathrm{C}$. . . . . . .

11. Activities of $\mathrm{CaO}$ and $\mathrm{SiO}_{2}$ in $\mathrm{CaO}^{-\mathrm{SiO}_{2}}$ at 1500,1550 , and $1600^{\circ} \mathrm{C}$. . . . . . . . . . . . . . . . . . . .

12. A Comparison of Silica Activities in the CaO-SiO 2 Binary System Calculated from Calcia Activities Measured by Different Workers . . . . . . . . . . . . . . . .

13. Phase Diagram for the $\mathrm{CaO}-\mathrm{SiO}_{2}$ System Calculated from the Model Using Values of W Given by Eq. 56 . . . . . . . . . . . .

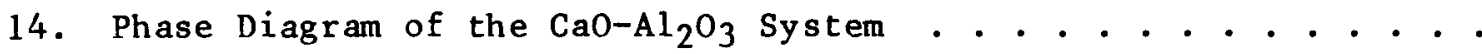


15. Activities in $\mathrm{CaO}-\mathrm{Al}_{2} \mathrm{O}_{3}$ Melts at $2060 \mathrm{~K}$ with Solids as Standard States............... . . . 30

16. Activities of $\mathrm{CaO}$ and $\mathrm{Al}_{2} \mathrm{O}_{3}$ in $\mathrm{CaO}-\mathrm{Al}_{2} \mathrm{O}_{3}$ Melts at $1500^{\circ} \mathrm{C}$ Relative to Solid as Standard State.......... 31

17. Calculated and Measured Phase Diagram for the $\mathrm{CaO}-\mathrm{AlO}_{1.5}$ System . . . . . . . . . . . . . . . . . . 33

18. Phase Diagram for the $\mathrm{CaO}-\mathrm{Al}_{2} \mathrm{O}_{3}$ System Calculated Using the Free Energies of Formation of the Compounds Given in Ref. 33 . . . . . . . . . . . . . . . 34

19. Phase Diagram of the $\mathrm{NaO}_{0} .5-\mathrm{SiO}_{2}$ System from Refs. 20,

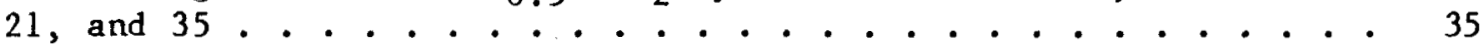

20. Phase Diagram of the $\mathrm{NaO}_{0.5}-\mathrm{SiO}_{2}$ System from Refs. 20

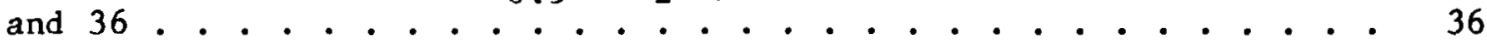

21. Phase Diagram of the $\mathrm{NaO}_{0} . \mathrm{S}^{-\mathrm{SiO}_{2}}$ System from Ref. $35 . . . . . .36$

22. Activities of $\mathrm{Na}_{2} \mathrm{O}$ as a Function of Temperature in the $\mathrm{Na}_{2} \mathrm{O}-\mathrm{SiO}_{2}$ System . . . . . . . . . . . . . . . . . . 37

23. Comparison of Different Measurements of the Activities of $\mathrm{Na}_{2} \mathrm{O}$ in the $\mathrm{Na}_{2} \mathrm{O}-\mathrm{SiO}_{2}$ system at $1200^{\circ} \mathrm{C} . . . . . . . . . . .38$

24. Calculated Phase Diagram in the $\mathrm{NaO}_{0.5}-\mathrm{SiO}_{2}$ System . . . . . . 41

25. Phase Diagram in the $\mathrm{NaAlO}_{2}-\mathrm{Al}_{2} \mathrm{O}_{3}$ System from Refs. 20 and 37

26. Phase Diagram in the $\mathrm{NaO}_{0.5}-\mathrm{AlO}_{1.5}$ System from Refs.

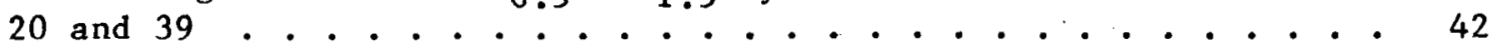

27. Phase Diagram in the $\mathrm{NaO}_{0.5}-\mathrm{AlO}_{1.5}$ System from Ref.40 . . . . . 43

28. Phase Diagram in the $\mathrm{AlO}_{1} .5-\mathrm{SiO}_{2}$ System from Ref. 44 . . . . . . 45

29. Phase Diagram in the $\mathrm{AlO}_{1.5}-\mathrm{SiO}_{2}$ System from Ref. $45 . . . . . .445$

30. Phase Diagram in the $\mathrm{AlO}_{1.5} \mathrm{SiO}_{2}$ System from Ref. $46 . . . . . .46$

31. Phase Diagram in the $\mathrm{AlO}_{1.5}-\mathrm{SiO}_{2}$ System from Ref. 42 . . . . . 46

32. Phase Diagram in the $\mathrm{AlO}_{1.5}-\mathrm{SiO}_{2}$ System from Ref. $43 . . . . . .47$

33. Activities of $\mathrm{SiO}_{2}$ in $\mathrm{SiO}_{2}-\mathrm{Al}_{2} \mathrm{O}_{3} \mathrm{-CaO}$ slags at $1600^{\circ} \mathrm{C}$. . . . . 48 
34. Activities in $\mathrm{SiO}_{2}-\mathrm{Al}_{2} \mathrm{O}_{3}-\mathrm{CaO}$ Slags at $1600^{\circ} \mathrm{C}$

Using the Gibbs-Duhem Equation and Our Model . . . . . . . . . 48

35. Activities of $\mathrm{SiO}_{2}-\mathrm{Al}_{2} \mathrm{O}_{3}-\mathrm{CaO}$ slags at $1450^{\circ} \mathrm{C} . . . . . . .49$

36. Activities of $\mathrm{SiO}_{2}$ in $\mathrm{SiO}_{2}-\mathrm{Al}_{2} \mathrm{O}_{3}-\mathrm{CaO} \mathrm{Slags}$ at $1500^{\circ} \mathrm{C}$. . . . . . . . . . . . . . . . .

37. Activities of $\mathrm{SiO}_{2}$ in $\mathrm{SiO}_{2}-\mathrm{Al}_{2} \mathrm{O}_{3}-\mathrm{CaO}$ slags at $1600^{\circ} \mathrm{C}$. . . . . . . . . . . . . . . . . 50

38. Activities of $\mathrm{CaO}$ in $\mathrm{SiO}_{2}-\mathrm{Al}_{2} \mathrm{O}_{3}-\mathrm{CaO}$ slags at $1500^{\circ} \mathrm{C}$..... 51

39. Calculated Values of Activities in $\mathrm{SiO}_{2}-\mathrm{Al}_{2} \mathrm{O}_{3}-\mathrm{CaO}$ Slags at $1600^{\circ} \mathrm{C}$, with $\mathrm{S}_{\mathrm{SiO}}$ Superimposed on $\mathrm{Fig.} 33$......... 53

40. Calculated Values of Activities in $\mathrm{SiO}_{2}-\mathrm{Al}_{2} \mathrm{O}_{3}-\mathrm{CaO} \mathrm{Slags}$ at $1600^{\circ} \mathrm{C}$, with $\mathrm{a}_{\mathrm{SiO}_{2}}$ Superimposed on Fig. 37 . . . . . . . 54

41. Calculated Values of Activities in $\mathrm{SiO}_{2}-\mathrm{Al}_{2} \mathrm{O}_{3}-\mathrm{CaO} \mathrm{Slags}$ at $1500^{\circ} \mathrm{C}$, with $\mathrm{SSiO}_{2}$ Superimposed on $\mathrm{Fig} .36$. . . . . . . . 54

42. Calculated Values of Activities in $\mathrm{SiO}_{2}-\mathrm{Al}_{2} \mathrm{O}_{3}-\mathrm{CaO}$ Slags at $1600^{\circ} \mathrm{C}$, with $\mathrm{a}_{\mathrm{AlO}} \mathrm{O}_{1,5}$ Superimposed on the Results of

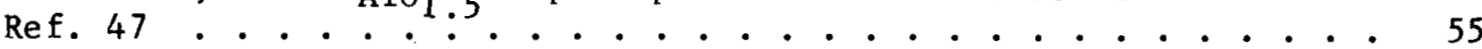

43. Calculated Values of Activities in $\mathrm{SiO}_{2}-\mathrm{Al}_{2} \mathrm{O}_{3}-\mathrm{CaO} \mathrm{Slags}$ at $1600^{\circ} \mathrm{C}$, with $\mathrm{a}_{\mathrm{CaO}}$ Superimposed on Fig. 34 .........

44. Calculated Values of Activities in $\mathrm{SiO}_{2}-\mathrm{Al}_{2} \mathrm{O}_{3}-\mathrm{CaO} \mathrm{Slags}$ at $1500^{\circ} \mathrm{C}$, with $\mathrm{a}_{\mathrm{CaO}}$ Superimposed on Fig. 38 . . . . . . . 56

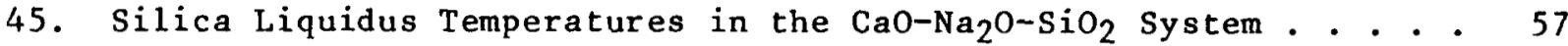

46. Values of $\log _{10} \mathrm{a}_{\mathrm{Na}} \mathrm{O}$ as a Function of Composition in the $\mathrm{Na}_{2} \mathrm{O}-\mathrm{CaO}-\mathrm{SiO}_{2}$ System . . . . . . . . . . . . . . . . . . 58

47. Measured Values of $\log _{10} a_{\mathrm{Na}_{2} \mathrm{O}}$ in the $\mathrm{Na}_{2} \mathrm{O}-\mathrm{Al}_{2} \mathrm{O}_{3}-\mathrm{SiO}_{2}$ System....................

48. Calculated Values of $\log _{10} \mathrm{a}_{\mathrm{SiO}_{2}}$ in the $\mathrm{Na}_{2} \mathrm{O}-\mathrm{Al}_{2} \mathrm{O}_{3}-\mathrm{SiO}_{2}$ System . . . . . . . . . . . . . . . . . .

49. Calculated Values of $\log _{10} \mathrm{a}_{\mathrm{Al}_{2} \mathrm{O}_{3}}$ in the $\mathrm{Na}_{2} \mathrm{O}-\mathrm{Al}_{2} \mathrm{O}_{3}-\mathrm{SiO}_{2}$ System . . . . . . . . . . . . . . . . . . . . 62 


\section{LIST OF FIGURES (contd)}

No.

50. Values of $\log _{10} a_{\mathrm{Na}} \mathrm{O}$ Calculated from the Model and $\mathrm{Plot}$ ted as a Function of $\mathrm{X}_{\mathrm{NaO}} \mathrm{O}_{5.5}$ for $\left(\mathrm{X}_{\mathrm{CaO}} / \mathrm{X}_{\mathrm{Al}} 0_{1.5}\right)$

$=1$ at Several values of $\mathrm{x}_{\mathrm{SiO}_{2}} /\left(\mathrm{x}_{\mathrm{SiO}_{2}}+\mathrm{x}_{\mathrm{AlO} 0_{1.5}}+\mathrm{x}_{\mathrm{CaO}}\right)$ in the Quaternary System, $\mathrm{Na}_{2} \mathrm{O}-\mathrm{CaO}-\mathrm{Al}_{2} \mathrm{O}_{3}-\mathrm{SiO}_{2}$. . . . . . . . . 64

51. Values of $\log _{10} \mathrm{a}_{\mathrm{Na}} \mathrm{O}$ Calculated from the Model and Plotted as a Function of $\mathrm{x}_{\mathrm{CaO}} /\left(\mathrm{x}_{\mathrm{AlO} 0_{1.5}}+\mathrm{X}_{\mathrm{CaO}}\right)$ for $\mathrm{X}_{\mathrm{NaO}_{0.5}}=$ 0.02 at Several values of $\mathrm{x}_{\mathrm{SiO}_{2}} /\left(\mathrm{x}_{\mathrm{SiO}_{2}}+\mathrm{x}_{\mathrm{A} 10_{1.5}}+\mathrm{x}_{\mathrm{CaO}}\right)$ in the Quaternary System, $\mathrm{Na}_{2} \mathrm{O}-\mathrm{CaO}-\mathrm{Al}_{2} \mathrm{O}_{3}-\mathrm{SiO}_{2}$...........

\section{LIST OF TABLES}

No.

1. Free Energies of Formation of Solid Compounds from the Solid oxides... . . . . . . . . . . . . . . . 31

2. Free Energies of Mixing in the Binary CaO-AlO1.5. . . . . . 32

3. Activities and Partial Molar Excess Free Energies of Mixing of $\mathrm{CaO}$ in the $\mathrm{CaO}-\mathrm{Al}_{2} \mathrm{O}_{3}$ System at $1773 \mathrm{~K}$. . . . . . . . 34 


\title{
COMPUTER-ASSISTED ANALYSES OF THE THERMODYNAMIC PROPERTIES OF SLAGS IN COAL COMBUSTION SYSTEMS
}

\author{
by
}

Milton Blander and Arthur D. Pelton

\author{
ABSTRACT
}

\begin{abstract}
Equations were developed for the analysis of the thermodynamic properties of molten silicate solutions; the equations take into account the unusual concentration and temperature dependence of the solution properties of ordered systems. For binary systems, these equations were coupled with an optimization computer program to analyze all reliable thermodynamic data, including phase diagrams, free energies and enthalpies of formation of compounds, activities of components, enthalpies of mixing, entropies of fusion, miscibility gaps, etc. In this manner, we analyzed data for five binary systems: $\mathrm{CaO}-\mathrm{SiO}_{2}, \mathrm{Na}_{2} \mathrm{O}-\mathrm{SiO}_{2}, \mathrm{CaO}-\mathrm{Al}_{2} \mathrm{O}_{3}, \mathrm{Na}_{2} \mathrm{O}-\mathrm{Al}_{2} \mathrm{O}_{3}$, and $\mathrm{Al}_{2} \mathrm{O}_{3}-\mathrm{SiO}_{2}$. The results of the binary systems were combined, and an analys is done of three ternary systems: $\mathrm{CaO}_{-} \mathrm{Al}_{2} \mathrm{O}_{3}-\mathrm{SiO}_{2}, \mathrm{Na}_{2} \mathrm{O}-\mathrm{CaO}-\mathrm{SiO}_{2}$, and $\mathrm{Na}_{2} \mathrm{O}-\mathrm{Al}_{2} \mathrm{O}_{3}-\mathrm{SiO}_{2}$. A tentative analysis of the quaternary system, $\mathrm{Na}_{2} \mathrm{O}-\mathrm{CaO}-\mathrm{Al}_{2} \mathrm{O}_{3}-\mathrm{SiO}_{2}$, was also undertaken.
\end{abstract}

\section{SUMMARY}

This report covers work completed as of the end of the fiscal year 1982 .

The volatility of alkali metals in coal combustion leads to the phenomenon of hot corrosion. To understand the volatility of alkali metals in coal combustion systems more fully, we performed an analysis of the thermodynamic properties of silicate melts containing the major constituents present in coal slags. The aim was to develop a set of equations which can be used to analyze all available thermodynamic data on a molten silicate system (e.g., phase diagrams, free energies of formation of compounds, activities of components, enthalpies of mixing, miscibility gaps, etc.); from this analysis, a small set of parameters can be derived to reliably predict the volatilities of alkali metals under defined conditions. Because of the known complexity of the solution thermodynamics of ordered solutions such as molten silicates, a new method of describing the solution properties was developed.

It is shown that standard methods for describing solution behavior are inadequate for ordered solutions such as silicates. A rationale is given for the use of an ad hoc modification of the quasi-chemical theory. A description is given of the quasi-chemical theory and the modifications necessary for its use in representing the thermodynamic properties of binary molten silicates. Two methods are described for combining results for the binary systems in order to represent ternary systems. An optimization procedure which permits 
one to simultaneously analyze different kinds of data for molten binary silicate systems (e.g., activities, liquidus data, miscibility gaps, free energies of formation of compounds, melting points, enthalpies of mixing, etc.) is described.

Optimized analyses of five binary systems ( $\mathrm{CaO}-\mathrm{SiO}_{2}, \mathrm{CaO}-\mathrm{AlO}_{1}, 5, \mathrm{Na}_{2} \mathrm{O}-$ $\mathrm{SiO}_{2}, \mathrm{Na}_{2} \mathrm{O}-\mathrm{AlO}_{1} .5$, and $\mathrm{AlO}_{1} .5-\mathrm{SiO}_{2}$ ) are presented. With our equations, the largest number of parameters needed to describe properties of the liquid solutions was five. The results for the binary systems were combined, and in al 1 but one case a ternary excess term was added to obtain a good representa-

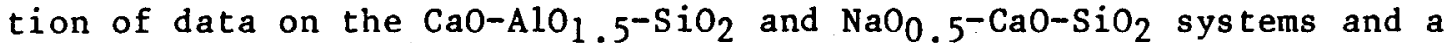
reasonable representation of data for the $\mathrm{NaO}_{0.5}-\mathrm{AlO}_{1} .5^{-\mathrm{SiO}_{2}}$ system.

A method of representing the quaternary system, $\mathrm{Na}_{2} \mathrm{O}-\mathrm{CaO}-\mathrm{AlO}_{1} .5^{-\mathrm{SiO}_{2}}$, is given. Since no data were available, a prediction of activities of $\mathrm{Na}_{2} \mathrm{O}$ in this quaternary is given based on well-defined assumptions. Our results can be used to predict the volatilization of $\mathrm{Na}_{2} \mathrm{O}$ from this quaternary mixture. A small number of reliable, self-consistent measurements for the activities of $\mathrm{Na}_{2} \mathrm{O}$ in the quaternary should permit one to improve greatly the reliability of these calculations. 


\section{INTRODUCTION}

In the burning of coal, alkali metals such as $\mathrm{Na}$ and $\mathrm{K}$ are volatilized, and they generally will condense later as sulfates on heat exchangers (or turbines in a direct cycle system). Corrosion by thin films of such sulfate deposits is a major problem for new technologies such as a direct cycle system, and control of alkali volatilization is necessary in order to minimize corrosion. One method of control is to alter the chemistry of the silicate slag phase in coal so that the volatility of alkalis is reduced. In order to do this effectively, one needs to have a knowledge of the thermodynamic properties of slag phases and, particularly, the activities of alkali oxides in them as a function of composition and temperature.

Silica-based slag systems are a difficult class of materials for thermodynamic analyses. They are often highly ordered liquids, and a single binary system may have both positive and negative deviations from ideal solution behavior. The complexity of their structures precludes a simple description of their properties, and statistical mechanical theories of even binary silicate solutions ${ }^{1-5}$ do not have mathematical forms which are convenient for computer-assisted analyses. These difficulties are compounded when cne attempts to analyze multicomponent slag systems; to our knowledge, no totally satisfactory, self-consistent analysis which incorporates all known data in a physically meaningful way exists for a system as ordered and as complex as silicates. The most complex systems studied to date are the cryolite-based (fluoride) slag systems for which the influence of ordering on the thermodynamic properties is not as extreme as for silicates.

In this report, we discuss our approach to the difficult problems inherent in thermodynamic analyses of silicate slag systems and illustrate the methods we have developed in the analyses of (1) the binary systems $\mathrm{CaO}-\mathrm{SiO}_{2}$, $\mathrm{CaO}-\mathrm{Al}_{2} \mathrm{O}_{3}, \mathrm{Al}_{2} \mathrm{O}_{3}-\mathrm{SiO}_{2}, \mathrm{Na}_{2} \mathrm{O}-\mathrm{Al}_{2} \mathrm{O}_{3}$, and $\mathrm{Na}_{2} \mathrm{O}-\mathrm{SiO}_{2}$, (2) the ternary systems $\mathrm{CaO}-\mathrm{Al}_{2} \mathrm{O}_{3}-\mathrm{SiO}_{2}, \mathrm{Na}_{2} \mathrm{O}-\mathrm{CaO}-\mathrm{SiO}_{2}$, and $\mathrm{Na}_{2} \mathrm{O}-\mathrm{Al}_{2} \mathrm{O}_{3}-\mathrm{SiO}_{2}$, and (3) the quaternary $\mathrm{Na}_{2} \mathrm{O}-\mathrm{CaO}-\mathrm{Al}_{2} \mathrm{O}_{3}-\mathrm{SiO}_{2}$. Our approach appears to be promising for such systems and should greatly improve our ability to provide an accurate representation of the thermodynamic properties of slag systems.

The organization of this report is as follows--in section II, we discuss the theoretical background for the analysis of the thermodynamic properties, define terms, and discuss the basis for prior attempts to represent the the rmodynamic properties of silicates. In section III, we discuss our methods for analysis of silicate systems. Our analyses of silicate systems are given in sections IV and $V$, and our conclusions are presented in section VI. 


\section{THEORETICAL BACKGROUND}

Theoretical discussions of solutions all start with the definition of a hypothetical ideal solution. If we restrict our considerations to simple oxides as components (e.g., $\mathrm{SiO}_{2}, \mathrm{MgO}$, etc.), the simplest ideal solution is one in which all cations are considered to be independent species. The Gibbs free energy of mixing of $\mathrm{n}$ liquid components, $\Delta \mathrm{G}_{\mathrm{m}}^{\mathrm{id}}$, would then be given by 6,7

$$
\left(\Delta G_{m}^{i d} / R T\right)=\sum_{i=i}^{n} x_{i} \ln x_{i}
$$

where $X_{i}$ is the ion fraction of the cation of the $i^{\prime}$ th component given by

$$
x_{i}=\frac{n_{i}}{\sum n_{i}}
$$

where $n_{i}$ is the number of moles of the $i$ 'th cation (and the number of moles of the $i$ 'th component). In this formulation, a mole of a component contains one mole of cations so that, for example, alumina is $\mathrm{AlO}_{1.5}$ and sodium oxide is $\mathrm{NaO}_{0.5}$. The ideal chemical potential of a component, $\mu_{i}^{i d}$, is then given by

$$
\mu_{i}^{i d}=\mu_{i}^{\circ}+R T \ln X_{i}
$$

where $\mu_{i}^{o}$ is the chemical potential of the pure component. The advantage of this Temkin 6,7 definition of ideality lies in its consistency with the limiting laws and with the absence of infinities in the deviations of the chemical potentials from ideality as one approaches infinite dilution. Without this property, it would not be possible to use a single representation of the the rmodynamic properties of a component over a wide range of compositions.

There is yet another definition of ideality which can be useful for silicate melts. 8 If one has a binary system such as $\mathrm{CaO}$ and $\mathrm{SiO}_{2}$, then in basic compositions $\left(\mathrm{XSiO}_{2}<0.33\right)$ one might consider the melt as consisting of a mixture of the ions $\mathrm{Ca}^{2+}, \mathrm{O}^{2-}$, and $\mathrm{SiO}_{4}^{4-}$. In this case, one would have two components, $\mathrm{CaO}$ (component 1) and $\mathrm{SiO}_{2}$ (component 2), which react to form the pseudocomponent $\mathrm{Ca}_{2} \mathrm{SiO}_{4}$. The Gibbs free energy of mixing of an ideal mixture of $\mathrm{CaO}$ and $\mathrm{Ca}_{2} \mathrm{SiO}_{4}, \Delta G_{m}$, is given by

$$
\left(\Delta G_{m} / R T\right)=X_{0} \ln X_{0}+X_{S i O_{4}} \ln X_{S_{i O}}
$$

and the ideal chemical potentials of $\mathrm{CaO}$ and $\mathrm{Ca}_{2} \mathrm{SiO}_{4}$ are given by

$$
\begin{gathered}
\mu_{\mathrm{CaO}}=\mu_{\mathrm{CaO}}^{\circ}+\mathrm{RT} \ln \mathrm{X}_{0} \\
{ }^{\mu} \mathrm{Ca}_{2} \mathrm{SiO}_{4}=\mu_{\mathrm{Ca}}^{\circ} \mathrm{SiO}_{4}+\mathrm{RT} \ln \mathrm{X}_{\mathrm{SiO}_{4}}
\end{gathered}
$$


where $\mathrm{X}_{0}$ and $\mathrm{X}_{\mathrm{SiO}_{4}}$ are the anion fractions of these species. In terms of the mole fractions of the components $\mathrm{CaO}$ (component 1) and $\mathrm{SiO}_{2}$ (component 2), $\mathrm{x}_{0}$ is given by the expression

$$
\begin{aligned}
x_{0} & =\frac{x_{1}-2 x_{2}}{x_{1}-x_{2}} \\
& =1-x_{S_{i O}}
\end{aligned}
$$

Such a formulation encounters problems as one approaches values of $x_{2}=1 / 3$, since the activity of component 1 then approaches zero. This is never true in real systems. There have been several ingenious attempts to circumvent this difficulty by considering that the $\mathrm{SiO}_{4}^{4-}$ ions partly dissociate according to the equilibria

$$
\mathrm{mSiO}_{4}^{4-} \rightleftharpoons \mathrm{Si}_{\mathrm{m}} \mathrm{O}_{2 \mathrm{~m}+2}^{4-}+2(\mathrm{~m}-1) 0^{2-}
$$

In some cases, this type of formulation has been incorporated into models of silicate solutions.1-5 Although such models appear to be conceptually attractive, they generally are not mathematically simple. In addition, many of these models explicitly or implicitly assume that the various silicate pseudocomponents, $\mathrm{Ca}_{2} \mathrm{Si}_{\mathrm{m}} \mathrm{O}_{2 \mathrm{~m}+2}$, mix ideally with $\mathrm{CaO}$. Often, this does not provide good representations of data, and corrections for nonideality need to be added. The reason for employing such formulations for an accurate analysis is that such corrections are much smaller than the nonideal terms one needs if one starts with Eq. 1 .

Real systems are generally not ideal, and the activity of a component $i\left(a_{i}\right)$ is defined so that the real chemical potential, $\mu_{i}$, is given by the expression

$$
\begin{aligned}
\mu_{i} & =\mu_{i}^{o}+R T \ln a_{i} \\
& =\mu_{i}^{i d}+R T \ln \gamma_{i}
\end{aligned}
$$

where $\gamma_{i}\left(=a_{i} / N_{i}\right)$ is an activity coefficient and $R T$ ln $\gamma_{i}$ is a partial molar excess free energy, $G_{i}^{E}$, or an excess chemical potential, $\mu_{i}^{E}$. The Gibbs molar free energy of mixing is given by

$$
\begin{aligned}
\Delta G_{m} / R T & =\Sigma X_{i} \ln a_{i} \\
& =\left(\Delta G_{m}^{i d} / R T\right)+\Sigma X_{i} \ln \gamma_{i} \\
& =\left(\Delta G_{m}^{i d}+G_{m}^{E}\right) / R T
\end{aligned}
$$


The term $G^{E}$ is the molar excess free energy of mixing. Both $G^{E}$ and $\mu_{i}^{E}$ are merely ${ }^{\mathrm{m}}$ convenient forms to represent deviations from ideal ${ }^{\mathrm{m}}$ solution behavior and are generally the quantities calculated from theories of solution. Knowledge of these quantities as a function of temperature and composition defines the solution behavior of a system. In addition, there are excess entropies, $\mathrm{S}^{\mathrm{E}}$, and (excess) enthalpies, $\mathrm{H}^{\mathrm{E}}$, of solution. Since the ideal enthalpy of mixing, $\Delta \mathrm{H}_{\mathrm{m}}^{\mathrm{id}}$, is zero, the enthalpy of mixing, $\Delta \mathrm{H}_{\mathrm{m}}$, is also the excess enthalpy of mixing, $\mathrm{H}_{\mathrm{m}}^{\mathrm{E}}$. Thus,

$$
\left(\mathrm{dG}_{\mathrm{m}}^{\mathrm{E}} / \mathrm{dT}\right)=-\mathrm{s}_{\mathrm{m}}^{\mathrm{E}}, \mathrm{d}\left(\mathrm{G}_{\mathrm{m}}^{\mathrm{E}} / \mathrm{T}\right) / \mathrm{d}(1 / \mathrm{T})=\Delta \mathrm{H}_{\mathrm{m}}
$$

and

$$
\left(d \mu_{i}^{E} / d T\right)=-s_{i}^{E}, d\left(\mu_{i}^{E} / T\right) / d(1 / T)=H_{i}^{E}
$$

where $s_{i}^{E}=\bar{S}_{i}-s_{i}^{o}-R$ ln $N_{i}$ and $H_{i}^{E}=\bar{H}_{i}-H_{i}^{o}$. For ordered solutions, these quantities do not have a simple dependence upon concentration or temperature. This places important constraints on our approach to the analysis of silicate slags.

The conventional representation of excess free energies of mixing is done with a power series

$$
\mathrm{G}_{\mathrm{m}}^{\mathrm{E}}=\sum \mathrm{a}(\mathrm{i}, \mathrm{j}, \mathrm{m}, \mathrm{n}) \mathrm{x}_{i}^{\mathrm{m}} \mathrm{x}_{j}^{\mathrm{n}}+\sum \mathrm{b}(\mathrm{i}, \mathrm{j}, \mathrm{k}, \mathrm{m}, \mathrm{n}, \mathrm{p}) \mathrm{x}_{i}^{\mathrm{m}} \mathrm{x}_{j}^{\mathrm{n}} \mathrm{x}_{\mathrm{k}}^{\mathrm{p}}+\cdots
$$

where the summations are multiple summations over the appropriate variables $i, j, k, m, n, p$, etc. An analogous power series for $\mu_{i}^{E}$ can be derived from Eq. 12. For ordinary solutions, only a relatively small number of terms in such power series are needed to provide a useful representation of thermodynamic properties. In some cases statistical mechanical expressions exist which relate some of the higher order terms to each other. ${ }^{9}$ However, for silicate systems, it is not this simple.

The influence of ordering and structure leads to solution behavior so complex that an extremely large number of terms and parameters are needed to represent the known thermodynamic properties using Eq. 12.10 Because (1) one generally does not have much data on solutions, (2) the data are of ten not highly accurate, and (3) there are a large number of parameters, the use of Eq. 12 to represent data on silicate solutions is merely a curvefitting exercise leading to results which are generally not unique. This non-uniqueness of the fit is a major failing since any interpolation or extrapolation of the results into unmeasured regions then has a very large uncertainty. In order to obtain reliability of the necessary interpolations and extrapolations, one cannot blindly use a power series. An approach which takes into account the ordered nature of the liquids is more likely to be useful. 
One way to characterize order in such liquids is by looking at the concentration dependence of the entropies and enthalpies of mixing. Ordered liquids tend to have a V-shaped dependence of $\Delta \mathrm{H}_{\mathrm{m}}$ along with a sharp dip in the entropy of mixing, $\Delta \mathrm{S}_{\mathrm{m}}$, at a particular stoichiometry. To illustrate this, measured and calculated values of $\Delta \mathrm{H}_{m}, \Delta \mathrm{S}_{\mathrm{m}}$, and $\overline{\mathrm{s}}-\mathrm{s}^{\circ}$ for several liquids having a class of ordering like that of silicates are plotted in Figs. 1-5. The $\mathrm{BeF}_{2}$ mixtures with alkali fluorides are known to have properties which are very similar to those of alkaline earth oxide-silica mixtures.

The calculated curves in these figures were obtained from a theory for such liquids in which a network component 1 ike $\mathrm{SiO}_{2}$ has four oxygen bridges between $\mathrm{Si}$ atoms (or ions). When an oxide of a divalent ion is added, it tends to break these bridges to form an unbridged si-o bond. When enough oxide is added, some of the oxides are not attached at all to a silicon atom. In the extreme case, a bridge is broken for each Mo added until all bridges are broken to form an $\mathrm{SiO}_{4}^{4-}$ entity. Curves representing this possibility are plotted for reference in four of the five graphs. Statistical mechanical theories for such systems are based on different methods for calculating the equilibria between such configurations and take into account the fact that on the average an MO molecule breaks less than one bond.

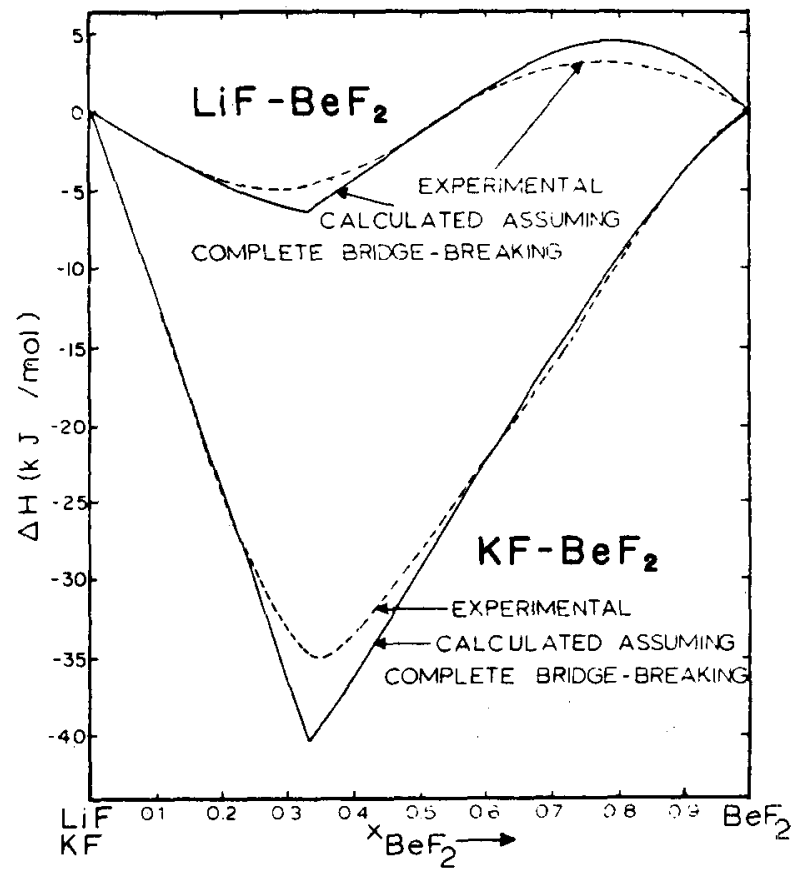

Fig. 1. Experimental Molar Enthalpies of Mixing in the $\mathrm{LiF}-\mathrm{BeF}_{2}$ and $\mathrm{KF}-\mathrm{BeF}_{2}$ Sys tems Compared with Values Calculated As suming Complete Bridge-Breaking (from Ref. 1). 


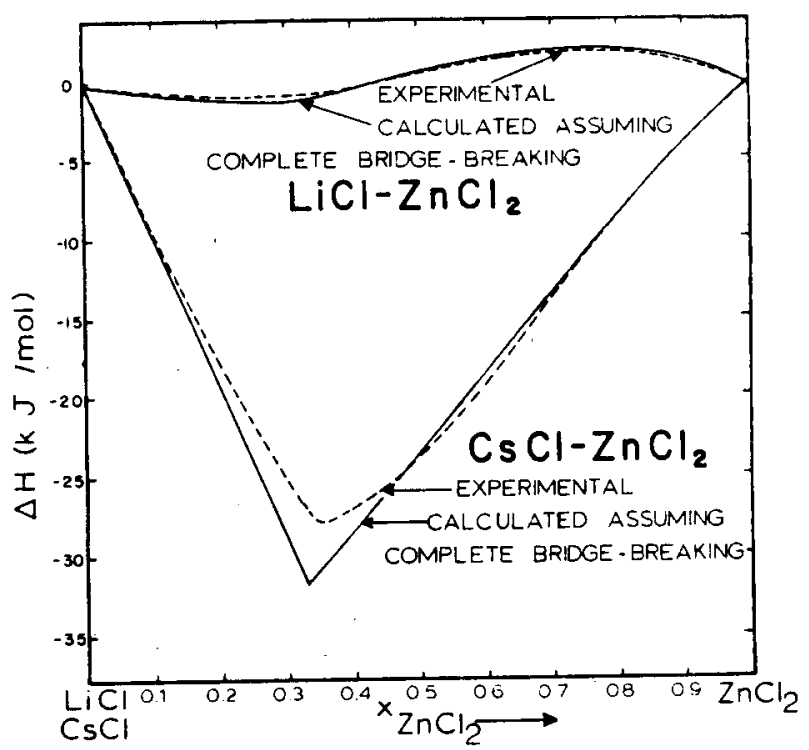

Fig. 2. Experimental Molar Enthalpies of Mixing in the $\mathrm{LiCl}-\mathrm{ZnCl}_{2}$ and $\mathrm{CsCl}_{\mathrm{ZnCl}} \mathrm{ZnC}_{2}$ Systems Compared with Values Calculated Assuming Complete BridgeBreaking (from Ref. 1).

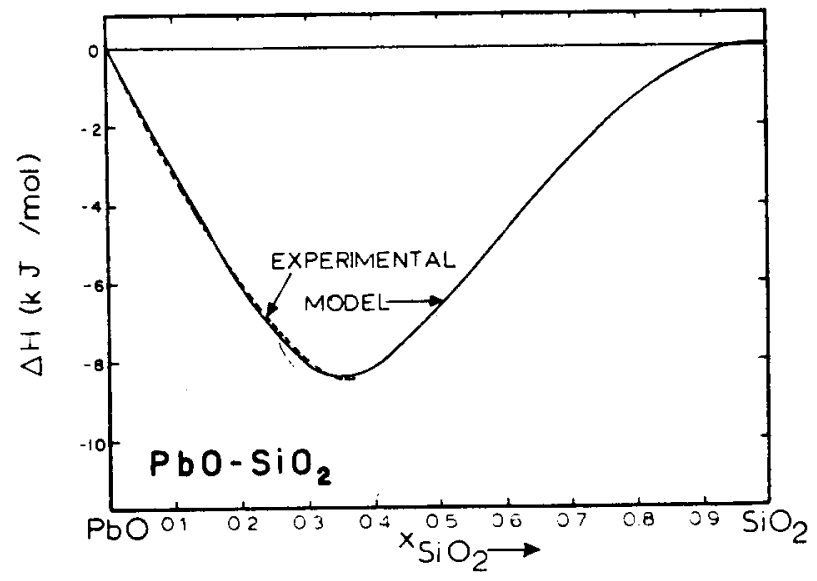

Fig. 3. Experimental Molar Enthalpies of Mixing in the $\mathrm{PbO}-\mathrm{SiO}_{2}$ System Compared with Calculations Based on the Lin-Pelton Model (from Ref. 1). 


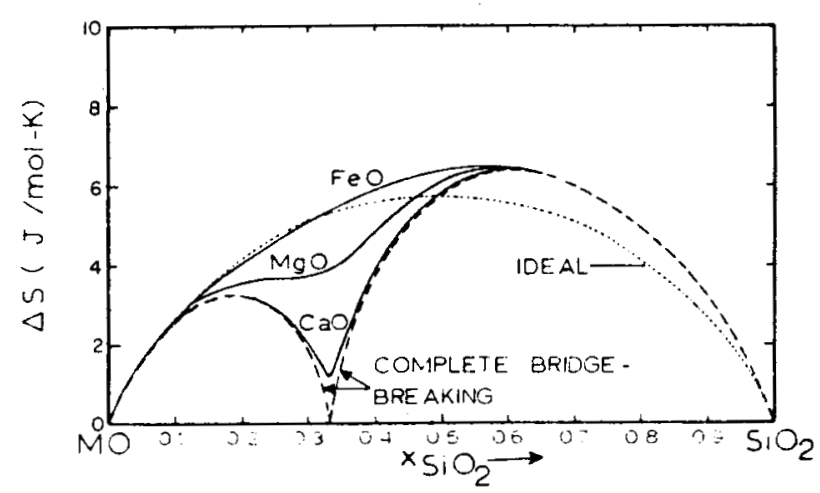

Fig. 4. Entropy of Mixing for $\mathrm{MO}-\mathrm{SiO}_{2}$ Systems (where $\mathrm{MO}=\mathrm{FeO}, \mathrm{MgO}$, or CaO) Compared with Those Calculated from the Lin-Pelton Model and from Complete BridgeBreaking (from Ref. 1).

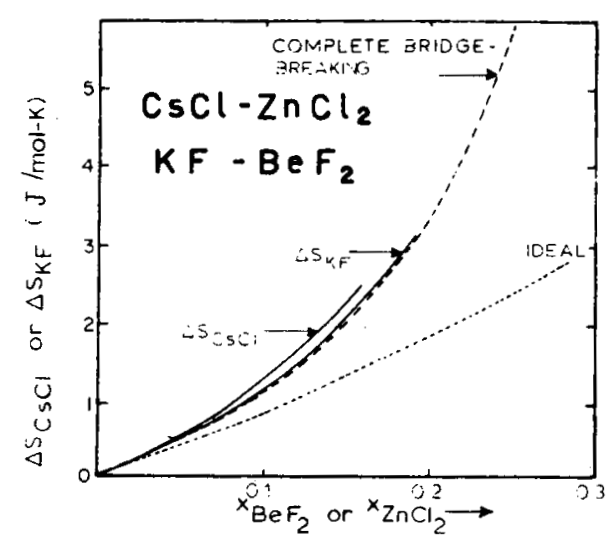

Fig. 5. Partial Molar Entropies of Mixing of $\mathrm{KF}$ in the $\mathrm{KF}-\mathrm{BeF}_{2}$ System and of $\mathrm{CsCl}$ in the $\mathrm{CsCl}_{-2 \mathrm{nCl}_{2}}$ System (deduced from measurements) Compared with Those for Ideal Solutions and for the Case of Complete BridgeBreaking (from Ref. 1). 
Thus, in order to represent the thermodynamic properties of silicate slags, equations are required which emulate the concentration and temperature dependence of systems exhibited in Figs. 1-5. In effect, there are three options.

(1) Use a chemical model in which one postulates a nonideal mixture of pseudocomponents, $\mathrm{M}_{2} \mathrm{Si}_{\mathrm{m}} \mathrm{O}_{2 \mathrm{~m}+2}$, with MO. All of the pseudocomponents are involved in equilibria with each other.

(2) Employ advanced models of silicate solutions.1

(3) Use a physical theory which has the proper characteristic dependence upon temperature and composition when modified in an ad hoc manner.

The advantages and disadvantages of these options are as follows:

Option (1) is conceptually simple, but mathematically complex. It is especially difficult to utilize for acid melts in which the average size of the anions $\mathrm{Si}_{\mathrm{m}} \mathrm{O}_{2 \mathrm{~m}+2}^{4-}$ must be very large. In addition, a description of the nonideal thermodynamics of mixing of pseudocomponents with large values of $\mathrm{m}$ is a problem for which no simple theory exists. We have tested aspects of this option, but found it to be less attractive than option (3).

Option (2) is the most attractive option from a conceptual point of view and should work well for binary systems. However, adapting it for systems containing more than one acid component $\left(\mathrm{SiO}_{2}\right.$ and $\left.\mathrm{Al}_{2} \mathrm{O}_{3}\right)$, as well as several basic components $\left(\mathrm{CaO}, \mathrm{Na}_{2} \mathrm{O}, \mathrm{K}_{2} \mathrm{O}\right)$, will probably lead to difficulties in formulating a suitable mathematical framework for performing the calculations.

Although we are continuing our considerations of options (1) and (2), we have chosen option ( 3 ) for the analyses given in this report. An ad hoc modification of the quasi-chemical theory $11,12,13$ was chosen. This theory, when modified, has all the characteristics exhibited in Figs. 1-5 and appears to be adaptable to multicomponent systems. The modified theory is not a proper theory and should be considered merely a mathematical formalism which appears to have the characteristics desired for relatively reliable extrapolations and interpolations. It appears probable, however, that some of the ad hoc modifications might be theoretically justified in the future. 


\section{METHODS FOR THE ANALYSIS OF SILICATE SYSTEMS}

In this section we discuss the quasi-chemical theory, the modifications we have made in the theory, the rationale for these modifications, and the optimization procedure. The quasi-chemical theory is based on a quasi-lattice model consisting of two interlocking sublattices $A$ and $B$ such that ions (or atoms) in the $B$ sublattice sites are neighbors only to ions (or atoms) in the A sublattice sites and vice versa. The site coordination number is $Z$. For ionic (and silicate) systems, it is the next-nearest-neighbor cations which occupy these lattices. For two types of cations ( 1 and 2 ), there are four kinds of pairs on the adjacent $A-B$ sites (namely, 1-1, 1-2, 2-1, and 2-2) with "pair bond energies" $e_{i j}$, where $e_{12}=e_{21}$. In the theory, one considers the site equilibria

$$
2[1-2] \rightleftharpoons[1-1]+[2-2]
$$

with an energy change $w\left[w=(z / 2)\left(2 e_{12}-e_{11}-e_{22}\right)\right]=w / N$, where $N$ is Avogadro's number and $W$ is an energy per mole and a nonconfigurational entropy change $s\left[s=(Z / 2)\left(2 s_{i j}-s_{i i}-s_{j j}\right)=s / N\right]$.

The number of particles of the $i$ 'th kind being mixed is $n_{i}$ (where $i$ represents cations such as $\mathrm{Na}^{+}, \mathrm{Ca}^{2+}, \mathrm{Si}^{4+}, \mathrm{Al}^{3+}$, etc.) and $\sum \mathrm{n}_{\mathrm{i}}=\mathrm{n}$ where $n$ is of the order of Avogadro's number. The cation fractions are given by $x_{i}=n_{i} / n$. The number of $i j$ bonds is defined as $n_{i j}$ where

$$
\begin{aligned}
& \mathrm{Zn}_{1}=2 \mathrm{n}_{11}+\mathrm{n}_{12} \\
& \mathrm{Zn}_{2}=2 \mathrm{n}_{22}+\mathrm{n}_{12}
\end{aligned}
$$

and the fraction of $i j$ bonds is $x_{i j}=n_{i j} /(n z / 2)$. Consequently, we can calculate $x_{11}$ and $x_{22}$ in terms of the cation fractions $x_{1}$ and $x_{2}$ and $x_{12}$ from the expressions

$$
\begin{aligned}
& x_{11}=x_{1}-x_{12} / 2 \\
& x_{22}=x_{2}-x_{12} / 2
\end{aligned}
$$

The molar enthalpy of mixing is given by

$$
\Delta H_{m}=\left(\frac{x_{12}}{2}\right) \mathrm{W}
$$

The total entropy of mixing is given by

$$
\begin{aligned}
\Delta S_{m}= & -(R / N)\left[n_{11} \ln \left(x_{11} / x_{1}^{2}\right)+n_{22} \ln \left(x_{22} / x_{2}^{2}\right)\right. \\
& \left.+n_{12} \ln \left(x_{12} / 2 x_{1} x_{2}\right)+n_{1} \ln x_{1}+n_{2} \ln x_{2}\right]-\frac{n_{12} s}{2 n}
\end{aligned}
$$


A relationship between the different $x_{i j}$ 's is given by

$$
\left(\mathrm{x}_{12}^{2} / \mathrm{x}_{11} \mathrm{x}_{12}\right)=4 \exp [-2(\mathrm{~W}-\mathrm{ST}) / \mathrm{ZRT}]
$$

Solving for $\mathrm{x}_{12}$, one obtains

$$
\left(x_{12} / 2\right)=2 x_{1} x_{2} /(1+x)
$$

where

$$
K=\left[1+4 X_{1} X_{2}(\exp [2(W-S T) / Z R T]-1)\right]^{1 / 2}
$$

When $S=0$, the partial molar Gibbs free energies and excess enthalpies of solution of components 1 and 2 are given by

$$
\begin{aligned}
& \bar{G}_{1}-G_{1}^{o}=R T \ln x_{1}+(z / 2) R T \ln \left(x_{11} / x_{1}^{2}\right) \\
& \bar{G}_{2}-G_{2}^{o}=R T \ln x_{2}+(z / 2) R T \ln \left(x_{22} / x_{2}^{2}\right)
\end{aligned}
$$

and

$$
\begin{aligned}
& \mathrm{H}_{1}^{\mathrm{E}}=\left(\mathrm{WX}_{2}^{2} / \mathrm{K}\right)\left(1+\frac{(\mathrm{K}-1) \mathrm{X}_{1}}{(\mathrm{~K}+1) \mathrm{X}_{2}}\right) \\
& \mathrm{H}_{2}^{\mathrm{E}}=\left(\mathrm{WX}_{1}^{2} / \mathrm{K}\right)\left(1+\frac{(\mathrm{K}-1) \mathrm{x}_{2}}{(\mathrm{~K}+1) \mathrm{x}_{1}}\right)
\end{aligned}
$$

Equations 21 and 22 give an ideal solution when $W$ and $S$ are both zero and give a strictly regular solution when $W / R T$ is small and $S$ is zero. For $W<<0$, Eqs. 21 and 22 lead to an ordered solution with (1) a V-shaped plot of the enthalpy of mixing with a minimum at $\mathrm{X}_{1}=\mathrm{X}_{2}=0.5$ and (2) a double curved plot of the entropy of mixing with a minimum at $x_{1}=x_{2}=0.5$.

We can apply one important constraint to these equations based on models for silicates. As seen in Fig. 4, at one composition, the entropy of mixing, $\Delta \mathrm{S}_{\mathrm{m}}$, of a completely ordered mixture (i.e., complete bridge-breaking) is zero. This complete ordering corresponds to the limit of $\Delta \mathrm{S}_{\mathrm{m}}$ of a 50-50 mixture at the limit $\mathrm{W}=-\infty$. At this limit, $\mathrm{K}=0$ and we calculate that at $\mathrm{x}_{1}=\mathrm{x}_{2}=0.5$,

$$
\frac{s^{E}}{R}=\frac{Z}{2}\left[x_{1} \ln x_{1}+x_{2} \ln x_{2}\right]
$$

The total entropy of mixing of this mixture $\left(\Delta S_{m}=\Delta S_{m}^{i d}+\Delta S^{E}\right)$ is zero for a value of $Z=2$. In the calculations that follow, we will choose this ad hoc value of the "coordination number " which appears to be necessary to correlate properties of real systems. 
Equations 14-22 are still not suitable for silicates because they are symmetric and do not exhibit minima or maxima in $\Delta H$ or $\Delta S$ at concentrations such as are exhibited in Figs. 1-4. These extrema can be incorporated into these equations in an ad hoc manner similar to a procedure which has been successful for molten salts.14,15 If one substitutes equivalent fractions $\left(y_{i}\right)$ for mole (ion) fractions $\left(x_{i}\right)$ into the excess thermodynamic functions, the extrema then occur at an equivalent fraction of 0.5 rather than a mole fraction of 0.5 , with equivalent fractions defined by the expression $y_{1}=a x_{1} /$ $\left(a x_{1}+b x_{2}\right)=1-y_{2}$. The definition of equivalent fractions for a binary system $A-B$ with an "ordered" composition at $A_{b} B_{a}$ [where the ratio $r$ is defined as $a /(a+b)]$ also defines the compositions of the extrema in the excess

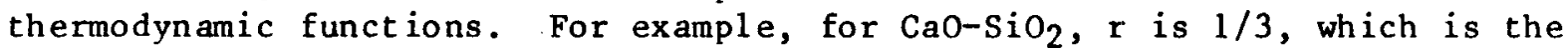
mole fraction of silica at the extrema in the excess thermodynamic functions. We must choose values of $a$ and $b$ carefully in order to impose the constraint that $\Delta \mathrm{S}_{\mathrm{m}} \cong 0$ at $\mathrm{y}_{1}=\mathrm{y}_{2}-0.5$ when $\mathrm{W}=-\infty$.

If a prime on the excess thermodynamic function denotes values per equivalent and the unprimed value is per mole, then, for example,

$$
\begin{aligned}
& G^{E}=\left(a X_{1}+b X_{2}\right) G^{E^{\prime}} \\
& G_{1}^{E}=\mu_{1}^{E}=a G_{1}^{E^{\prime}}=a \mu_{1}^{\prime} \\
& G_{2}^{E}=\mu_{2}^{E}=b G_{2}^{E^{\prime}}=b \mu_{2}^{\prime}
\end{aligned}
$$

with similar equations for $s^{E}, \Delta H_{m}, s_{i}^{E}$, and $H_{i}^{E}$. The primed quantities are then calculated using Eqs. 15-20, but with $y_{i}$ replacing $x_{i}$. Thus,

$$
\left(G^{E} E / R T\right)=\left(a x_{1}+b_{2}\right)(z / 2)\left[y_{1} \ln \frac{k-1+2 y_{1}}{y_{1}(k+1)}+y_{2} \ln \frac{k-1+2 y_{2}}{y_{2}(k+1)}\right]
$$

and

$$
\begin{aligned}
\left(G_{1}^{E} / R T\right) & =a(Z / 2) \ln \frac{K-1+2 y_{1}}{y_{1}(K+1)} \\
& =a(Z / 2) \ln \left(x_{11} / y_{1}^{2}\right)-a\left(x_{12} / 2\right) y_{2} d(W-s T) / d y_{2} \\
K & =\left[1+4 y_{1} y_{2}[\exp (2 W / Z R T)-1]\right]^{1 / 2}
\end{aligned}
$$

Similar equations can be derived for $G_{2}^{E}, \Delta H_{m}$, and $H_{i}^{E}$.

The quantities $x_{11}, x_{22}$, and $x_{12}$ can be calculated from the expressions $\mathrm{Zan}_{1}=2 \mathrm{n}_{11}+\mathrm{n}_{12}, \mathrm{Zbn}_{2}=2 \mathrm{n}_{22}+\mathrm{n}_{12}$, and $\mathrm{X}_{\mathrm{ij}}=2 \mathrm{n}_{\mathrm{ij}} / \mathrm{nZ}$ combined with Eqs. 15 and 18. In effect, the quantities $\mathrm{Za}$ and $\mathrm{Zb}$ are like "coordination numbers" for components 1 and 2 . The expression for $x_{12}$ is $x_{12}=2 y_{1} y_{2} /(1+K)$ where $\mathrm{K}$ is given by Eq. 29 . 
The total entropy of mixing at $y_{1}=y_{2}=0.5$ and $z=2$ at the 1 imit $W=-\infty$ calculated from these equations is given by the expressions

$$
\begin{aligned}
\Delta S_{m} / R=\left(\Delta S^{i d} / R\right)+\left(S^{E} / R\right)= & -x_{1} \ln x_{1}-x_{2} \ln x_{2}+\left(a x_{1}+b x_{2}\right)(z / 2) \\
& \left(y_{1} \ln y_{1}+y_{2} \ln y_{2}\right) \\
= & -(1-r) \ln (1-r)-r \ln r+(2 b r) \ln 0.5 \\
= & 0
\end{aligned}
$$

For the system $\mathrm{CaO}-\mathrm{SiO}_{2}, \mathrm{r}=1 / 3$. For the entropy to be zero at $\mathrm{X}_{\mathrm{SiO}_{2}}=1 / 3$, values of $b=1.38$ and $a=0.69$ are deduced. It should be emphasized that this choice is merely a mathematical artifice and is not a unique method for incorporating the ordered properties of solution into the equations. Other possible methods might be better justified theoretically. At the present stage of development, the equations we present are adequate for our purposes. However, the equations might be modified for theoretical consistency even though such modifications may not alter our results significantly. It should be noted that in ternary systems in which the three cations have three different valences, this choice cannot be made self-consistently for all of the components. We will always set $\mathrm{Z}=2$ and choose appropriate values of a and b. This point will be discussed later.

One further property of the quasi-chemical equations which needs to be modified stems from the assumption that the "pair bond energies" $e_{11}, e_{12}$, and $e_{22}$ are additive and are independent of the local configurations and environments of the ions involved. For example, $e_{12}$ is not likely to be the same if an atom of type 1 is surrounded by $Z$ atoms of type 2 as when it is surrounded by $(z-1)$ atoms of type 1 and one of type 2. Although there has been recent theoretical work on the chemistry of solutions in which the configuration dependence of these bond energies is taken into account, 15 mathematical extension to binary systems is still too complex for computer calculations of the type we wish to perform. It is hoped that simplified mathematical approximations for such theories can be developed. In lieu of such a fundamental development, we can take such configuration dependence into account in a manner similar to that employed for silicates. 1 This is done by making $W$ and $S$ each a function of concentration. We use an expression of the form

$$
w-S T=\sum_{i=0}\left(h_{i}-T s_{i}\right) y_{2}^{i}
$$

where we use a small set of values of $h_{i}$ and $s_{i}$. This concentration dependence of $W$ and $S$ does not influence the form of the functions $G^{E}$ and $\Delta \mathrm{H}_{\mathrm{m}}$, but does alter the form of the equations for the partial molar quantities as follows: 


$$
\begin{aligned}
& G_{1}^{E} / R T=(a Z / 2) \ln \left(x_{11} / y_{1}^{2}\right)-a\left(x_{12} / 2\right) y_{2}\left[d(W-s T) / d y_{2}\right] \\
& G_{2}^{E} / R T=(b Z / 2) \ln \left(x_{22} / y_{2}^{2}\right)+b\left(x_{12} / 2\right) y_{1}\left[d(w-s T) / d y_{2}\right]
\end{aligned}
$$

Equations 32 and 33 have the kinds of properties expected of binary silicate systems (i.e., those exhibited in Figs. 1-5). If our rationale is correct, these equations should minimize the number of parameters needed to fit known data on silicate systems. This point is illustrated in section IV of this report, where we discuss calculations for five binary systems. The number of adjustable parameters needed to perform the analyses accurately is far smaller than has been achieved before.

The expressions for ternary systems are somewhat more complex. In addition to $1-1,2-2$, and 1-2 bonds, one needs to consider 1-3, 2-3, and 3-3 bonds. If as in the binary systems, we define "coordination numbers" for components (i.e., $Z_{1}=a Z, Z_{2}=b Z$ with $Z=2$ ), we can define a "coordination number" for the third component $z_{3}=c z$. We can then deduce the following relations between the values of $n_{i j}\left(n_{j i}\right)$ and $n_{i}$ :

$$
\begin{aligned}
& Z_{1}=2 n_{11}+n_{12}+n_{13} \\
& Z a n_{2}=2 n_{22}+n_{21}+n_{23} \\
& Z a n_{3}=2 n_{33}+n_{31}+n_{32}
\end{aligned}
$$

and

$$
\begin{aligned}
& x_{11}=y_{1}-x_{12} / 2-x_{13} / 2 \\
& x_{22}=y_{2}-x_{12} / 2-x_{23} / 2 \\
& x_{33}=y_{3}-x_{31} / 2-x_{32} / 2
\end{aligned}
$$

where $y_{1}=a x_{1} /\left(a x_{1}+b x_{2}+c x_{3}\right), * \sum y_{i}=1$, and $x_{i j}=n_{i j} / \sum_{i<j} n_{i j}$.

The distribution of bonds is governed by three distribution functions

$$
\left(x_{i j}^{2} / x_{i j} x_{j j}\right)=\exp \left[-2\left(w_{i j}-s_{i j} T\right) / Z R T\right]=\alpha_{i j}^{2}
$$

where $W_{i j}$ and $S_{i j}$ are the appropriate energies and nonconfigurational entropies for the $\mathrm{ij}$ binary system. Substituting Eq. 36 into Eq. 35, one obtains three simultaneous quadratic equations with three unknowns which can be solved nume rically.

${ }^{*} y_{2}$ and $y_{3}$ are defined similarly. 
The power series representations for $w_{12}, w_{13}$, and $w_{23}$ in ternary systems can be approximated in several ways. Two methods which are considered here are analogous to mathematical approximations used for other functions in the calculation of phase diagrams. One method is a symmetric representation

$$
\begin{aligned}
w_{12} & =c_{0}+c_{1}\left[y_{2} /\left(y_{1}+y_{2}\right)\right]+c_{2}\left[y_{2} /\left(y_{1}+y_{2}\right)\right]^{2} \ldots \\
& =c_{0}+c_{1} t_{12}+c_{2} t_{12}^{2}+\cdots \\
W_{23} & =c_{0}^{\prime}+c_{1}^{\prime} t_{23}+c_{2}^{\prime} t_{23}^{2}+\cdots \\
W_{31} & =c_{0}^{\prime \prime}+c_{1}^{\prime \prime} t_{31}+c_{2}^{\prime \prime} t_{31}^{2}+\cdots
\end{aligned}
$$

where $t_{i j}=y_{j} /\left(y_{i}+y_{j}\right)$. A similar expansion can be made for $s_{i j}$. In this case, the partial molar excess free energy of solution of a component is given by

$$
\begin{aligned}
G_{1}^{E} / R T= & (a Z / 2) \ln \left(X_{11} / y_{1}^{2}\right)-a\left(x_{12} / 2 R T\right)\left[y_{2} /\left(y_{1}+y_{2}\right)^{2}\right] \partial\left(W_{12}-s_{12} T\right) / \partial t_{12} \\
& +a\left(X_{31} / 2 R T\right)\left[y_{3} /\left(y_{1}+y_{3}\right)^{2}\right] \partial\left(W_{31}-s_{31} T\right) / \partial t_{31}
\end{aligned}
$$

and similar expressions can be written for $G_{2}^{E}$ and $G_{3}^{E}$. It should be noted that all terms containing derivatives drop out in the expression for the total free energy of mixing.

The second method is an asymmetric representation, in which one component is assumed to be different. Such a method would probably be best in a ternary system such as $\mathrm{Na}_{2} \mathrm{O}-\mathrm{K}_{2} \mathrm{O}-\mathrm{SiO}_{2}$. The expressions for $\mathrm{W}_{12}, \mathrm{~W}_{23}$, and $\mathrm{W}_{31}$ in this representation are

$$
\begin{aligned}
& \mathrm{w}_{12}=c_{0}+c_{1} \mathrm{y}_{1}+c_{2} \mathrm{y}_{1}^{2}+\ldots \\
& \mathrm{W}_{31}=c_{0}^{\prime}+c_{1}^{\prime} \mathrm{y}_{1}+c_{2}^{\prime} \mathrm{y}_{1}^{2}+\ldots \\
& \mathrm{W}_{23}=c_{0}^{\prime \prime}+c_{2}^{\prime \prime} t_{23}+c_{3}^{\prime \prime} t_{23}^{2} \ldots
\end{aligned}
$$

where component 1 is "different"; $\mathrm{SiO}_{2}$ would be chosen as component 1 in the $\mathrm{Na}_{2} \mathrm{O}-\mathrm{K}_{2} \mathrm{O}-\mathrm{SiO}_{2}$ system. For this case, the expressions for the partial molar excess free energy of solution are

$$
\begin{aligned}
G_{l}^{E} / R T= & (a z / 2) \ln \left(x_{11} / y_{1}^{2}\right)+a\left(x_{12} / 2 R T\right)\left(1-y_{1}\right) \partial\left(W_{12}-s_{12} T\right) / \partial y_{1} \\
& +a\left(x_{31} / 2 R T\right)\left(1-y_{1}\right) \partial\left(W_{31}-s_{31} T\right) / \partial y_{1}
\end{aligned}
$$




$$
\begin{aligned}
G_{2}^{E} / R T= & (b z / 2) \ln \left(x_{22} / y_{2}^{2}\right)-b\left(x_{12} / 2 R T\right)\left(y_{1}\right) \partial\left(W_{12}-s_{12} T\right) \partial y_{1} \\
& -b\left(x_{31} / 2 R T\right)\left(y_{1}\right) \partial\left(w_{31}-s_{31} T\right) / \partial y_{1} \\
& -b\left(x_{23} / R T\right)\left[y_{3} /\left(y_{2}+y_{3}\right)^{2}\right] \partial\left(W_{23}-s_{23} T\right) / \partial t_{23} \\
G_{3}^{E} / R T= & (c z / 2) \ln \left(x_{33} / y_{3}^{2}\right)-c\left(x_{12} / 2 R T\right)\left(y_{1}\right) \partial\left(W_{12}-s_{12} T\right) / \partial y_{1} \\
& -c\left(x_{31} / 2 R T\right)\left(y_{1}\right) \partial\left(w_{31}-s_{31} T\right) / \partial y_{1} \\
& +c\left(x_{23} / 2 R T\right)\left[y_{2} /\left(y_{2}+y_{3}\right)^{2}\right] \partial\left(w_{23}-s_{23} T\right) / \partial t_{23}
\end{aligned}
$$

As in all such expressions, all terms containing derivatives drop out upon combining these three partial molar quantities to calculate the total free energy of mixing. The equations for quaternary systems are more complex but are straightforward extensions of the equations for ternary systems.

In order to perform the complex analyses of binary systems in an efficient manner, we incorporated an optimization procedure into the computer program for these analyses. The nature of the equations we used did not readily lend itself to such optimizations, and considerable effort was made to adapt an optimization procedure for use with the modified quasi-chemical equations. Following introductory general remarks on linear least-squares optimization, we discuss our optimization procedure below.

If one has a variable $y$ which is a linear function of the dependent variables $x_{1}, x_{2}, \cdots, x_{m}$ (i.e., $y ; x_{1}, x_{2}, x_{3}, \cdots x_{m}$ ),

$$
y=c_{1} x_{1}+c_{2} x_{2}+c_{3} x_{3}+c_{4} x_{4}+\ldots=\sum c_{j} x_{j}
$$

and $n$ experimental points $y_{i} ; x_{i 1}, x_{i 2}, x_{i 3}, \cdots, x_{i m}$ (where $i=1, n$ ), then the "best" values of $c_{1}, c_{2}, \cdots, c_{m}$ are determined by minimizing the function

$$
\sum_{i=1}^{n}\left(y_{i}-\sum c_{j} x_{i j}\right)^{2}
$$

by a linear least-squares method.

Suppose instead that we have only one independent variable $z$ and $n$ data points $y_{i} ; z_{i}$ (where $i=1, n$ ) and wish to find the best fit to an expression such as

$$
y=c_{1}+c_{2} z+c_{3} z^{2}+c_{4} \exp (z)
$$


We can use the same linear method as was utilized for Eq. 43, if we make the following identifications:

$$
\begin{aligned}
x_{i 1} & =1.0 \\
x_{i 2} & =z_{i} \\
x_{i 3} & =z_{i}^{2} \\
x_{i 4} & =\exp \left(z_{i}\right)
\end{aligned}
$$

In general, if $y=\sum c_{j} f_{j}(z)$, then one can use a linear least-squares method by letting $f_{j}\left(z_{i}\right)=x_{i j}$.

In the optimization procedure used at Montreall for the excess thermodynamic properties of a binary system expressed as a power series, one has

$$
\begin{aligned}
G^{E} & =X_{B}\left(1-X_{B}\right)\left(c_{1}+c_{2} X_{B}+c_{3}^{2} X_{B}+\ldots\right) \\
& =X_{B}\left(1-X_{B}\right) \sum c_{j} X_{B}{ }^{j-1}
\end{aligned}
$$

where $\mathrm{X}_{\mathrm{B}}$ is the mole fraction of component $\mathrm{B}$. If there are $\mathrm{n}$ experimental points for the total molar excess free energy $G^{E}\left[G_{i}^{E} ; X_{B i}(i=1, n)\right]$, we can write $y .=\sum c_{j} F_{j}\left(x_{B}\right)$. with $y_{i}=G_{1}^{E}$ and $f_{j}\left(x_{B i}\right)=\left(1-x_{B}\right) x_{B}^{j}$. If in addition, one also has $k$ experimental values of the partial molar excess free energy $G_{B}^{E}\left[G_{B i}^{E} ; X_{B i}(i=n+1, n+k)\right]$, one can calculate an expression for $G_{B}^{E}$ from Eq. 46 by proper differentiation

$$
G_{B}^{E}=\left(1-x_{B}\right)^{2} \sum j c_{j} x_{B}{ }^{j-1}
$$

where the coefficients $c_{j}$ in Eqs. 46 and 47 are the same. Equation 47 can be written in the form $y=\sum_{j} c_{j} f_{j}\left(x_{B}\right)$ if $y_{i} \equiv G_{B i}^{E}$ and $f_{j}\left(x_{B i}\right)=\left(1-x_{B i}\right)^{2} j x_{B i}^{j-1}$. Consequently, all $\mathrm{n}$ data ${ }^{j}$ points for $G^{E}$ and $a 11 \mathrm{k}$ data points for $G_{B}^{E}$ can be simultaneously fitted in one least-squares procedure by setting $y=\sum c_{j} f_{j}\left(x_{B}\right)$ and letting $y_{i}=G_{i}^{E}$ when $i=1, n ; y_{i}^{E}=G_{B i}$ when $i=(n+1),(n+k)$; $f_{j}\left(x_{B}\right)=\left(1-x_{B}\right)\left(x_{B}\right) j$ when $i=1, n$; and $f_{j}\left(x_{B}\right)=j\left(1-x_{B}\right)^{2} x_{B} j-1$ when $i=(n+1),(n+k)$. Data for $G_{A}^{E}$, the partial molar excess free energy of mixing of component $A$, and other thermodynamic properties could also all be simultaneously optimized.

Because of the nature of the quasi-chemical equations we employ, application of the standard optimization procedure was not possible. For example, the expression for the enthalpy of mixing

$$
\Delta \mathrm{H}_{\mathrm{m}}=\left(\mathrm{ax}_{\mathrm{A}}+\mathrm{bX}_{\mathrm{B}}\right) \frac{\mathrm{y}_{\mathrm{A}} \mathrm{y}_{\mathrm{B}}}{1+\mathrm{K}} \mathrm{w}
$$


cannot be written in the form $\sum c_{j} f_{j}\left(y_{B}\right)$ because $k$ is a function of $w$, which is a function of $y_{B}$. However, if one has an experimental point $\Delta H_{m i}$ at $y_{B i}$, then one can find, by trial and error, the value of $w_{i}$ at $y_{B i}$ which, when substituted into Eq. 48 , will give $\Delta \mathrm{H}_{\mathrm{m}}$. This is simple to perform since $\Delta \mathrm{H}_{\mathrm{m}}$ varies monotonically with $\mathrm{W}$. Hence, experimental data points $\Delta \mathrm{H}_{\mathrm{mi}} ; \mathrm{y}_{\mathrm{Bi}}$ can be converted into "experimental" points $W_{i} ; y_{B i}$ to give a linear equation for $W$ :

$$
W=c_{0}+c_{1} y_{B}+c_{2} y_{B}^{2}+\ldots+c_{j} y_{B}^{j}
$$

For experimental values of excess free energies of mixing, $\mathrm{G}^{\mathrm{E}}$, the procedure is essentially the same as for $\Delta \mathrm{H}_{m}$ since $\mathrm{G}^{\mathrm{E}}$ at a given composition varies monotonically with $W$. Experimental points $G_{i}^{E} ; y_{B i}$ can thus be converted into sets of points $W_{i} ; y_{B i}$ and the linear Eq. 49 can be used for expressing $W$ in terms of $y_{B}$.

For experimental partial molar properties such as $G_{A}^{E}$ (or $G_{B}^{E}$ ),

$$
\begin{aligned}
G_{A}^{E} / R T= & (a z / 2) \ln \left[\left(1+k-2 y_{B}\right) /\left(y_{A}(1+k)\right)\right] \\
& -2 a y_{A} y_{B}^{2} /[R T(1+K)]\left(d W / d y_{B}\right)
\end{aligned}
$$

In this case, $E^{o}$ e can not convert experimental data pairs $G_{A}^{E} ; y_{B i}$ into $W_{i} ; y_{B i}$ pairs since $G_{A}^{E}$ depends not only on $W$ but also on ( $d W / d y_{B}$ ). To surmount this difficulty, we rewrite the two terms on the right-hand side of Eq. (50) as

$$
G_{A}^{E}=F(W)-C(W)\left(d W / d y_{B}\right)
$$

where the definitions of $F(W)$ and $C(W)$ are obvious. Although $F(W)$ is a strong function of $W, C(W)$ is a relatively weak function of $W(K)$, which is a function of $K$ (where $K$ varies only from 0 to 1 ). Let $W^{\circ}$ be an initial guess for the value of $W$ as a function of $y_{B}$, i.e.,

$$
W^{\circ}=\sum_{i=0}^{n} c_{i}^{0} y_{B}^{i}
$$

and then perform a Taylor expansion on $F(W)$ about $F\left(W^{\circ}\right)$ up to the first order term and replace $C(W)$ with $C\left(W^{\circ}\right)$. Hence,

$$
G_{A}^{E}=F\left(W^{\circ}\right)+F^{\prime}\left(W^{\circ}\right)\left(W-W^{\circ}\right)-C\left(W^{\circ}\right)\left(d W^{\circ} / d y_{B}\right)
$$

Upon performing the differentiations and substitutions and rearranging, one obtains 
where $\mathrm{K}^{\circ} \equiv \mathrm{K}\left(\mathrm{W}^{\circ}\right)$. Equation 54 is linear so that we can simultaneously optimize $G_{A}^{E}, G_{B}^{E}, \Delta H_{m}$, and $G^{E}$. The procedure is as follows: First, a suitable guess for $W^{\circ}$ is made and one iteration is made. The resulting expression for $W$ can be taken as a second guess for $W^{\circ}$, and so on. In practice, it was found that any guess for $W^{\circ}$ that had the correct sign and was of the right order led to an expression for $W$ which changed negligibly with another iteration. The Taylor expansion appears to work very well except when $W^{\circ}$ is very far from the final result.

The optimization procedure was also applied to miscibility gap data. If $x_{B}$ and $y_{B}$ are mole and equivalent fractions on one side of the gap in equilibrium with compositions $X_{B}^{\star}, y_{B}^{\star}$ on the other side, and if we equate $\bar{G}_{A}-G_{A}$ on the two sides and use the notation of Eq. 53, we can arrive at a linear equation

$$
\begin{aligned}
& \text { RT } \ln \left(x_{A} / x_{A}^{*}\right)+F\left[W^{\circ}\left(y_{B}\right), y_{B}\right]-F\left[W^{\circ}\left(y_{B}^{*}\right), y_{B}^{*}\right] \\
& -F^{\prime}\left[W^{\circ}\left(y_{B}\right), y_{B}\right] W^{\circ}\left(y_{B}\right)+F^{\prime}\left[W^{\circ}\left(y_{B}^{*}\right), y_{B}^{*}\right] W^{\circ}\left(y_{B}^{*}\right) \\
& =\sum c_{i}\left(F^{\prime}\left[W^{\circ}\left(y_{B}^{*}\right), y_{B}^{*}\right] y_{B}^{*_{i}}-F^{\prime}\left[W^{\circ}\left(y_{B}\right), y_{B}\right] y_{B}^{i}\right) \\
& +c\left[W^{\circ}\left(y_{B}\right), y_{B}\right] \sum i c_{i} y_{B}^{i-1}-c\left[w^{\circ}\left(y_{B}^{*}\right), y_{B}^{*}\right] \sum i c_{i} y_{B}^{* i-1}
\end{aligned}
$$

where the summations in the last terms are for $\underline{i}=1,2, \cdots$. Equation 55 is linear. A similar equation can be written for $\bar{G}_{B}-G_{B}^{\circ}$, the partial molar free energy of mixing of component $B$, on the two sides of the miscibility gap. Consequently, one can simultaneously optimize miscibility gap information along with information on $G_{A}^{E}, G_{B}^{E}, \Delta H_{m}$, and $\Delta G_{m}$. This includes all phase diagram data, free energies of formation of compounds, enthalpies of fusion, enthalpies of mixing, activities, and other related data. 


\section{CALCULATIONS FOR THE BINARY AND TERNARY SYSTEMS CONTAINING $\mathrm{Na}_{2} \mathrm{O}, \mathrm{CaO}, \mathrm{Al}_{2} \mathrm{O}_{3}$, AND $\mathrm{SiO}_{2}$}

In this section, we present our optimized analyses of the binary systems, $\mathrm{NaO}_{0} .5-\mathrm{SiO}_{2}, \mathrm{NaO}_{0} .5-\mathrm{AlO}_{1} .5, \mathrm{CaO}-\mathrm{AlO}_{1} .5, \mathrm{NaO}_{0} .5-\mathrm{SiO}_{2}$, and $\mathrm{SiO}_{2}-\mathrm{AlO}_{1} .5$, as well as the three ternary systems $\mathrm{CaO}-\mathrm{AlO}_{1.5}-\mathrm{SiO}_{2}, \mathrm{NaO}_{0} .5-\mathrm{CaO}-\mathrm{SiO}_{2}$, and $\mathrm{NaO}_{0} .5^{-\mathrm{AlO}_{1}} \mathrm{~S}^{-\mathrm{SiO}_{2}}$.

There are no data on the $\mathrm{CaO}-\mathrm{NaO}_{0.5}$ binary system. Because of its simplicity, we will assume as a working hypothesis that the liquid and solid solution phases of these two components are ideal. In later calculations for multicomponent systems, this assumption can be modified in the light of experimental data.

The computer program which was written for binary systems accepts, as input, values of $\mathrm{Z}, \mathrm{a}$, and $\mathrm{b}$, as well as data on miscibility gaps, eutectics, melting points, and other liquidus data, activities of components, enthalpies and free energies of formation of compounds, enthalpies of fusion, etc. All of this data is simultaneously optimized, and a set of parameters $c_{0}, c_{1}$, $c_{2}, \cdots$ is calculated. These parameters, along with the chosen values of $\mathrm{z}$, $\mathrm{a}$, and $\mathrm{b}$, were used to calculate the phase diagram, the activities of components, and other thermodynamic quantities for comparisons with the input data and for testing of the self-consistency of the procedure. For binary systems, the values of $a$ and $b$ chosen need to have correct values of $r[=a /(a+b)]$ where $a$ and $b$ can be chosen so that entropies of mixing are zero (or close to zero) at $y_{B}=0.5$ when $w=-\infty$. For multicomponent systems, this can not be done in a self-consistent manner, using equations given earlier; i.e., aZ for $\mathrm{CaO}$ in $\mathrm{CaO}^{-\mathrm{SiO}_{2}}$ mixtures will not be the same as in $\mathrm{CaO}-\mathrm{AlO}_{1.5}$ mixtures, even though we must set a constant value in the ternary $\mathrm{CaO}-\mathrm{Al}_{1} \cdot 5-\mathrm{SiO}_{2}$. To get around this, we have arbitrarily chosen values of $a$ and $b$ (with $z=2$ ) for the $\mathrm{CaO}-\mathrm{SiO}_{2}$ system using Eq. 30. All other values are calculated by multiplying by the charge ratio. Consequently, the parameters used are 1.3774 for $\mathrm{SiO}_{2}, 0.6887$ for $\mathrm{CaO}, 1.0331$ for $\mathrm{AlO}_{1.5}$, and 0.3444 for $\mathrm{NaO}_{0.5}$. Although this choice is somewhat arbitrary, it makes very little difference in the calculation. For example, differences in entropies of mixing for different choices are only about 0.1 to $0.2 \mathrm{cal} / \mathrm{k}$.

Before discussing specific systems, we will present a general discussion of the sources of data. Much of the data used is contained in the $F^{*} A^{*} C^{*} T$ data system,16,17 which is stored in the computer used for the calculations. A large fraction of this data is from Barin and Knacke 18 and the JANAF tables.19 other data used in the calculations were derived from references 20-53. Free energies of fusion, $\Delta G_{f}$, of the four components considered are as follows:

CaO: $\Delta G_{f}=19000-6.678 \mathrm{~T} \mathrm{cal}, T_{f}=2845 \mathrm{~K}=2572^{\circ} \mathrm{C}$

Most tabulations agree on $19000 \mathrm{cal}$ for the enthalpy of fusion, $\Delta \mathrm{H}_{\mathrm{f}}$. The reported values of the melting point, $T_{f}$, vary from $2845 \mathrm{~K}^{21}$ up to $3200 \mathrm{~K}$. We chose $2845 \mathrm{~K}$ and calculated the entropy of fusion, $\Delta \mathrm{S}_{\mathrm{f}}$. Values of the differences between the heat capacities of the liquid and solid, $\Delta C_{p}$, are too uncertain to permit higher order terms in the above equation for $\Delta G_{f}$. 
$\underline{\mathrm{SiO}_{2}}: \Delta \mathrm{G}_{\mathrm{f}}(\mathrm{cristobalite})=2290-1.1473 \mathrm{~T} \mathrm{cal}, \mathrm{T}_{\mathrm{f}}=1996 \mathrm{~K}=1723^{\circ} \mathrm{C}$

Most tabulations agree quite closely on the value of $\mathrm{T}_{\mathrm{f}}$, but there are differences in $\Delta \mathrm{H}_{\mathrm{f}}$. We used a value given by Barin and Knacke ${ }^{18}$ and JANAF ${ }^{19}$ and ignored $\Delta \mathrm{C}_{\mathrm{p}}$. The free energy change for the tridymite-cristobalite transition $\Delta G_{t r}=310-0.1779 \mathrm{~T}, \mathrm{~T}_{\mathrm{tr}}=1743 \mathrm{~K}=1470^{\circ} \mathrm{C}$. There is good agreement on $\mathrm{T}_{\mathrm{tr}}=1743 \mathrm{~K}$ in different compilations. Wicks and Block 26 indicate a value of $310 \mathrm{cal}$ for $\Delta \mathrm{H}_{\mathrm{tr}}$. Our calculations are very insensitive to this quantity.

$$
\begin{aligned}
\mathrm{AlO}_{1.5}: \Delta \mathrm{G}_{\mathrm{f}}= & 10602.15+16.7745 \mathrm{~T}+5.4925\left(10^{-4}\right) \mathrm{T}^{2} \\
& -2.90949 \mathrm{~T} \text { In } \mathrm{T}-289000 \mathrm{~T}^{-1} \mathrm{cal}, \mathrm{T}_{\mathrm{f}}=2327 \mathrm{~K}=2054^{\circ} \mathrm{C}
\end{aligned}
$$

Data are from references 18,19 , and 27 .

$\mathrm{NaO}_{0.5}: \Delta \mathrm{G}_{\mathrm{f}}=5700-4.0570 \mathrm{~T}, \mathrm{~T}_{\mathrm{f}}=1405 \mathrm{~K}=1132^{\circ} \mathrm{C}$

Data are from references 18 and 19 . Earlier authors gave $\mathrm{T}_{\mathrm{f}}=1193 \mathrm{~K}$. Most recent work seems to agree on $1405 \mathrm{~K}$. Because of uncertainties in $\Delta \mathrm{C}_{\mathrm{p}}$, we did not attempt to use higher order terms in the equation for $\Delta G_{f}$. There is a solid state transformation at $1243 \mathrm{~K}$.

With this introductory discussion, we can present our analyses of five binary systems.

A.

\section{Data Considered}

a. Phase Diagram

Elliott and Gleiser's diagram 21 is in substantial agreement with that of Phillips and Muan20,22 (Fig. 6). A recent determination of the peritectic temperature involving the liquid and the solids $\mathrm{CaO}$ and $\mathrm{Ca}_{3} \mathrm{SiO}_{5}$ places it at $2150^{\circ} \mathrm{C}$ (Fig. 7). Two measurements of the miscibility gap (Figs. 8 and 9) agree on the monotectic composition but are in substantial disagreement on the upper consolute temperature. $20,24,28$

\section{b. Activities}

Sharma and Richardson 29 measured the activities of CaO (relative to solid as standard state) at 1500 and $1550^{\circ} \mathrm{C}$, as is shown in Fig. ' 10 . Rein and Chipman ${ }^{30}$ measured $\mathrm{aSiO}_{2}$ (relative to solid as standard state) at 1600 and $1550^{\circ} \mathrm{C}$. Activities for $\mathrm{CaO}$ and $\mathrm{SiO}_{2}$ at 1500,1550 , and $1600^{\circ} \mathrm{C}$ are exhibited in Fig. 11. A very small dependence of $\mathrm{aSiO}_{2}$ on temperature was observed, and it appears that ${ }^{a} \mathrm{CaO}$ does have a significant dependence on $\mathrm{T}$. A comparison of different measurements of asio (Fig. 12) as given by Sharma and Richardson indicates that the uncertainties in measurements by different workers may be larger than the apparent temperature dependence. 


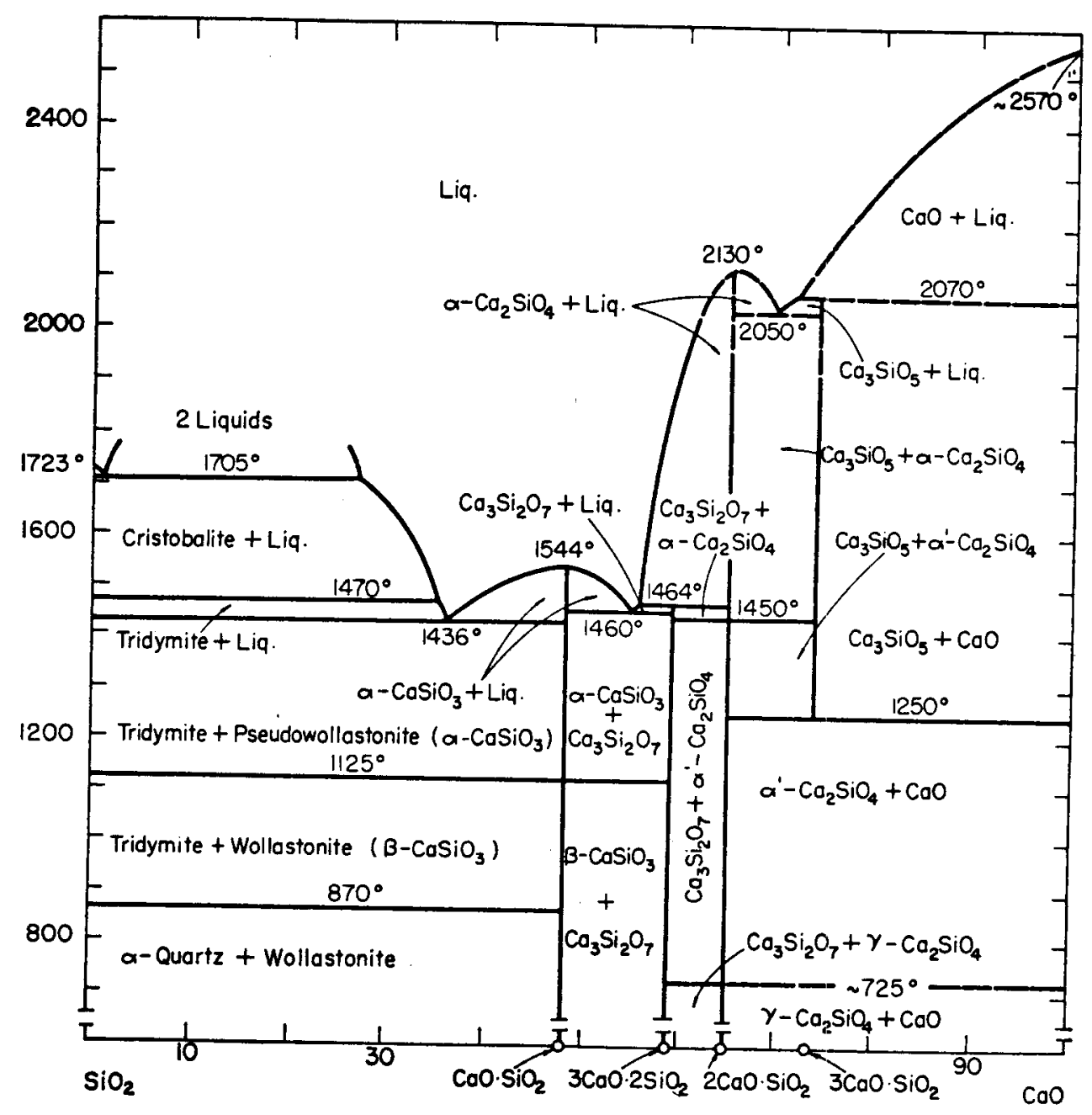

Fig. 6. Measured Phase Diagram in the $\mathrm{CaO}-\mathrm{SiO}_{2}$ System from Phillips and Muan 22 (from Ref. 20, Phase Diagrams for Ceramists, Fig. 237). Abscissa is in weight percent.

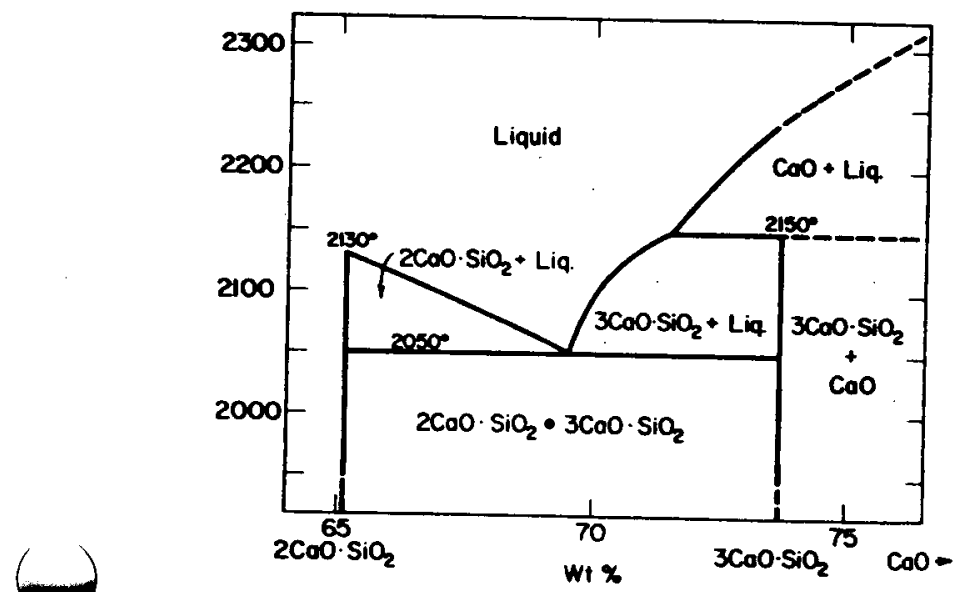

Fig. 7.

Measured Phase Diagram in the $\mathrm{CaO}-\mathrm{SiO}_{2}$ System from Revised Version in Gutt ${ }^{23}$ (from Ref. 20, Phase Diagrams for Ceramists, 1975 Supplement, Fig. 4311). 


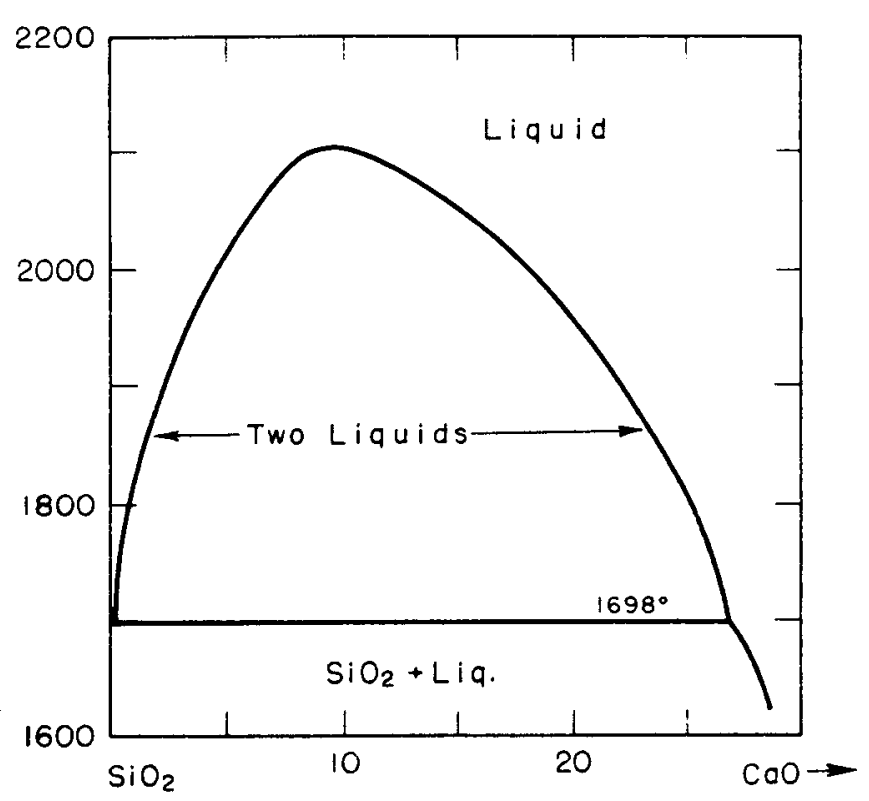

Fig. 8. Measured Phase Diagram in the $\mathrm{CaO}-\mathrm{SiO}_{2}$ System, with Miscibility Gap Measured by 01 'shanskii24 (from Ref. 20, Phase Diagrams for Ceramists, 1969 Supplement, Fig. 2302). Abscissa is in weight percent.

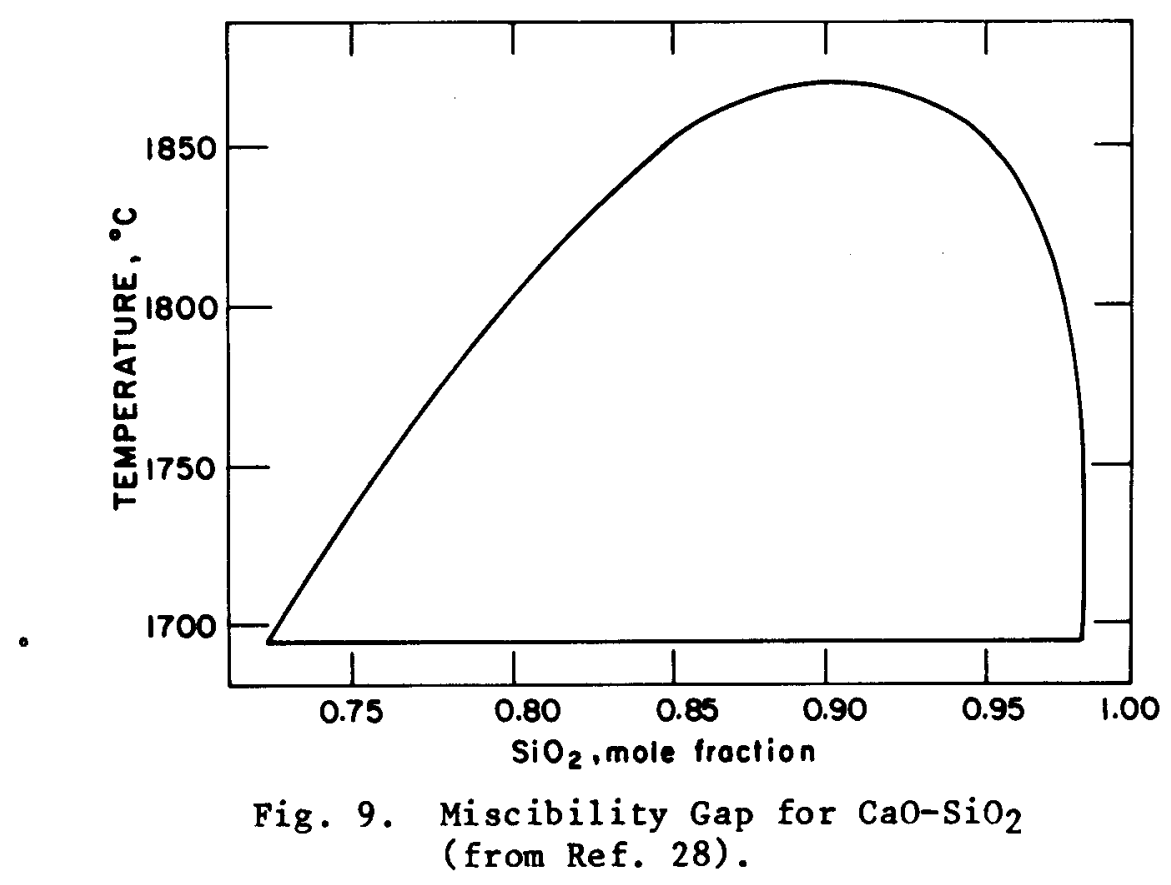




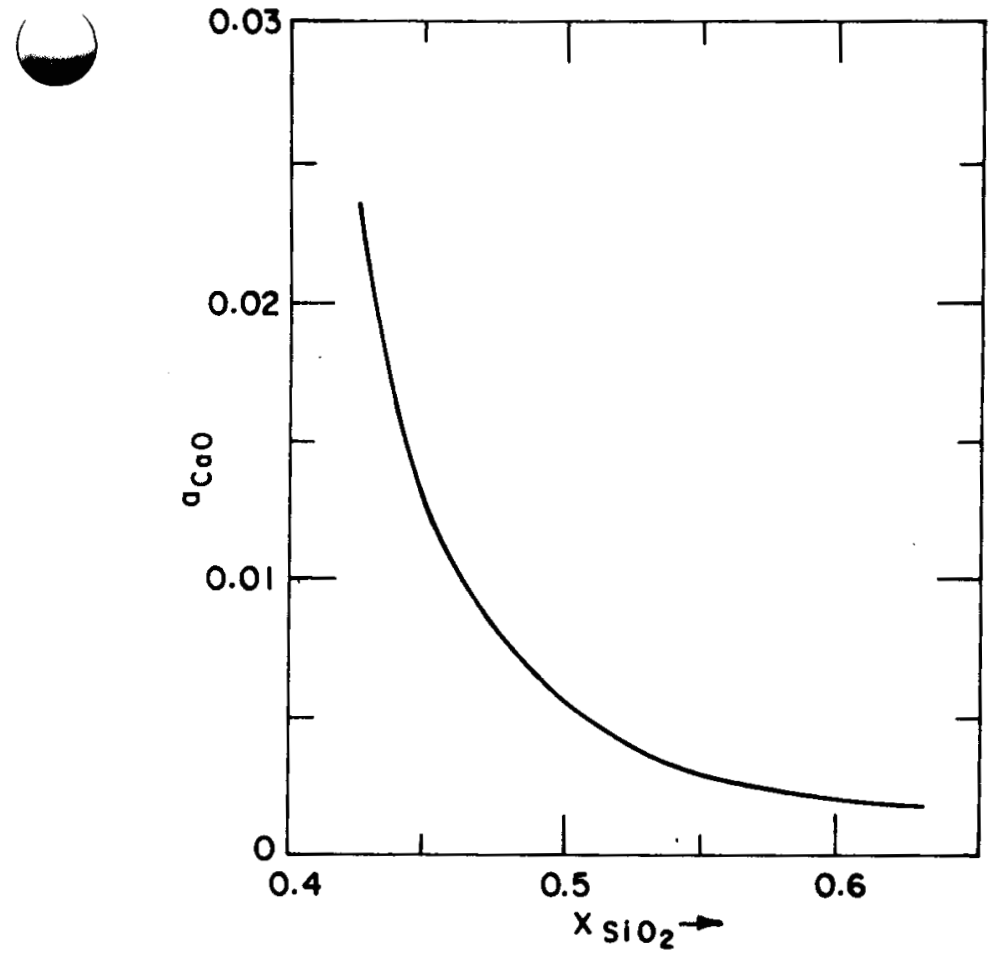

Fig. 10 .

Measured Activities of $\mathrm{CaO}$, Relative to Solid as Standard State, in the CaO- $\mathrm{SiO}_{2}$ System at 1500 and $1550^{\circ} \mathrm{C}$ (from Ref. 29).

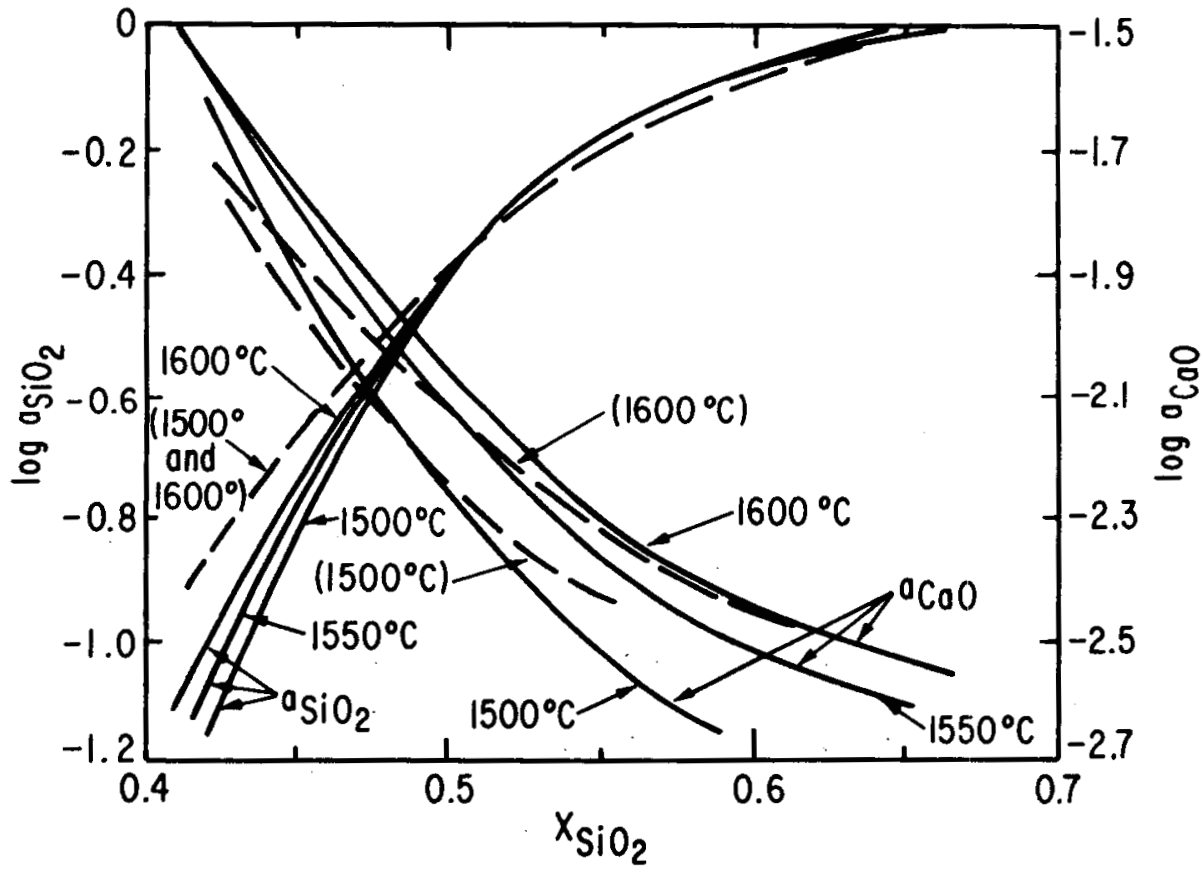

Fig. 11. Activities of $\mathrm{CaO}$ and $\mathrm{SiO}_{2}$ in $\mathrm{CaO}-\mathrm{SiO}_{2}$ at 1500, 1550 , and $1600^{\circ} \mathrm{C}$. From Ref. 30 (solid lines). The activities of $\mathrm{SiO}_{2}$ were measured and those of CaO were calculated by a Gibbs-Duhem integration. The dashed lines were calculated from the model discussed in the text. 


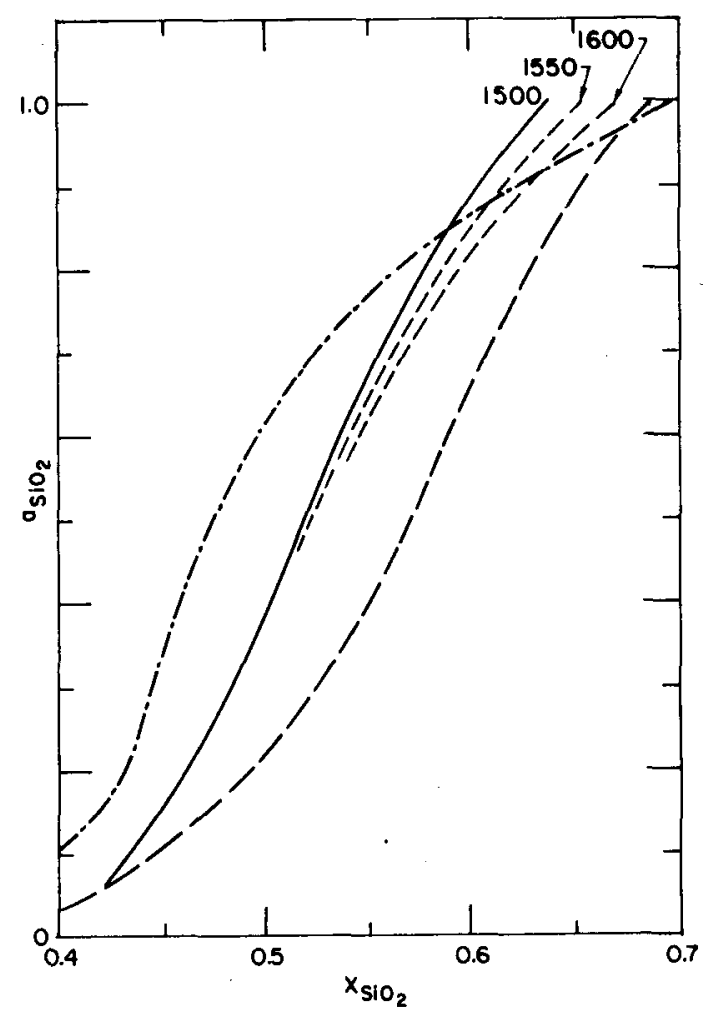

Fig. 12.

A Comparison of Silica Activities in the $\mathrm{CaO}-\mathrm{SiO}_{2}$ Binary System Calculated from Calcia Activities Measured by Different Workers (from Ref. 29). Solid and dashed lines are from Ref. 29. Dot-dashed curve is from measurements of Yang et al. (see Ref. 29) at $1627^{\circ} \mathrm{C}$. Longdashed curve measurements of Rein and Chipman 30 at $1600^{\circ} \mathrm{C}$ were recalculated by Sanbongi and Amori.

\section{c. Free Energies of Formation of Compounds}

$\mathrm{CaSiO}_{3}$. Barin and $\mathrm{Knacke}^{18}$ give the standard free energy of formation, at the melting point of $1544^{\circ} \mathrm{C}$, as $\Delta G^{\circ}=-13907 \mathrm{cal}$ for $1 / 2 \mathrm{CaO}(l)+$ $1 / 2 \mathrm{SiO}_{2}(l) \neq 1 / 2 \mathrm{CaSiO}_{3}(\mathrm{~s})$, which is equal to the value of $\Delta G_{\mathrm{m}}$ at $1817 \mathrm{~K}$. From the data of Rein and Chipman ${ }^{30}$ with a correction for the free energy of fusion, we calculate $-14122 \mathrm{cal}$. Agreement is well within uncertainties in the data.

$\mathrm{Ca}_{2} \mathrm{SiO}_{4}$. At the melting point of 2403K (from the data of Rein and Chipman corrected for the free energy of fusion), we calculate -14591 cal for $2 / 3 \mathrm{CaO}(\ell)+1 / 3 \mathrm{SiO}_{2}(\ell)+1 / 3 \mathrm{Ca}_{2} \mathrm{SiO}_{4}(\mathrm{~s})$ which is $\Delta \mathrm{G}_{\mathrm{m}}$ at $2403 \mathrm{~K}$ at $\mathrm{X}_{\mathrm{SiO}_{2}}=$ 0.3333. A $600^{\circ}$ extrapolation of the data of Robie et al. 25 gives -15424 cal, which agrees within the uncertainties in the data and the extrapolation.

In the optimization procedure, we used the following data:

i. $\mathrm{aSiO}_{2}$ from Ref. 30 at $1600^{\circ} \mathrm{C}$.

ii. a $\mathrm{CaO}$ from Ref. 29 at $1500^{\circ} \mathrm{C}$.

iii. $\Delta G_{m}$ at $X=0.333$ and 0.500 , from the free energies of formation of $\mathrm{CaSiO}_{3}$ and $\mathrm{Ca}_{2} \mathrm{SiO}_{4}$ at the melting point.

iv. Some $\mathrm{SiO}_{2}$ liquidus points between 1436 and $1700^{\circ} \mathrm{C}$.

v. A CaO liquidus point of $2150^{\circ} \mathrm{C}, \mathrm{X}_{\mathrm{SiO}_{2}}=0.27$.

vi. The miscibility gap boundaries from Fig. 9. 


\section{Results}

The optimization procedure led to the following expression for $W$

$$
W=(-44,434+6 \mathrm{~T})-17403 \mathrm{y}_{\mathrm{SiO}_{2}}^{3}+(51078-10 \mathrm{~T}) \mathrm{y}_{\mathrm{SiO}_{2}}^{6} \mathrm{cal}
$$

The exponents of $\mathrm{ySiO}_{2}$ in this series were chosen in a series of tests by trial and error; once chosen, the coefficients $c_{i}$ (see Eqs. 49 and 54) without the temperature coefficients were calculated in the optimization calculation. This led to a very good fit to almost all of the data. The two temperaturedependent terms in Eq. 56 led to only small changes in the overall fit and provided an excellent representation of all of the data.

The calculated phase diagram, shown in Fig. 13, may be compared with Figs. 6 and 7. Small adjustments in the free energies of formation of the compounds were made in the calculation to give accurate peritectic and eutectic temperatures. When this was done, the compositions of the eutectics and peritectics were accurately calculated with the same values. For the compound $\mathrm{Ca}_{3} \mathrm{SiO}_{5}$, the free energies of formation from the oxides were chosen in the calculation so as to reproduce the invariants at 2150 and $1250^{\circ} \mathrm{C}$. The free energies of formation of the three compounds in this system, which led to an excellent representation of the phase diagram (as shown in Fig. 13), are

$$
\begin{array}{r}
1 / 2 \mathrm{CaO}(l)+1 / 2 \mathrm{SiO}_{2}(l)+1 / 2 \mathrm{CaSiO}_{3}(\mathrm{~s}) \\
\Delta G^{\circ}=-21266+3.9 \mathrm{~T} \mathrm{cal} \\
2 / 3 \mathrm{CaO}(l)+1 / 3 \mathrm{SiO}_{2}(l)+1 / 3 \mathrm{Ca}_{2} \mathrm{SiO}_{4}(\mathrm{~s}) \\
\Delta G^{\circ}=-23248+3.54 \mathrm{~T} \mathrm{cal} \\
3 / 4 \mathrm{CaO}(l)+1 / 4 \mathrm{SiO}_{2}(l)+1 / 4 \mathrm{Ca}_{3} \mathrm{SiO}_{5}(\mathrm{~s}) \\
\Delta G^{\circ}=-21438+3.8333 \mathrm{~T} \mathrm{cal}
\end{array}
$$

From these, we calculate the free energy of formation of $1 / 2 \mathrm{CaSiO}_{3}$ at the melting point $(1817 \mathrm{~K})$ to be $-14180 \mathrm{cal}$, in comparison to the tabulated value ${ }^{18}$ of $-13907 \mathrm{cal}$ and calculate the free energy of formation of $1 / 3 \mathrm{Ca}_{2} \mathrm{SiO}_{4}$ to be $-14741 \mathrm{cal}$ at the melting point $(2303 \mathrm{~K})$, as compared with the tabulated value 9 of $-14591 \mathrm{cal}$. The calculated entropies of fusion of $1 / 2 \mathrm{CaSiO}_{3}$ and $1 / 3$ $\mathrm{Ca}_{2} \mathrm{SiO}_{4}$ are 3.16 and $1.23 \mathrm{cal} / \mathrm{K}$, respectively. In Fig. 11 are shown the measured 29,30 and calculated activities of $\mathrm{CaO}$ and $\mathrm{SiO}_{2}$ in the $\mathrm{CaO}^{-\mathrm{SiO}_{2}}$ binary. Agreement is well within the uncertainties related to measurements of activities and entropies of fusion. Remarkably, our results have the same temperature dependence as do the measurements (almost zero for $\mathrm{aSiO}_{2}$; significant for ${ }^{a} \mathrm{CaO}$ ). 


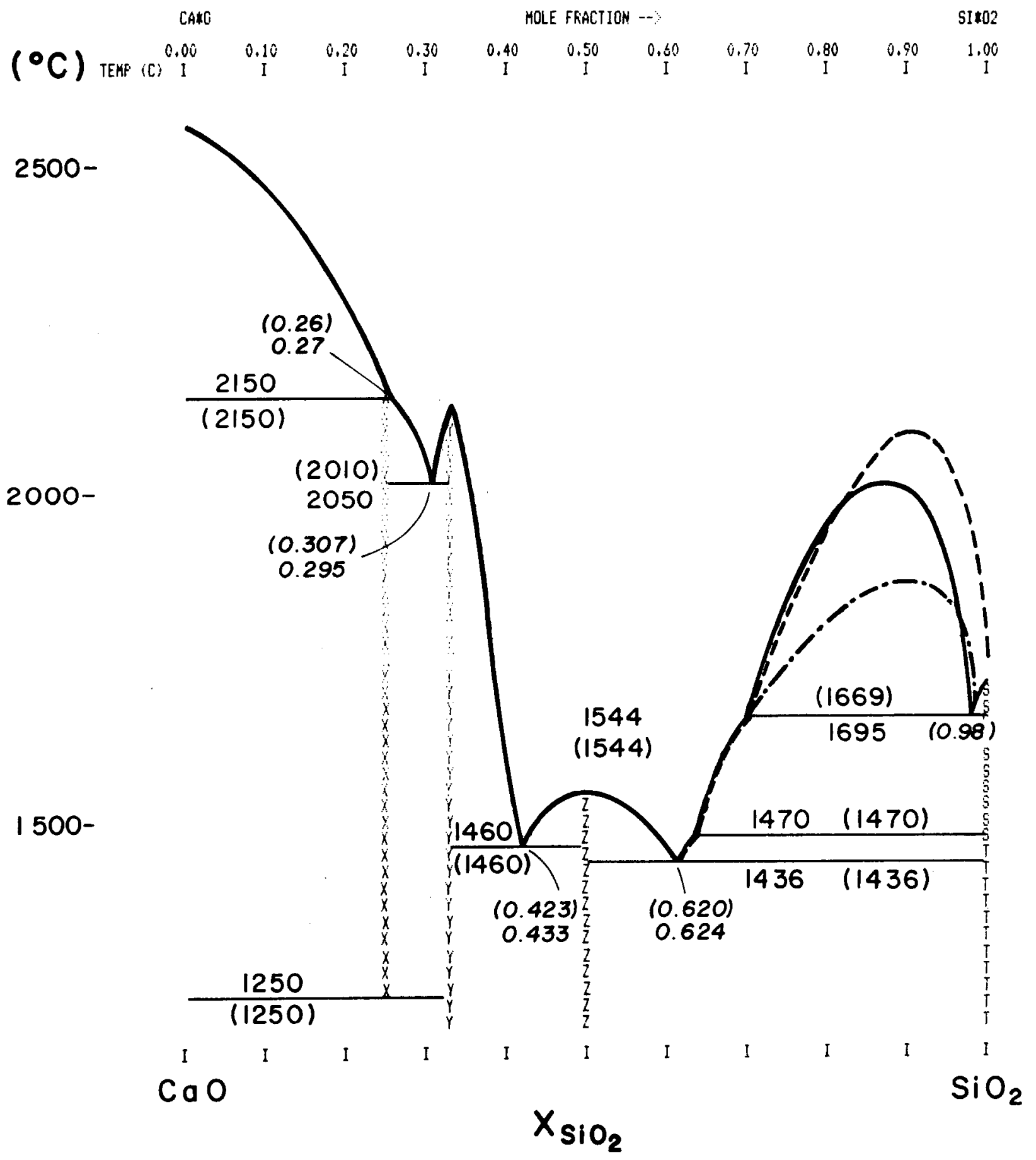

Fig. 13. Phase Diagram for the $\mathrm{CaO}-\mathrm{SiO}_{2}$ System Calculated from the Model Using Values of W Given by Eq. 56. Numbers not in parentheses are calculated from the model; those in parentheses are from measured phase diagrams . 
The miscibility gap between 69 and $299 \%$ silica was also calculated. Our calculated upper consolute temperature of $2203 \mathrm{~K}$ is below the value reported by 01 'shanskii ( $2373 \mathrm{~K})^{24}$ and above that reported by Tewhey and Hess $(\sim 2154 \mathrm{~K}) .28$ If one or the other is shown to be correct, the parameter $s_{6}$ can be adjusted to reproduce the "exact" consolute temperature. The adjustment would make a negligibly small difference in all the thermodynamic properties. The calculated monotectic temperature is $1942 \mathrm{~K}$, as compared with the measured value of $1968 \mathrm{~K}$, with boundaries between 0.70 and $0.98 \mathrm{SiO}_{2}$ (at both measured monotectic temperatures, $1971 \mathrm{~K}$ and 1968K). The calculated low silica boundary was very close to that of 01 'shanskii up to $2190 \mathrm{~K}$ and was closer to that of Tewhey and Hess at the high silica boundary up to about $2100 \mathrm{~K}$.

The thermodynamic properties in this system are very well represented with the five parameters in Eq. 56. Our results represent the first accurate analysis and representation of data on a system with solution behavior as complex as the $\mathrm{CaO}_{-} \mathrm{SiO}_{2}$ binary. The fact that this was accomplished with only five parameters in the solution model lends support to the rationale underlying our approach. The small discrepancies and uncertainties in the data related to the miscibility gap represent extremely small differences in free energies of mixing. Better data and a better representation of the miscibility gap will change the representation of the activities negligibly.

\section{B. $\mathrm{CaO}-\mathrm{A} 10_{1.5}$ \\ 1. Data Considered}

\section{a. Phase Diagram}

We have utilized the most recent phase diagram of Nurse et al., 32 which is exhibited in Fig. 14. In this diagram, there is no phase field for the compound $\mathrm{C}_{12} \mathrm{~A}_{7}\left(\mathrm{C}=\mathrm{CaO} ; \mathrm{A}=\mathrm{Al}_{2} \mathrm{O}_{3}\right)$ having melting and eutectic temperatures between 1390 and $1415^{\circ} \mathrm{C}$; this compound is exhibited in an earlier diagram by Elliott and Gleiser. 21

\section{b. Activities}

Activities were measured at $2060 \mathrm{~K}$ by Allibert et al.33 (Fig. 15) by mass spectroscopy and also at $1500^{\circ} \mathrm{C}$ by Sharma and Richardson ${ }^{\circ}$ (Fig. 16). older measurements reviewed by Sharma and Richardson are also shown in Fig. 16 .

\section{c. Free Energies of Formation of Compounds}

By combining activity data with the phase diagram and thermodynamic data in the literature, Allibert et al.33 deduced recommended values for the free energies of formation of the binary compounds in this system. Four of these are listed in Table 1. By combining these values with the phase diagram and with the free energies of fusion, Allibert et al. calculated

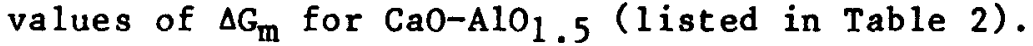




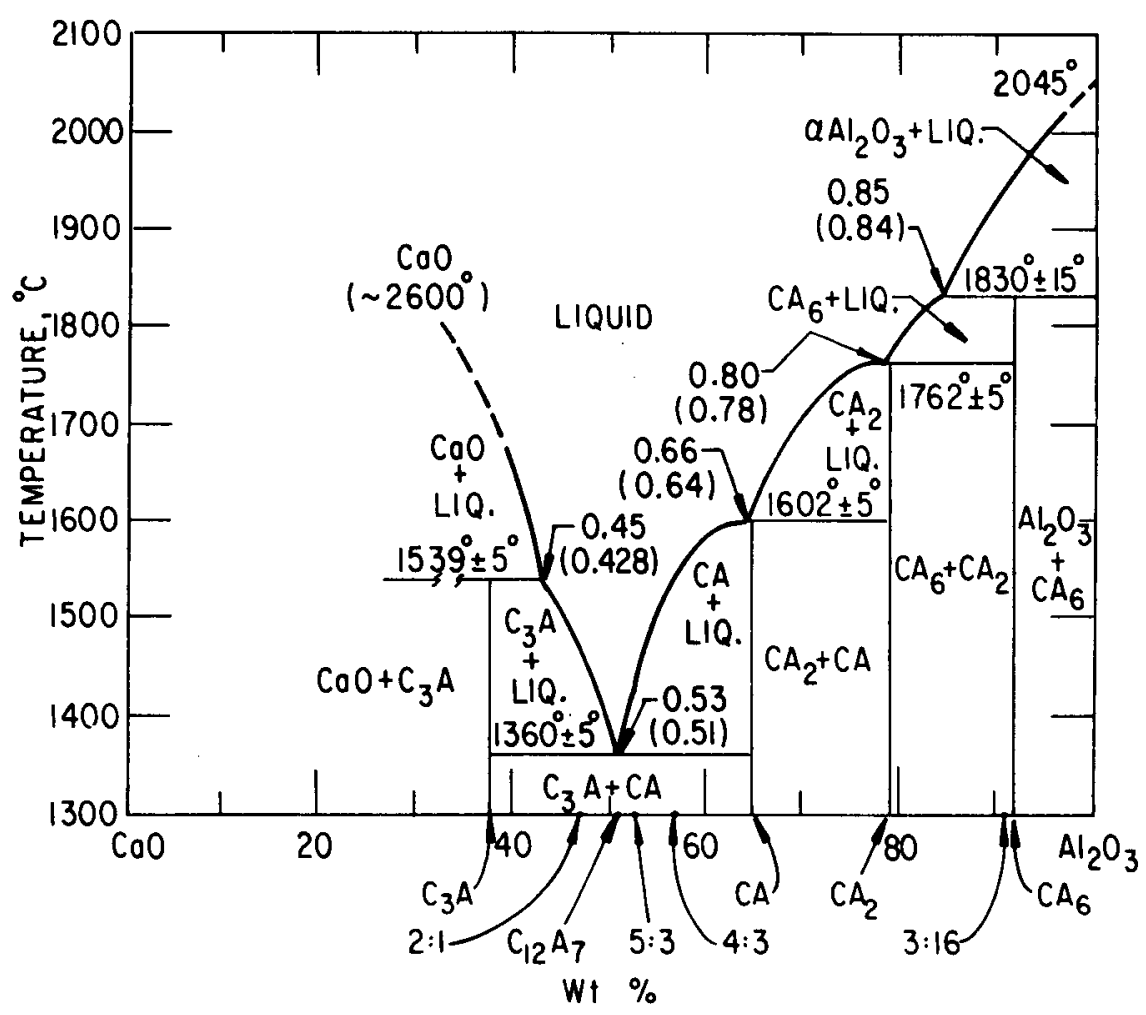

Fig. 14. Phase Diagran of the $\mathrm{CaO}-\mathrm{Al}_{2} \mathrm{O}_{3}$ System $(\mathrm{C}=\mathrm{CaO}$; $\mathrm{A}=\mathrm{Al}_{2} \mathrm{O}_{3}$ ). At the invariant points, the numbers indicate the concentrations in both mole percent and, in parentheses, weight percent (from Ref. 32).

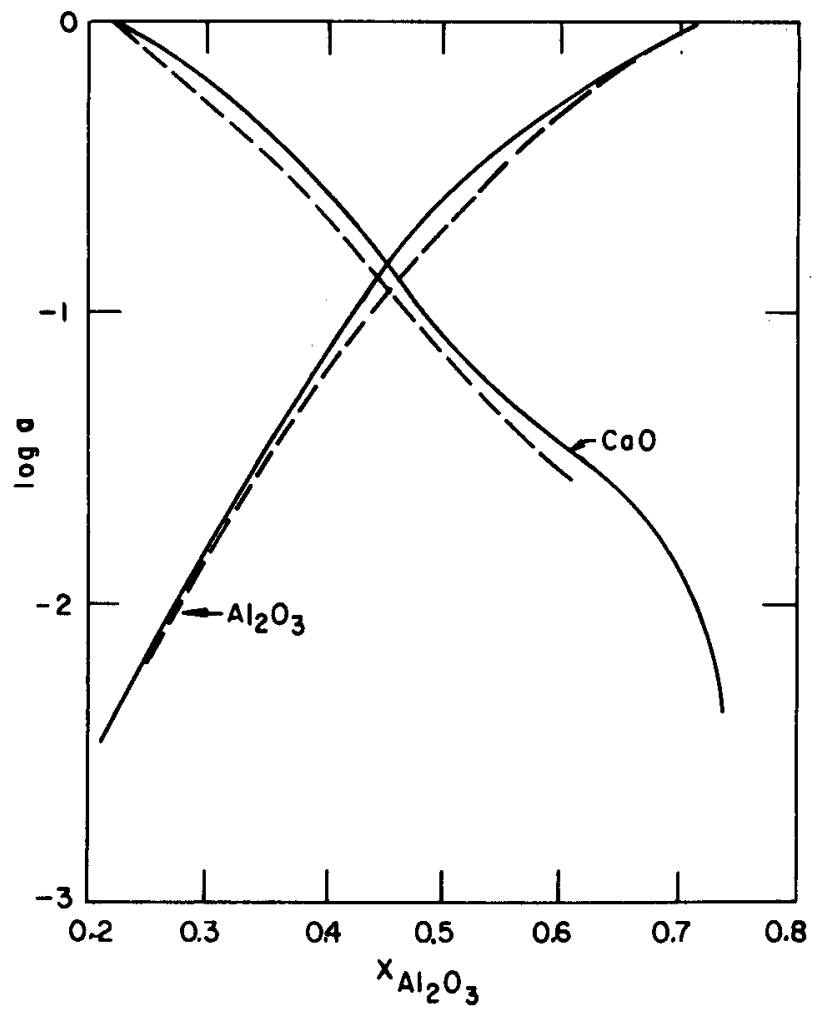

Fig. 15.

Activities in $\mathrm{CaO}-\mathrm{Al}_{2} \mathrm{O}_{3}$ Melts at $2060 \mathrm{~K}\left(1787^{\circ} \mathrm{C}\right)$ with Solids as Standard States. Solid lines represent measurements (from Ref. 33). Dashed lines are calculated from our model. 


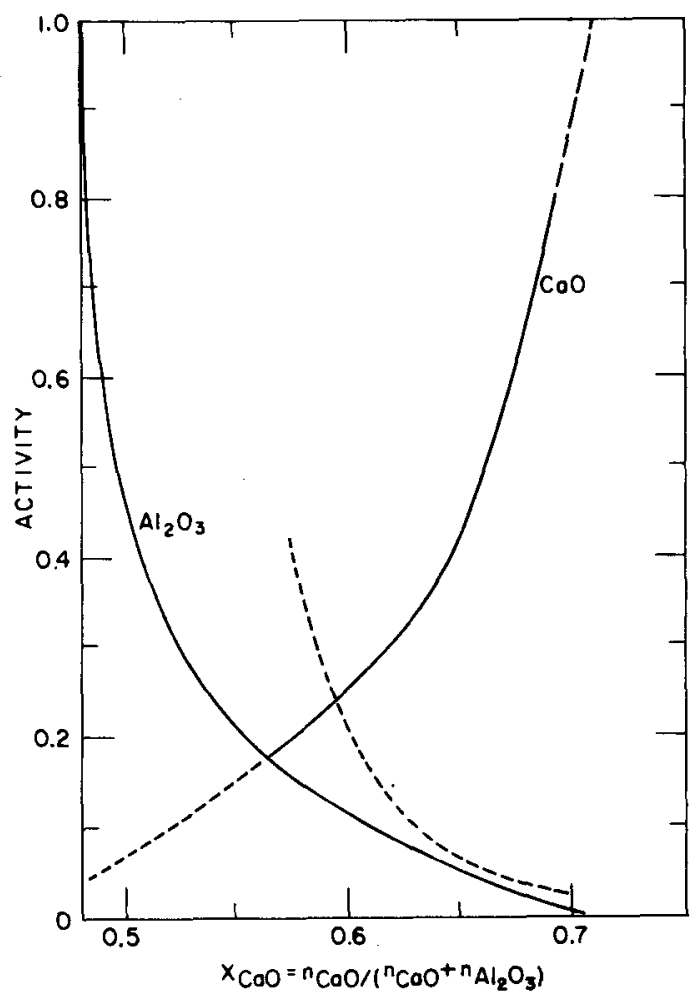

Fig. 16 .

Activities of $\mathrm{CaO}$ and $\mathrm{Al}_{2} \mathrm{O}_{3}$ in $\mathrm{CaO}-\mathrm{Al}_{2} \mathrm{O}_{3} \mathrm{Melts}$ at $1500^{\circ} \mathrm{C}$ Relative to Solid as Standard State (from Ref. 29). Solid lines are from Sharma and Richardson; dashed line from Ch ipman. 30

Table 1. Free Energies of Formation of Solid Compounds from the Solid Oxides (Values calculated in Ref. 33 and in this study).

\begin{tabular}{lrr}
\hline \multirow{2}{*}{ Compound } & \multicolumn{3}{c}{$\Delta \mathrm{G}^{\circ}, \mathrm{cal}$} \\
\cline { 2 - 4 } $1 / 13 \mathrm{CaAl}_{12} \mathrm{O}_{19}$ & $-320.5-0.684 \mathrm{~T}$ & $-250.5-0.684 \mathrm{~T}$ \\
$1 / 5 \mathrm{CaAl}_{4} \mathrm{O}_{7}$ & $-783.9-1.281 \mathrm{~T}$ & $-1180-1.281 \mathrm{~T}$ \\
$1 / 3 \mathrm{CaAl}_{2} \mathrm{O}_{4}$ & $-1443.6-1.483 \mathrm{~T}$ & $-1505-1.483 \mathrm{~T}$ \\
$1 / 5 \mathrm{Ca}_{3} \mathrm{Al}_{2} \mathrm{O}_{6}$ & $-812.6-1.530 \mathrm{~T}$ & $-655-1.530 \mathrm{~T}$ \\
\hline
\end{tabular}


Table 2. Free Energies of Mixing in the Binary $\mathrm{CaO}-\mathrm{AlO}_{1} .5$

\begin{tabular}{lcc}
\hline $\mathrm{T}, \mathrm{K}$ & $\mathrm{X}_{\mathrm{Al}} \mathrm{O}_{1.5}$ & $\Delta G_{\mathrm{m}}, \mathrm{a}$ cal/mo \\
\hline 2103 & 0.85 & -5327 \\
2035 & 0.80 & -5885 \\
1875 & 0.661 & -8264 \\
1633 & 0.53 & -9576 \\
1812 & 0.45 & -9408 \\
\hline
\end{tabular}

${ }^{a}$ Calculated from Allibert et a1.33

The input for the optimization procedure included the following:*

i. Activities at $2060 \mathrm{~K}$.

ii. Activities at $1773 \mathrm{~K}$.

iii. $\Delta G_{\mathrm{m}}$ from Table 2 .

iv. $\mu_{A 10_{1.5}}$ on the liquidus at $\mathrm{T}=2103 \mathrm{~K}, \mathrm{X}=0.85$.

v. $\mu_{\mathrm{CaO}}$ on the liquidus at $\mathrm{T}=1812 \mathrm{~K}, \mathrm{X}=0.45$.

\section{Results}

The optimization and analysis led to the following expression for $\mathrm{W}$ :

$$
\mathrm{W}=(-20212+2 \mathrm{~T})-24684 \mathrm{y}^{3} \mathrm{AlO}_{1.5} \mathrm{cal}
$$

The calculated invariant points are compared with the measured phase diagram given in Fig. 17. In order to get the peritectics at the correct temperatures, adjustments had to be made in the free energies of formation of the compounds. When this was done, all of the invariant points in the phase diagrams except the eutectic at $1360^{\circ} \mathrm{C}$ and $\mathrm{X}_{\mathrm{Al}} 0_{1.5}$ at 0.53 can be well represented by the calculations (Figs. 14 and 17). Our calculated eutectic temperature is $1450^{\circ} \mathrm{C}$, considerably higher than the measured values. However, this difference represents only a small difference in the free energy of mixing of the liquid. It should be pointed out that the eutectic has been questioned and some workers report a compound $\mathrm{Ca}_{12} \mathrm{Al}_{14} \mathrm{O}_{33}$. Even if this compound is present, 1 iquidus temperatures near the eutectic (as low as $1390^{\circ} \mathrm{C}$ ) are lower than our calculated

* Note: The input data in items iv and $v$ are peritectic points involving the solids $\mathrm{AlO}_{1.5}$ and $\mathrm{CaO}$, respectively. 
values. To illustrate the sensitivity of liquidus temperatures to small changes in the free energies of formation of compounds, we plot a phase diagram in Fig. 18, which was calculated using the free energies of formation of Allibert et al.33 The differences between Fig. 18 and Fig. 17 are very large.

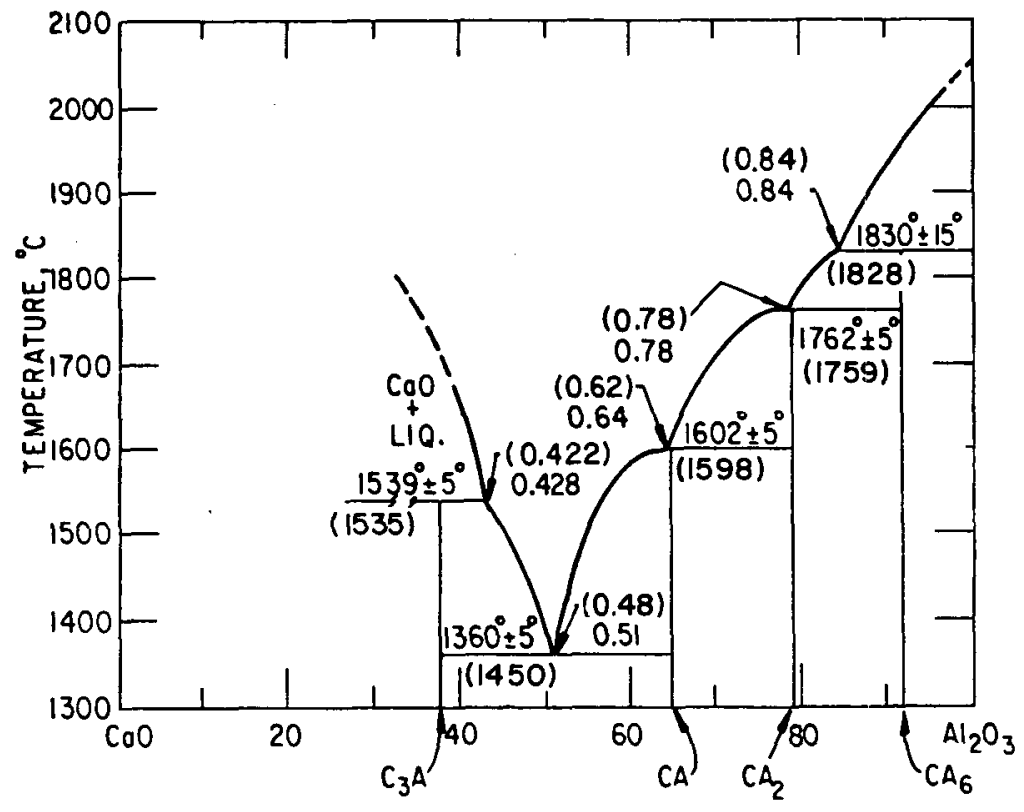

WI $\%$

Fig. 17. Calculated and Measured Phase Diagram for the $\mathrm{CaO}-\mathrm{AlO}_{1.5}$ System. Values of compositions and temperatures in parentheses are invariant points calculated from the model, using adjusted values for the free energy of formation of the compounds given in Table 1 .

Our calculated activities at $2060 \mathrm{~K}$ are plotted in Fig. 15. The agreement of measured and calculated data is well within the uncertainties in the data. Calculated and measured activities (solid as standard state) and partial molar excess free energies of $\mathrm{CaO}$ ( 1 iquid as standard state) at $1773 \mathrm{~K}$ are given in Table 3 . The agreement is very good.

Values for the free energies of formation of the four compounds which we deduce from our analysis are compared with recommended values of Allibert et al.33 in Table 1 . The differences between our results and those of Allibert et al.33 are within experimental uncertainties except for $\mathrm{CaAl}_{4} \mathrm{O}_{7}$. Since both analyses for this compound are based on independent interpretations of measurements, we cannot rule out either one. We will examine this discrepancy more carefully. 


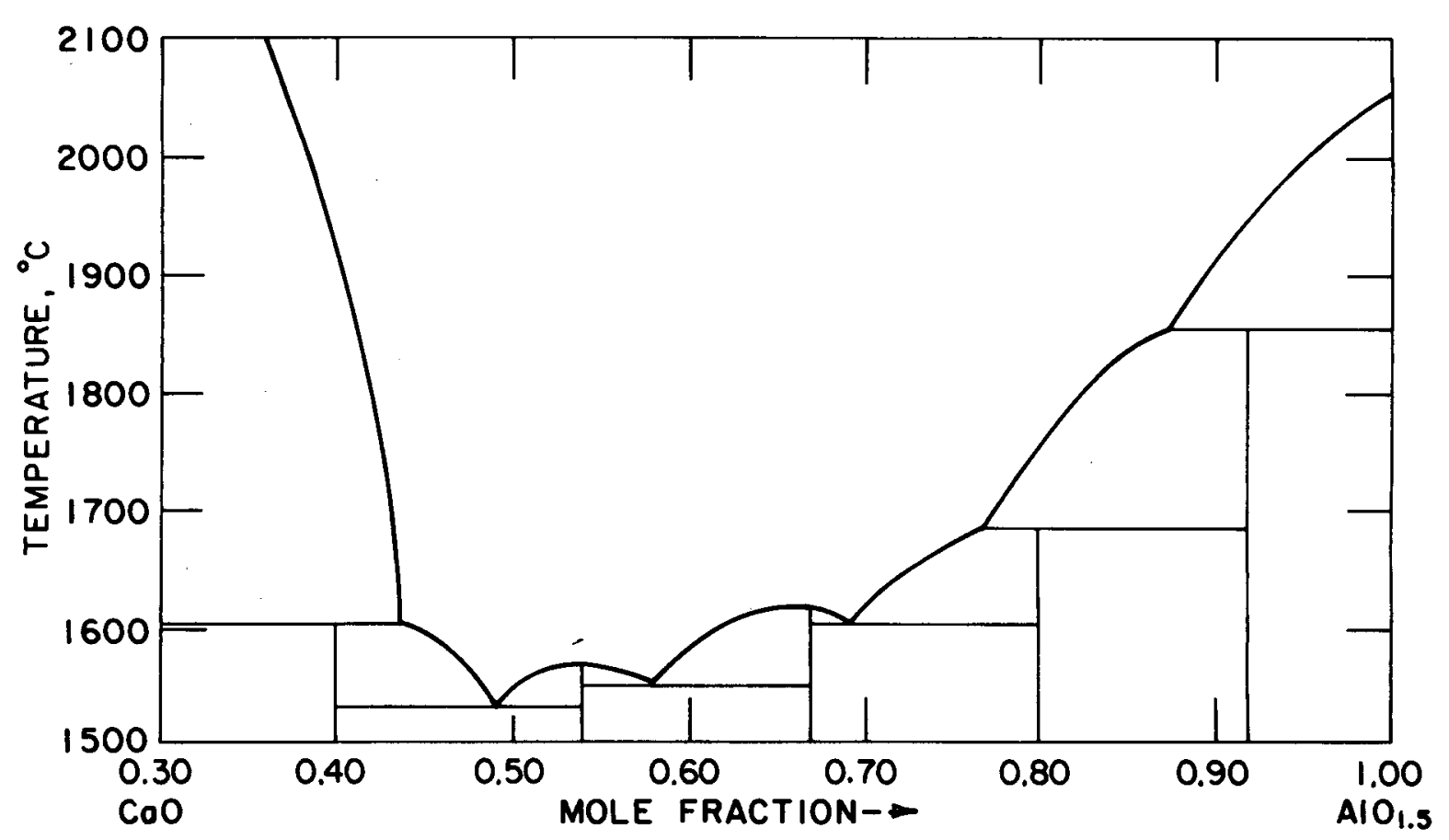

Fig. 18. Phase Diagram for the $\mathrm{CaO}-\mathrm{Al}_{2} \mathrm{O}_{3}$ System Calculated Using the Free Energies of Formation of the Compounds Given in Ref. 33. Comparison of this figure with Fig. 17 illustrates the sensitivity of liquidus temperatures to small changes in the free energies of formation of compounds.

Table 3. Activities and Partial Molar Excess Free Energies of Mixing of $\mathrm{CaO}$ in the $\mathrm{CaO}-\mathrm{Al}_{2} \mathrm{O}_{3}$ system at $1773 \mathrm{~K}$. Measured by Sharma and Richardson 29 and calculated using the parameters in Eq. 60 .

\begin{tabular}{|c|c|c|c|c|}
\hline \multirow[b]{2}{*}{$\mathrm{x}_{\mathrm{A} 10_{1.5}}$} & \multicolumn{2}{|c|}{${ }^{\mathrm{a}} \mathrm{CaO}$} & \multicolumn{2}{|c|}{$\overline{\mathrm{G}}_{\mathrm{CaO}, \mathrm{cal}}^{\mathrm{E}}$} \\
\hline & Calc.a & Meas. ${ }^{a}$ & Calc.b & Meas.b \\
\hline 0.592 & 0.22 & 0.21 & -9381 & -9499 \\
\hline 0.571 & 0.27 & 0.25 & -8815 & -9062 \\
\hline 0.551 & 0.33 & 0.30 & -8258 & -8581 \\
\hline 0.529 & 0.40 & 0.38 & -7700 & -7916 \\
\hline 0.507 & 0.50 & 0.50 & -7094 & -7110 \\
\hline 0.485 & 0.63 & 0.67 & -6440 & -6233 \\
\hline 0.450 & 0.97 & 1.00 & -5167 & -5054 \\
\hline
\end{tabular}

a Solid as standard state.

b Liquid as standard state. 
The representations of activities of components in the liquid are very good, and our analysis is accurate enough for reliable predictions of activities and for baseline data in the analysis of higher order systems. This was accomplished with the use of only three parameters to represent the thermodynamic properties of the liquid solutions.

C. $\mathrm{NaO}_{0.5} \mathrm{SiO}_{2}$

\section{Data Considered}

a. Phase Diagram

The measurements of $\mathrm{Kracek}^{35}$ (from Ref. 21) are given in Fig. 19; details for one eutectic 20,36 on the high-silica side are in Fig. 20; and the liquidus near pure $\mathrm{SiO}_{2}$ is in Fig. 21. In Fig. 19, the implied melting point of $\mathrm{Na}_{2} \mathrm{O}$ is very high, whereas recent data indicate a value of $1132^{\circ} \mathrm{C}$. In Ref. 18 , the (congruent) melting point of the compound $2 \mathrm{Na}_{2} \mathrm{O} \cdot \mathrm{SiO}_{2}$ is given as $1120^{\circ} \mathrm{C}$, which corresponds to the reported peritectic in Fig. 19. Although we will assume that $1120^{\circ} \mathrm{C}$ is the congruent melting point of this compound, it is clear that there is significant uncertainty in the phase diagram near this compound. The data used from the phase diagram measurements in Figs. 19-21 are the invariant points at mole fractions of $\mathrm{SiO}_{2}$ above 0.27 and the silica liquidus points. Below 0.27 mole fraction $\mathrm{SiO}_{2}$, the phase equilibria involve the phase $\mathrm{Na}_{4} \mathrm{SiO}_{4}$, for which different studies obtained widely differing liquidus temperatures and temperatures of the congruent (or incongruent) melting of the compound.

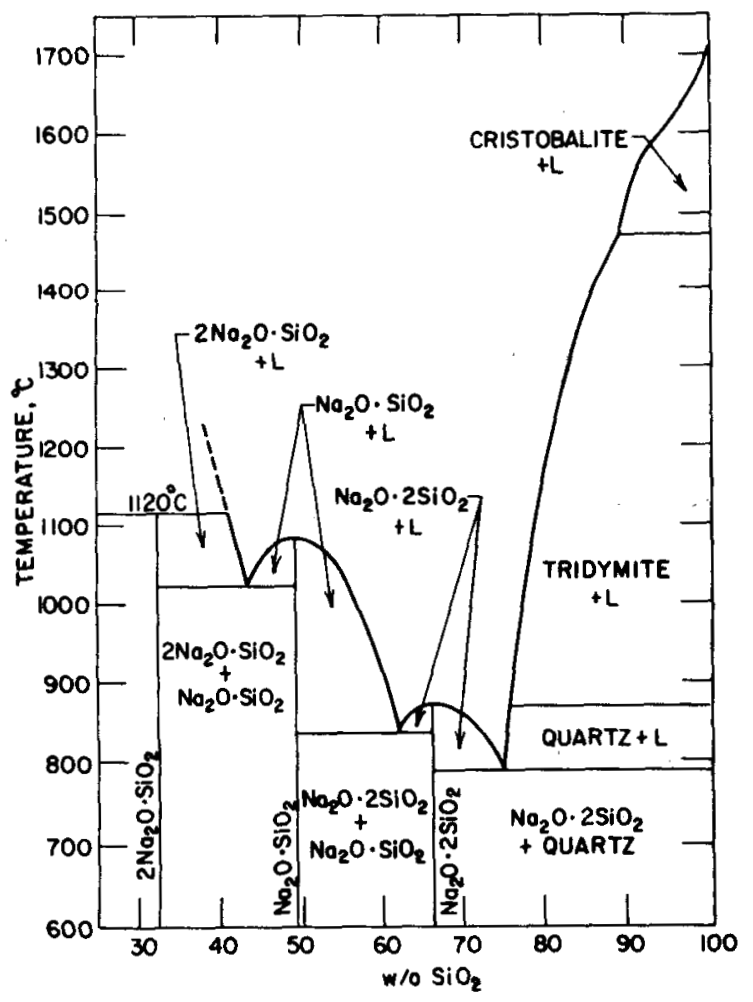

Fig 19.

Phase Diagram of the $\mathrm{NaO}_{0} .5-\mathrm{SiO}_{2}$ System from Refs. 20, 21, and 35 . 


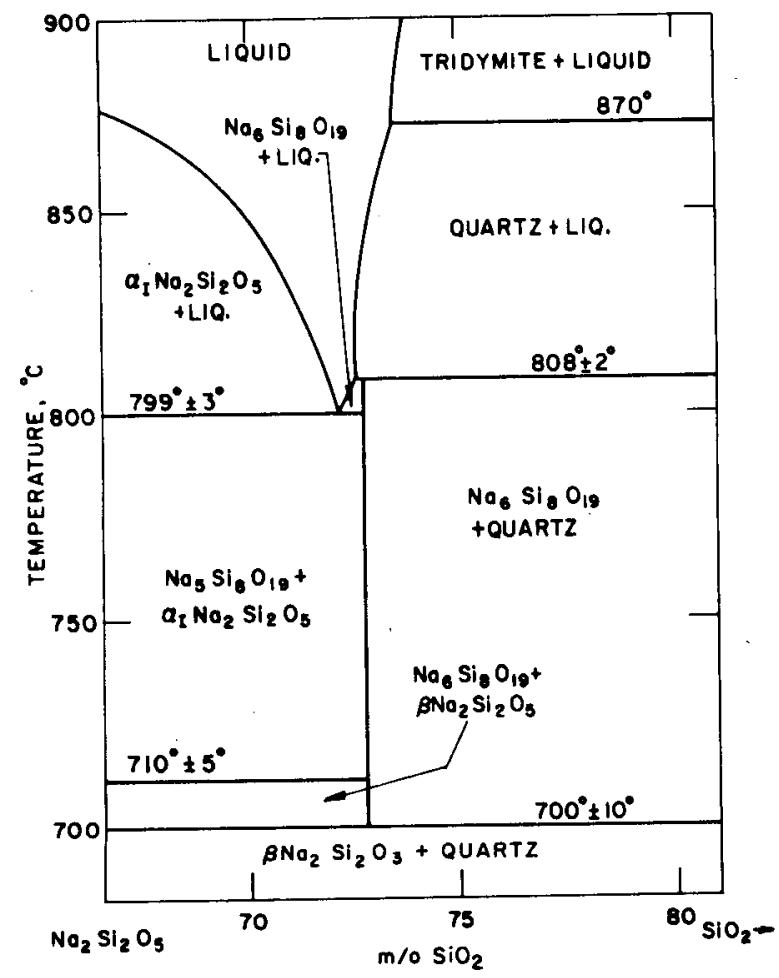

Fig. 20 .

Phase Diagram of the $\mathrm{NaO}_{0} \cdot 5^{-\mathrm{SiO}_{2}}$ System from Refs. 20 and 36 .

Fig. 21 .

Phase Diagram of the $\mathrm{NaO}_{0} \cdot \mathrm{S}^{-\mathrm{SiO}_{2}}$ System from Ref. 35. (Reprinted with permission. Copyright 1930 American Chemical Society.)

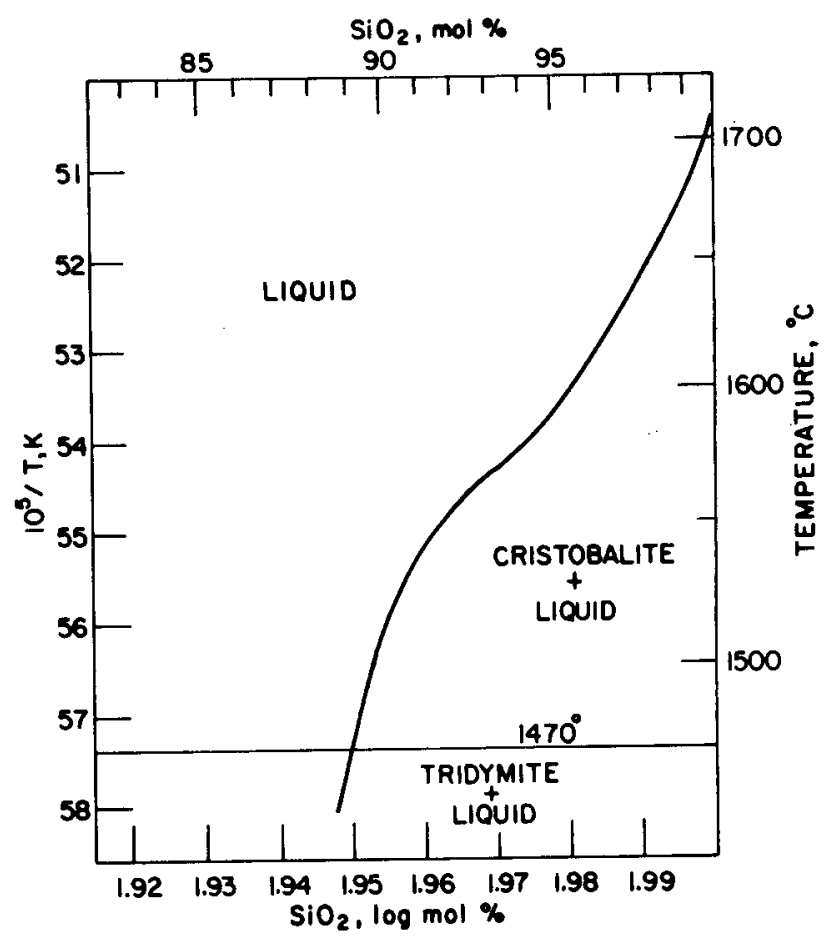




\section{b. Activities}

Neudorf and Elliot ${ }^{37}$ have measured the activities of $\mathrm{Na}_{2} \mathrm{O}$ at temperatures of 1000 to $1100^{\circ} \mathrm{C}$, which are given in Fig. 22. A comparison of the results of different authors by Neudorf and Elliott is given in Fig. 23, which shows large differences in results obtained by different workers.

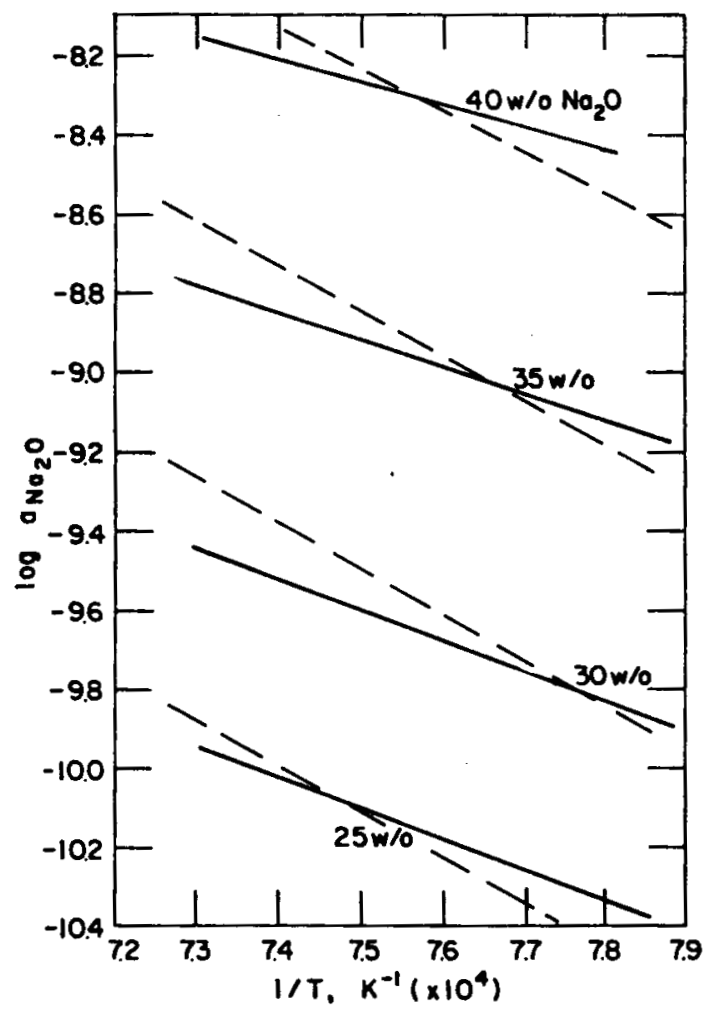

Fig. 22 .

Activities of $\mathrm{Na}_{2} \mathrm{O}$ (at 25, 30, 35 , and 40 wt $\left.\% \mathrm{Na}_{2} \mathrm{O}\right)$ as a Function of Temperature in the $\mathrm{Na}_{2} \mathrm{O}-\mathrm{SiO}_{2}$ System. Solid lines are from Ref. 37; dashed lines are based on calculated values.

\section{c. Free Energies of Formation of Compounds}

$\mathrm{Na}_{2} \mathrm{Si}_{2} \mathrm{O}_{5}$ : The standard free energy and enthalpy of formation and the enthalpy of fusion of $1 / 4 \mathrm{Na}_{2} \mathrm{Si}_{2} \mathrm{O}_{5} 18$ can be used to calculate the $\Delta G_{m}$ and $\Delta H_{m}$ of the liquid at $X_{S_{i O}}=0.5$ at the melting point of $1174 \mathrm{~K}$ :

$$
\begin{aligned}
\Delta G_{m} & =-15392 \mathrm{cal} \\
\Delta H_{m} & =-15977 \mathrm{cal}
\end{aligned}
$$

The value of $\Delta G_{m}$ is in agreement with the data of Neudorf and Elliott, whereas for $\Delta \mathrm{H}_{m}$ the data disagree. 


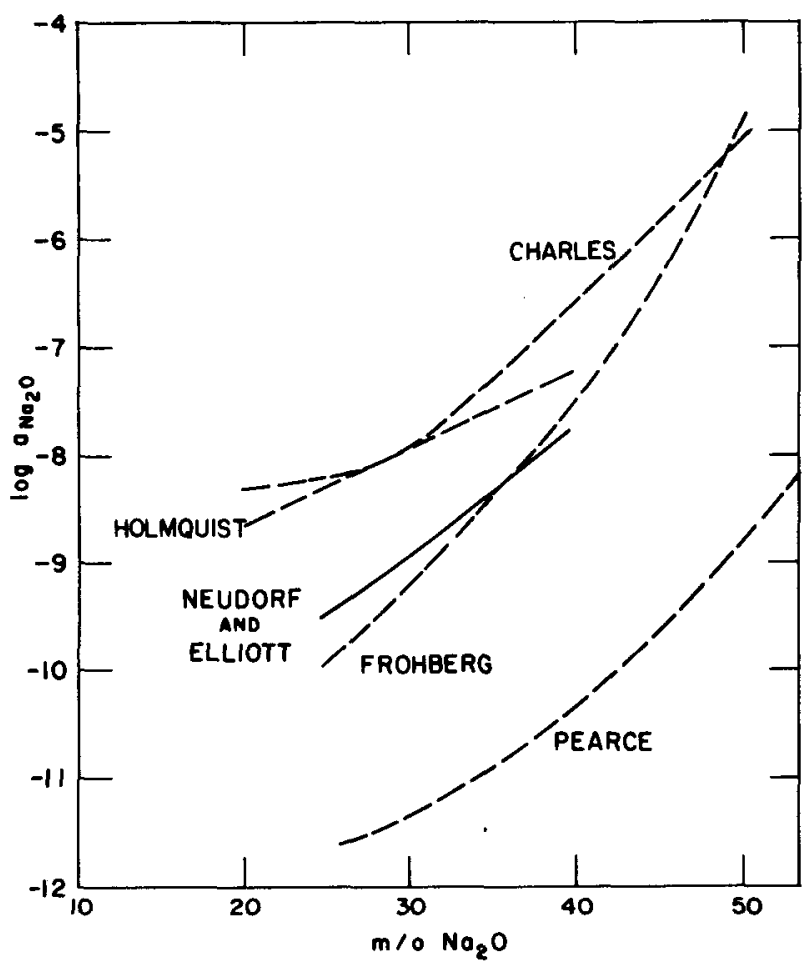

Fig. 23.

Comparison of Different Measurements of the Activities of $\mathrm{Na}_{2} \mathrm{O}$ in the $\mathrm{Na}_{2} \mathrm{O}-\mathrm{SiO}_{2}$ System at $1200^{\circ} \mathrm{C}$ (from $\operatorname{Ref}$. 37).

$\mathrm{Na}_{2} \mathrm{SiO}_{3}$ : From the data of Barin and Knacke ${ }^{18}$ for the melting point of $1362 \mathrm{~K}$, we can deduce the following values of $\Delta G_{\mathrm{m}}$ and $\Delta \mathrm{H}_{\mathrm{m}}$ at $\mathrm{X}_{\mathrm{SiO}_{2}}=$ 0.3333 for $1 / 3 \mathrm{Na}_{2} \mathrm{SiO}_{3}$ :

$$
\begin{aligned}
\Delta G_{\mathrm{m}} & =-18439 \mathrm{cal} \\
\Delta H_{\mathrm{m}} & =-20237 \mathrm{cal}
\end{aligned}
$$

$\mathrm{Na}_{4} \mathrm{SiO}_{4}$ : From the data of Barin and Knacke ${ }^{18}$ and the assumption that this compound melts congruently at $1120^{\circ} \mathrm{C}$, we get at $\mathrm{X}_{\mathrm{SiO}_{2}}=0.2$ for $1 / 5 \mathrm{Na}_{4} \mathrm{SiO}_{4}$ :

$$
\begin{aligned}
\Delta G_{m} & =-16451 \mathrm{cal} \\
\Delta H_{m} & =-22025 \mathrm{cal}
\end{aligned}
$$

It should be noted that the data on these three compounds from Ref. 18 are considered to be of low-to-fair accuracy and are especially uncertain at $\mathrm{X}_{\mathrm{SiO}_{2}}=0.2$. Superimposed upon this uncertainty are the discrepancies in the measured phase diagrams near $\mathrm{X}_{\mathrm{SiO}_{2}}=0.2$ discussed earlier. Consequently, near this composition, little credence can be placed in the data.

In the optimization procedure, we used

i. The data of Neudorf and Elliott ${ }^{37}$ on $\mathrm{aSiO}_{2}$ at $1200^{\circ} \mathrm{C}$, ignoring the temperature dependence (see below). 


\begin{abstract}
ii. $\Delta G_{m}$ and $\Delta \mathrm{H}_{\mathrm{m}}$ deduced at the melting points of the compounds, $\mathrm{Na}_{2} \mathrm{Si}_{2} \mathrm{O}_{5}, \mathrm{Na}_{2} \mathrm{SiO}_{3}$, and $\mathrm{Na}_{4} \mathrm{SiO}_{4}$.

iii. Points along the $\mathrm{SiO}_{2}$ liquidus taken from the phase diagrams in Figs. 19-21.

iv. The eutectic point at $799^{\circ} \mathrm{C}$ in Fig. 20. We ignore the compound, $\mathrm{Na}_{6} \mathrm{Si}_{8} \mathrm{O}_{19}$. This neglect has only a very minor influence on the result because of the small range of temperatures at which this solid is in equilibrium with the liquid.

v. Since there are no data points for $\mathrm{X}_{\mathrm{SiO}_{2}}<0.2$, we need some information here on solution properties to help to fix the thermodynamic properties for the analysis. Since this binary is the most ordered system we consider in this report, we made the assumption that the activity coefficients of $\mathrm{NaO}_{0.5}$ are about unity in this region. This is consistent with observations in other ordered systems such as the $\mathrm{CaO}-\mathrm{SiO}_{2}$ binary.
\end{abstract}

\title{
2. Results
}

The resultant equation for $W$ is

$$
W=(-77479+8 \mathrm{~T})-277162 \mathrm{y}_{\mathrm{SiO}}^{6}+274367 \mathrm{y}_{\mathrm{SiO}_{2}}^{7} \mathrm{cal}
$$

As with prior calculations, a very large number of combinations of exponents (up to the seventh power in this case) were tried, and the equation with the highest powers of $\mathrm{ySiO}_{2}$ (i.e., 6,7) gave the best fit to the data in this system.

The calculated activities of $\mathrm{Na}_{2} \mathrm{O}$ are plotted in Fig. 22 and may be compared with the data of Neudorf and Elliott, 37 which are also plotted. The measurements are well represented by the calculations. The maximum deviation in $\log \mathrm{a}_{\mathrm{Na}_{2} \mathrm{O}}$ is about 0.15 , and most of the measurements are much closer than that to the calculated values. The slopes of the experimental and calculated curves are very different because, as pointed out by Neudorf and Elliott, the experimental curves are inconsistent with the enthalpies of formation of some of the compounds. We gave greater weight to the enthalpies of formation, and in our calculation we ignored the temperature dependence of $\mathrm{a}^{\mathrm{NaO}} 0.5$ given in Ref. 37. The differences between the measured and calculated values in Fig. 22 are much smaller than the differences between the different measurements in Fig. 23.

The calculated free energies and enthalpies of mixing at the melting points of the compounds are as follows: 


$$
\begin{array}{ll}
1 / 4 \mathrm{Na}_{2} \mathrm{Si}_{2} \mathrm{O}_{5} \text { at } 1147 \mathrm{~K}: & \Delta \mathrm{G}_{\mathrm{m}}=-15845, \Delta \mathrm{H}_{\mathrm{m}}=-15945 \\
1 / 3 \mathrm{Na}_{2} \mathrm{SiO}_{3} \text { at } 1362 \mathrm{~K}: & \Delta \mathrm{G}_{\mathrm{m}}=-18584, \Delta \mathrm{H}_{\mathrm{m}}=-19689 \\
1 / 5 \mathrm{Na}_{4} \mathrm{SiO}_{4} \text { at } 1393 \mathrm{~K}: & \Delta \mathrm{G}_{\mathrm{m}}=-19205
\end{array}
$$

The free energies and enthalpies of mixing for the first two compounds are in good agreement with the data cited earlier (section IV.C.1.c). As expected, the calculated values of $\Delta G_{m}$ (and of $\Delta H_{m}$ ) at $X_{S_{i O}}=0.2$ differ from the measured data, largely because of the considerable uncertainties in the phase diagram and the lack of any reliable independent data on activities of $\mathrm{SiO}_{2}$ in this region.

The calculated phase diagram of the $\mathrm{NaO}_{0} \cdot 5^{-\mathrm{SiO}_{2}}$ system is given in Fig. 24. The temperatures and compositions of the invariant points are indicated. The invariant points and liquidus temperatures at values of

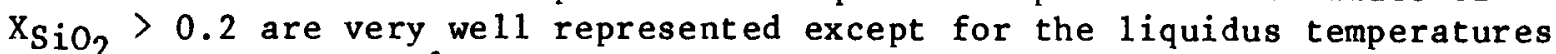
of silica above $1470^{\circ} \mathrm{C}$. As discussed in a later section, there may be a fundamental reason for this difference, which, if verified, may permit us to correct calculated liquidus temperatures at these higher temperatures.

The major aim of this investigation is to obtain an accurate representation of the activities of $\mathrm{Na}_{2} \mathrm{O}$ as a function of composition and temperature in multicomponent silicate melts. This can best be accomplished by analyses of $\mathrm{Na}_{2} \mathrm{O}$-containing binaries which are as close as is possible to the available data, especially to the data on activities. Our results accomplished this aim and provide a good representation of the data we consider to be most reliable. The most uncertain results in our calculations are the temperature coefficients of the activities.

D. $\mathrm{NaO}_{0.5-\mathrm{AlO}_{1.5}}$

1. Data Considered (In general, data for this system are poor.)

a. Phase Diagram

Figure 25 is a phase diagram for the $\mathrm{NaAlO}_{2}-\mathrm{Al}_{2} \mathrm{O}_{3}$ system. 20,38 In Fig. 26 is given a tentative phase diagram deduced by DeVries and Roth.20,39 There are significant uncertainties in these diagrams. Another and perhaps less reliable phase diagram is shown in Fig. 27.40 close to $\mathrm{Al}_{2} \mathrm{O}_{3}$, the measured liquidus exhibits slightly positive deviations from ideality; at higher concentrations of $\mathrm{Na}_{2} \mathrm{O}$, deviations become negative.

\section{b. Free Energies of Formation of Compounds}

$\mathrm{NaAlO}_{2}:$ The existence of gamma and delta forms shown in Fig. 26 is speculative. Barin and Knackel8 give the free energy of formation of the solid. If we choose the melting point of $1645^{\circ} \mathrm{C}$ from Fig. 26, we obtain for the reaction

$$
0.5 \mathrm{NaO}_{0.5}(l)+0.5 \mathrm{AlO}_{1.5}(\ell)=0.5 \mathrm{NaAlO}_{2}(\mathrm{~s})
$$




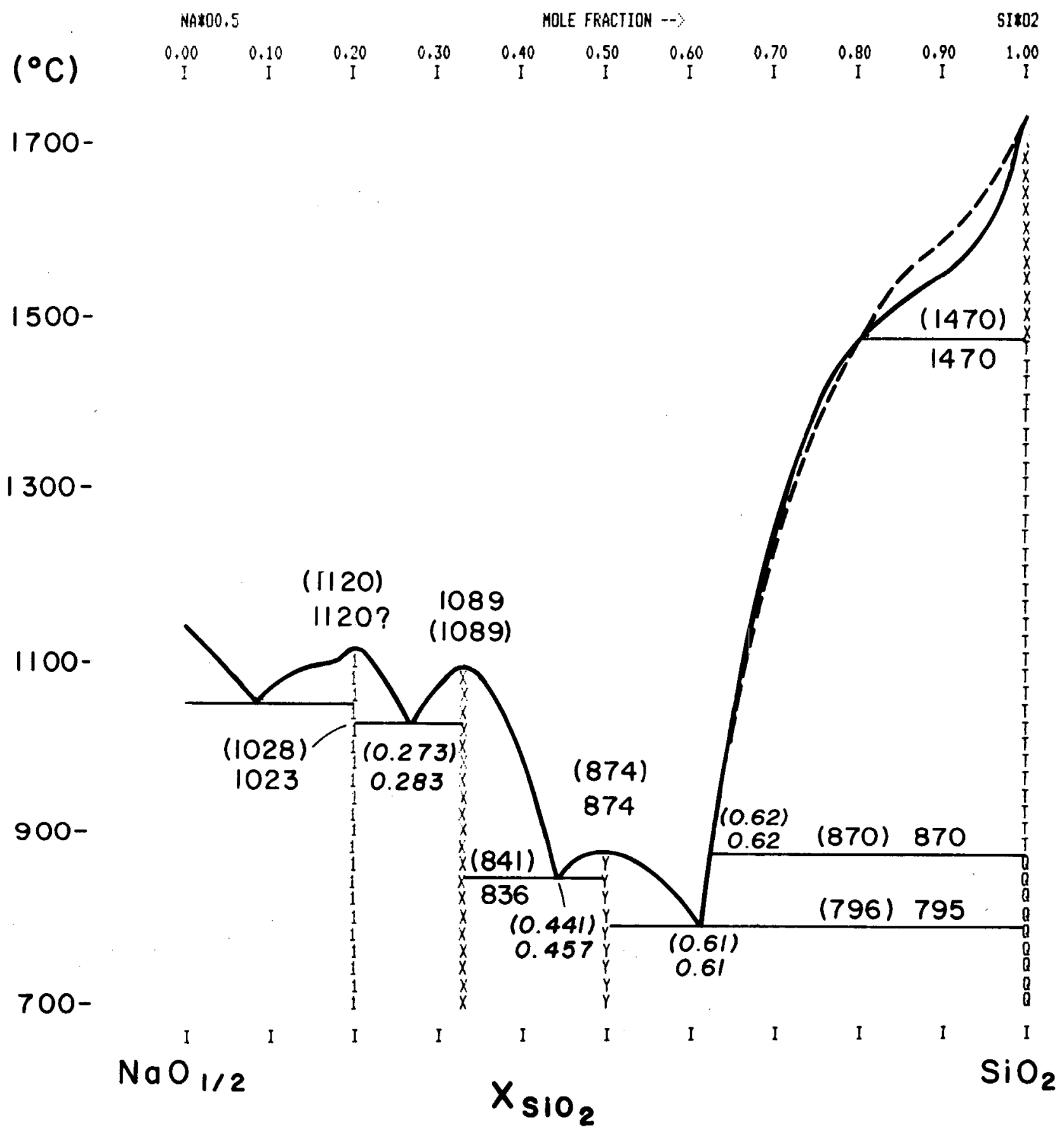

Fig. 24. Calculated Phase Diagram in the $\mathrm{NaO}_{0} .5-\mathrm{SiO}_{2}$ System. Numbers in parentheses are calculated temperatures or concentrations of invariant points. Dashed $\mathrm{line}$ is measured $\mathrm{SiO}_{2}$ liquidus from Ref. 35. 


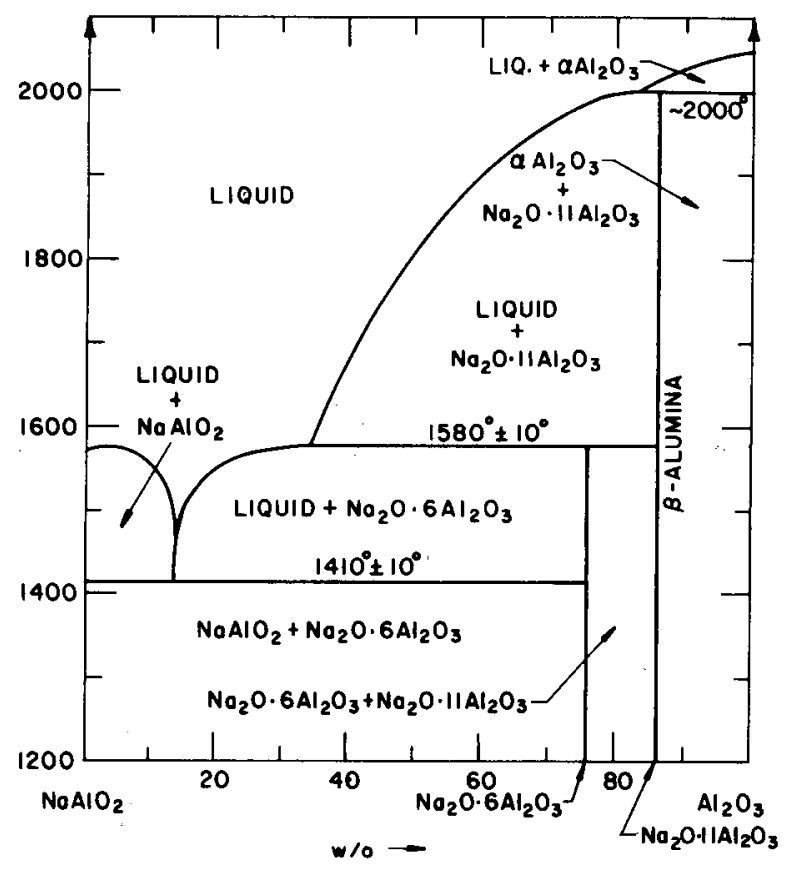

Fig. 25.

Phase Diagram in the $\mathrm{NaAlO}_{2}-\mathrm{Al}_{2} \mathrm{O}_{3}$ System from Refs. 20 and 37.

Fig. 26 .

Phase Diagram in the $\mathrm{NaO}_{0} .5^{-\mathrm{Al} 10_{1} .5}$ System from Refs. 20 and 39.

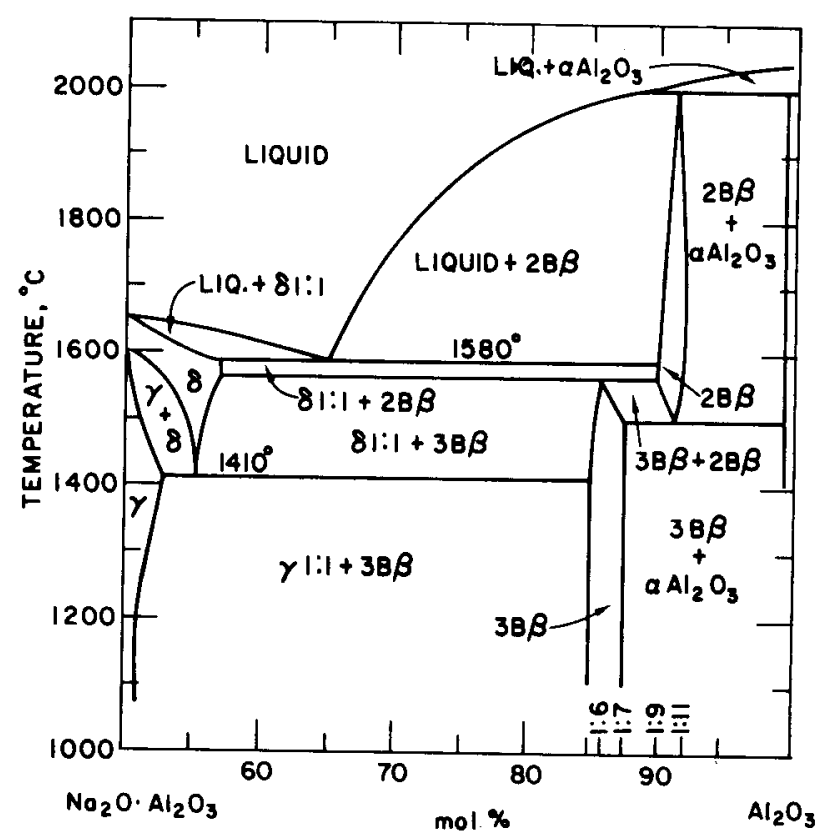




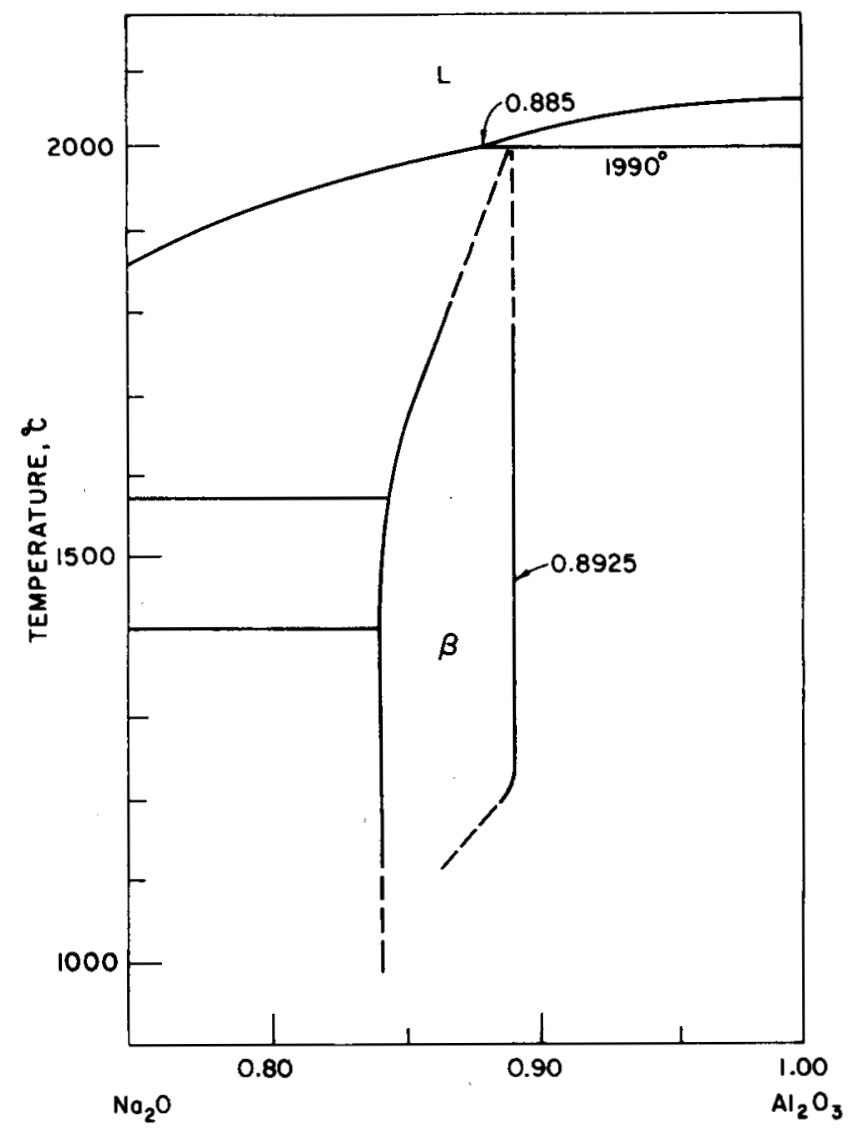

Fig. 27.

Phase Diagram in the $\mathrm{NaO}_{0} .5^{-\mathrm{AlO}_{1.5}}$ System from Ref. 40 .

a value of $\Delta G^{0}=-10918 \mathrm{cal}$ at $1645^{\circ} \mathrm{C}$, which is the same as that for $\Delta G_{\mathrm{m}}$ at $\mathrm{X}_{\mathrm{AlO}} \mathrm{I}_{1.5}=0.5$.

Beta Alumina: Dubreuil et al.41 measured the activity of $\mathrm{Na}_{2} \mathrm{O}$ (sol) in $\mathrm{B}$-alumina in equilibrium with $\mathrm{Al}_{2} \mathrm{O}_{3}$ over the range $300-1100^{\circ} \mathrm{C}$. They obtained the expression

$$
\log \mathrm{a}_{\mathrm{Na}} \mathrm{O}(\mathrm{s})=\frac{-11490}{\mathrm{~T}}-0.03 \pm 0.32
$$

If we extrapolate from 1100 to $2000^{\circ} \mathrm{C}$ and take the free energy of fusion of $\mathrm{Na}_{2} \mathrm{O}$ discussed earlier, we obtain

$$
\overline{\mathrm{G}}_{\mathrm{NaO}_{0.5}}-\mathrm{G}_{\mathrm{NaO}}^{0} \mathrm{O}_{0.5}=-31990+3.9883 \mathrm{~T}, \mathrm{cal}
$$

Thus, in the liquid at the peritectic exhibited in Fig. $27\left(\mathrm{X}_{\mathrm{A} 10_{1.5}}=0.885\right.$ at $1990^{\circ} \mathrm{C}$ ), we obtain

$$
\overline{\mathrm{G}}_{\mathrm{NaO}_{0.5}}-\mathrm{G}_{\mathrm{NaO}}^{0} \mathrm{O}_{0.5}=-22964 \mathrm{cal}\left(\mathrm{at} 1990^{\circ} \mathrm{C}\right)
$$


In the optimization procedure, we used only the value of $\Delta G_{m}$ at $1645^{\circ} \mathrm{C}$. The partial molar free energy of solution at $1990^{\circ} \mathrm{C}$ given above is extrapolated by $900^{\circ} \mathrm{C}$ and is not as reliable.

\section{Results} expression:

The optimization procedure for $\mathrm{NaO}_{0} .5^{-\mathrm{AlO}} \mathrm{O}_{1.5}$ leads to the

$$
W=-49,500 \mathrm{cal}
$$

The calculated free energy of mixing of the liquid at $\mathrm{x}_{\mathrm{AlO}} \mathrm{O}_{15}=$ 0.5 and $1645^{\circ} \mathrm{C}$ is $-10,943 \mathrm{cal}$ (which may be compared with $-10,918 \mathrm{cal} \cdot 5_{\mathrm{calcu}}$ lated from the free energies of formation and of fusion of $\mathrm{NaAlO}_{2}$ ). The calculated partial molar free energy of solution of $\mathrm{NaO}_{0} .5$ at the peritectic is $-26640 \mathrm{cal}$. This may be compared with the data of -22964 at $1990^{\circ} \mathrm{C}$ and $\mathrm{X}_{\mathrm{A} 10_{1.5}}=0.885$. However, the 1 atter value was extrapolated almost $900^{\circ} \mathrm{C}$ up from measurements at lower temperature.

In conclusion, the fit of the data at $\mathrm{X}_{\mathrm{AlO}} \mathrm{f}_{1.5} \geq 0.5$ is uncertain because of (1) the paucity of data and (2) probable inconsistencies in the available data. More data on this system are needed. Generally the errors in these results will have only small effects on errors in the activities of $\mathrm{NaO}_{0.5}$ in a multicomponent slag containing only small amounts of $\mathrm{AlO}_{1.5} \cdot$ However, we hope to improve our analysis of this system if more data become available, since our method is intrinsically capable of better representing an adequate set of self-consistent data on such a system.

E. $\quad \mathrm{AlO}_{1} \cdot 5^{-\mathrm{SiO}_{2}}$

1. Data Considered

a. Phase Diagrams

There is a large degree of inconsistency amongst the $\mathrm{AlO}_{1.5} \mathrm{SiO}_{2}$ phase diagrams from different laboratories, as is exhibited in the different results plotted in Figs. 28-32.20,42-46,49 It is difficult to ascertain which is the correct phase diagram. The corundum liquidus temperatures are close to their ideal values in a majority of studies, as can be seen by comparison with the calculated ideal liquidus temperatures plotted in the figures. On the silica side of the phase diagrams exhibited (Figs. 30 and 32), there are a miscibility gap and a eutectic at $\mathrm{X}_{\mathrm{AlO}} \mathrm{O}_{1,5} \cong 0.1$ and $\mathrm{T}=1546-1670^{\circ} \mathrm{C}$, indicating positive deviations from ideal behavior: However, this result is not in accord with the measured $\mathrm{a}_{\mathrm{SiO}_{2}}$ of Rein and $\mathrm{Chipman} 47$ and Kay and Taylor, 48 which, when extrapolated a short distance to the binary, indicates a solution which is close to ideal. This discrepancy is discussed below in the light of recent data on the miscibility gap. 49

On all of the diagrams, there is a large change of the slope of the liquidus on passing from the $\mathrm{Al}_{2} \mathrm{O}_{3}$ phase field to the mullite phase field. If this is correct, it would indicate an entropy of formation of mullite which is much larger than is given in the most-reliable compiled data. ${ }^{25}$ Apparently, either the mullite data are wrong or (as is more likely) mullite may not be a line compound or a simple solid solution at high temperatures. 


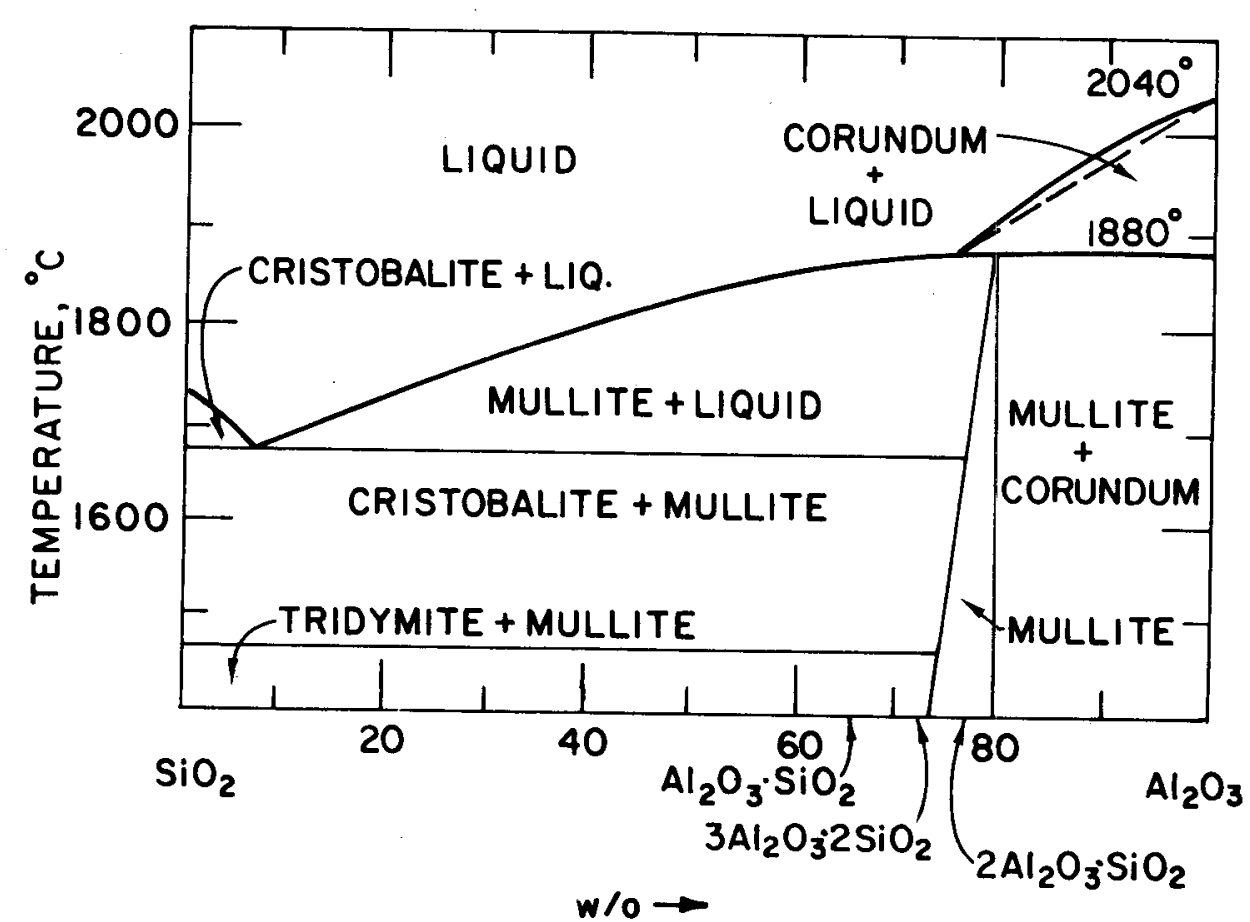

Fig. 28. Phase Diagram in the $\mathrm{AlO}_{1} \cdot 5^{-\mathrm{SiO}_{2}}$ System (dashed lines represent ideal $\mathrm{AlO}_{1.5}$ activities) from Ref. 44. (HMSO, Crown copyright.)

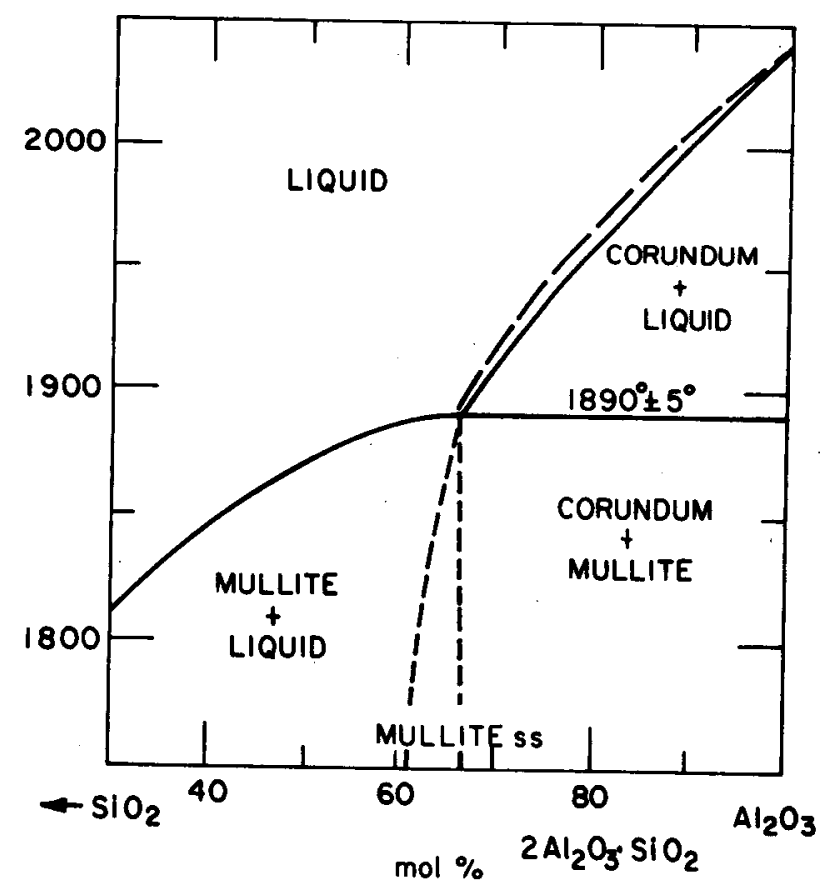

Fig. 29 .

Phase Diagram in the $\mathrm{AlO}_{1} .5-\mathrm{SiO}_{2}$ System (dashed lines represent ideal $\mathrm{AlO}_{1.5}$ Activities) from Ref. 45. 


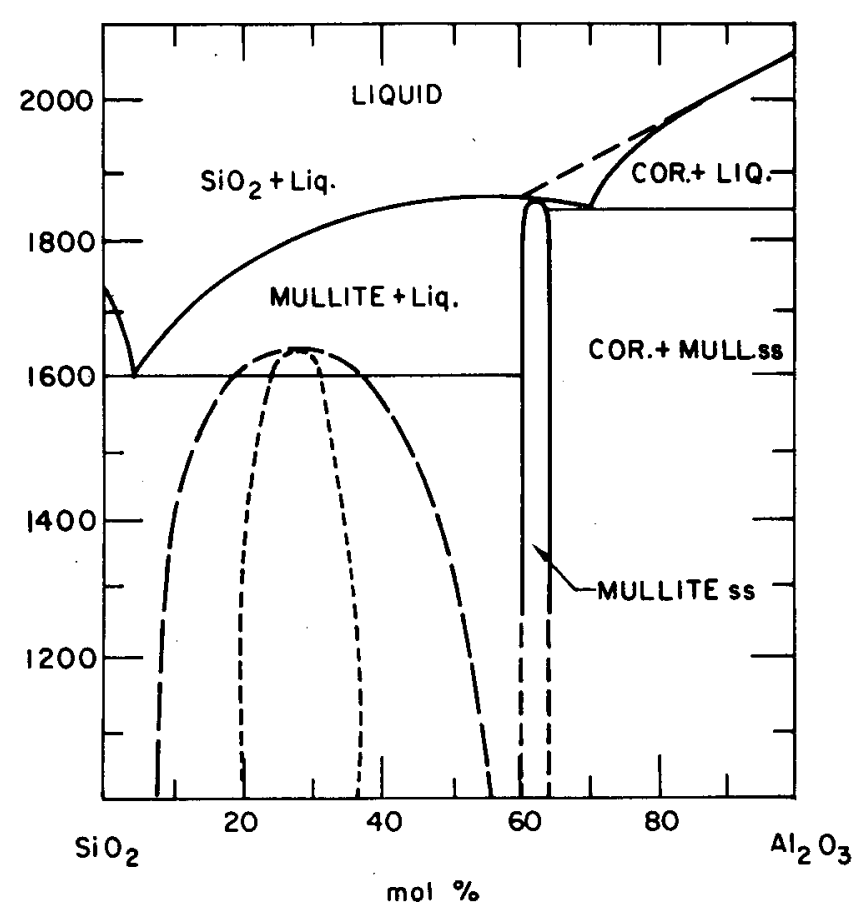

Fig. 30 .

Phase Diagram in the $\mathrm{AlO}_{1} .5-\mathrm{SiO}_{2}$ System (dashed lines represent ideal $\mathrm{AlO}_{1.5}$ activities) from Ref. 46.

Fig. 31 .

Phase Diagram in the $\mathrm{AlO}_{1} .5-\mathrm{SiO}_{2}$ System (dashed lines represent ideal $\mathrm{AlO}_{1.5}$ activities) from Ref. 42 .

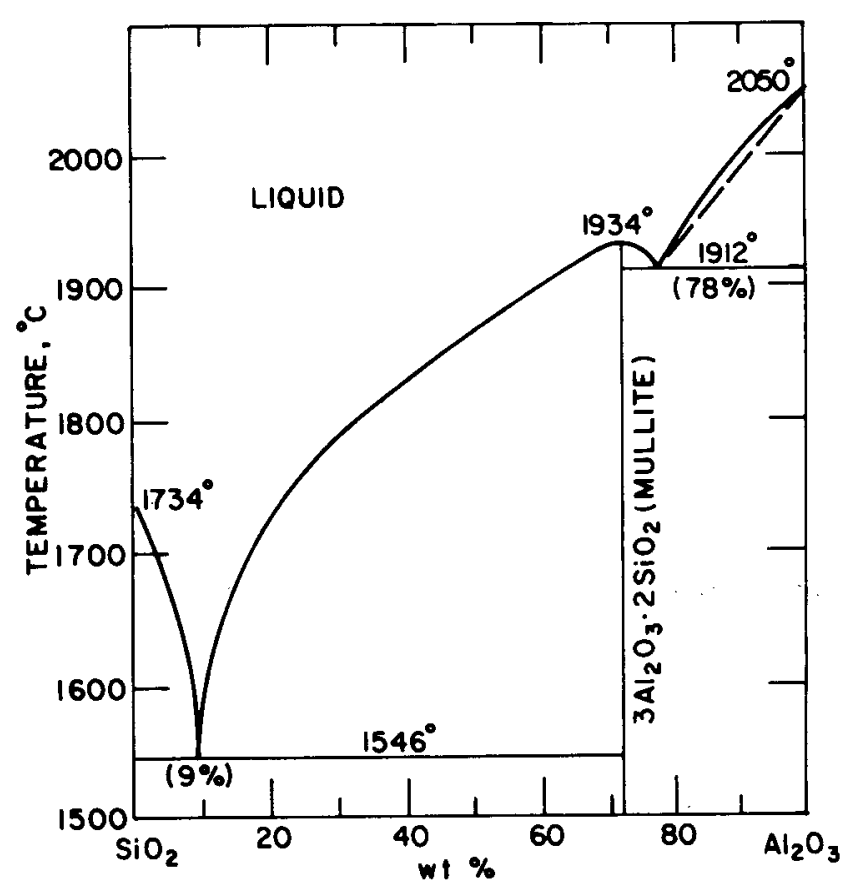




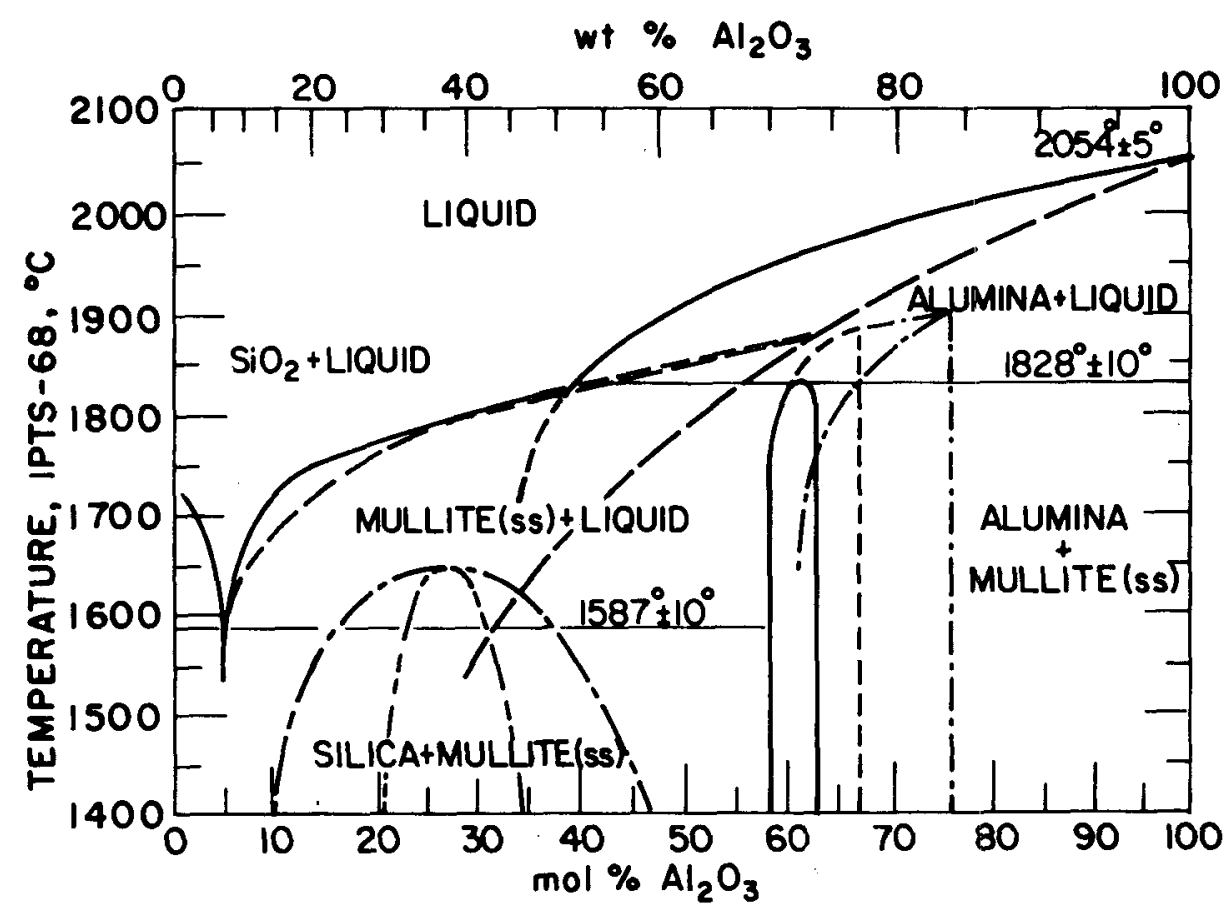

Fig. 32. Phase Diagram in the $\mathrm{AlO}_{1} .5-\mathrm{SiO}_{2}$ System (dashed lines represent ideal $\mathrm{AlO}_{1.5}$ activities) from Ref. 43.

\section{b. Activities}

Activities of $\mathrm{SiO}_{2}$ in the $\mathrm{Al}_{2} \mathrm{O}_{3}-\mathrm{SiO}_{2}-\mathrm{CaO}$ ternary system measured by Rein and $\mathrm{Chipman} 47$ and Kay and Taylor 48 at $1600^{\circ} \mathrm{C}$ are exhibited in Figs. 33 and 37. A short extrapolation of these activities (which are relative to solid as standard state in the figures) permits one to deduce the fact that the activities of $\mathrm{SiO}_{2}$ relative to liquid as standard state are close to ideal. (The data of Rein and Chipman 47 are slightly positive, and those of Kay and Taylor 48 are closer to ideality.) This adds to the mass of conflicting data in this system. It appears possible that the liquid solution properties do not deviate greatly from ideality despite some evidence to the contrary. Since the major aim of our work is to deduce an accurate representation of activities, we will place the greatest weight on the activity data of Rein and Chipman. This implies that at high temperature, mullite is not a simple line compound (having the thermodynamic properties given in Ref. 25) and that the silica liquidus temperatures (which are generally hard to measure) are not reliable.

system are:

The data we utilize for the optimization of the $\mathrm{AlO}_{1.5}-\mathrm{SiO}_{2}$

i. The extrapolated activity data of Rein and Chipman.47

ii. Ideality of the $\mathrm{AlO}_{1.5}$ component at its liquidus. 


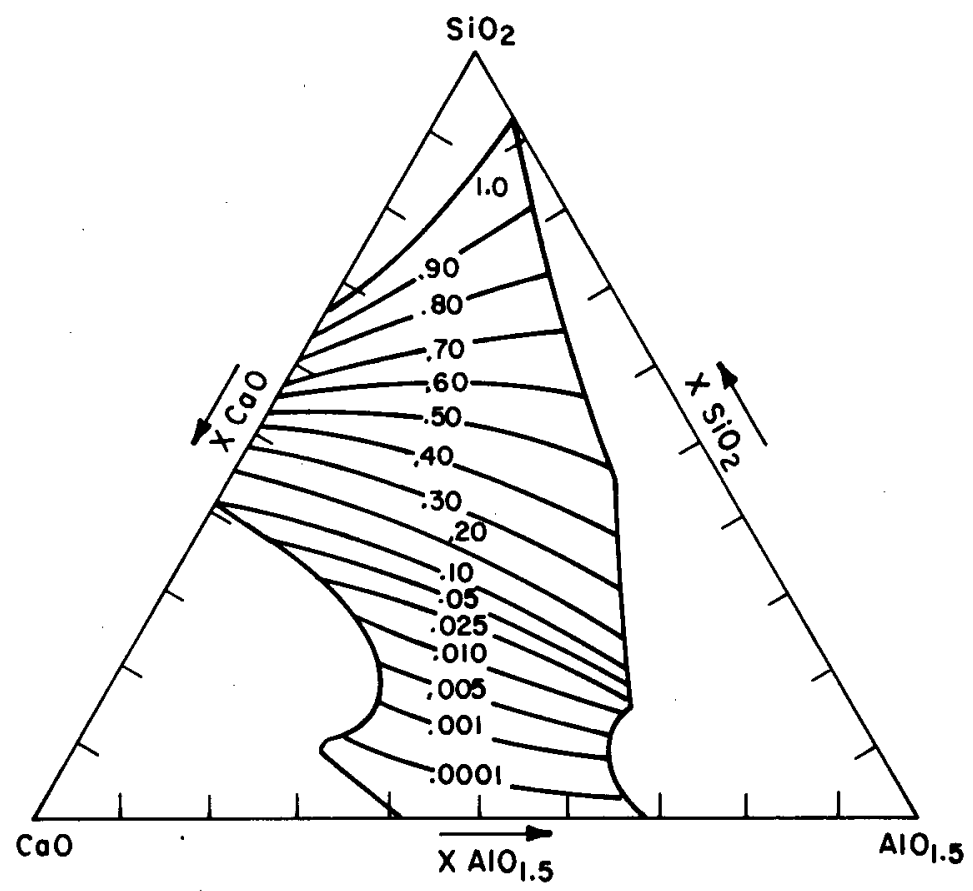

Fig. 33. Activities of $\mathrm{SiO}_{2}$ in $\mathrm{SiO}_{2}-\mathrm{Al}_{2} \mathrm{O}_{3}-\mathrm{CaO}$

Slags at $1600^{\circ} \mathrm{C}$ (from Refs. 30 and 47).

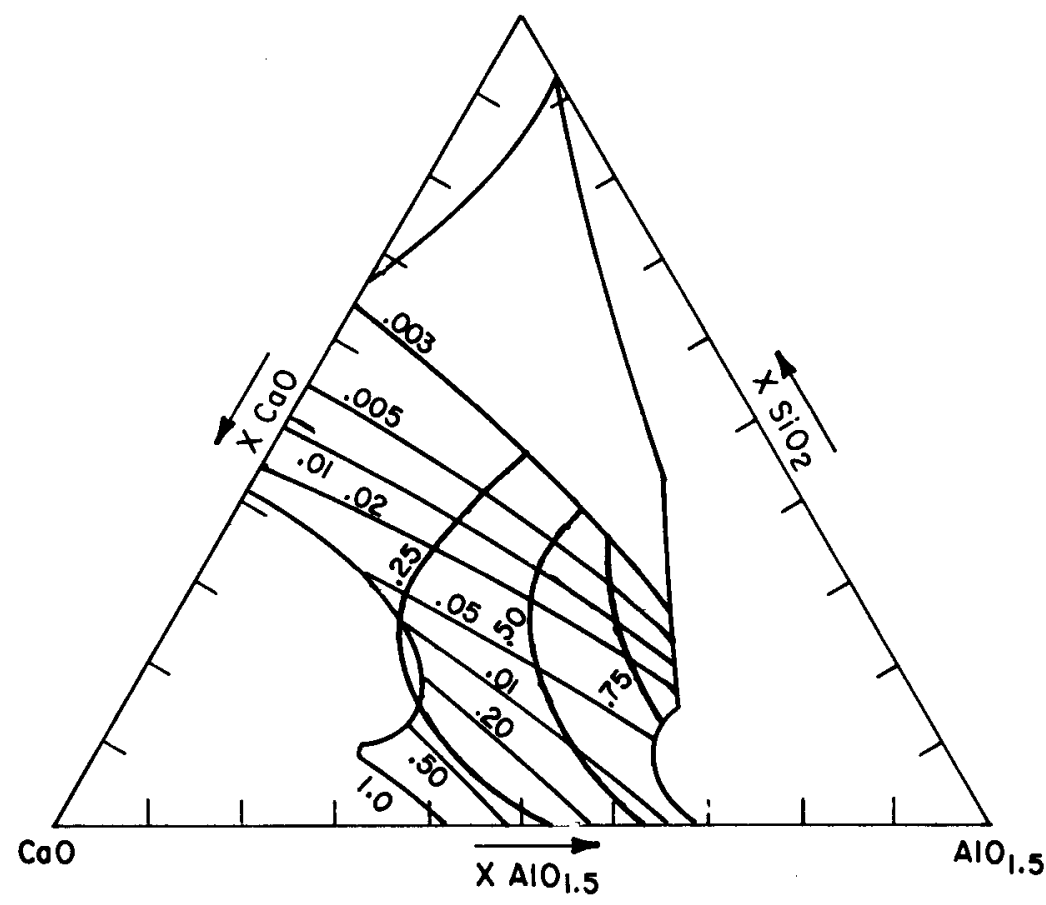

Fig. 34. Activities in $\mathrm{SiO}_{2}-\mathrm{Al}_{2} \mathrm{O}_{3}-\mathrm{CaO} \mathrm{Slags}$ at $1600^{\circ} \mathrm{C}$ Using the Gibbs-Duhem Equation and Our Model. Activities of $\mathrm{CaO}$ (solid lines) and $\mathrm{AlO}_{1.5}$ (solid lines) calculated from Fig. 33 using the GibbsDuhem equation (from Refs. 30 and 47). Dashed lines are activities of $\mathrm{CaO}$ calculated from our model. 


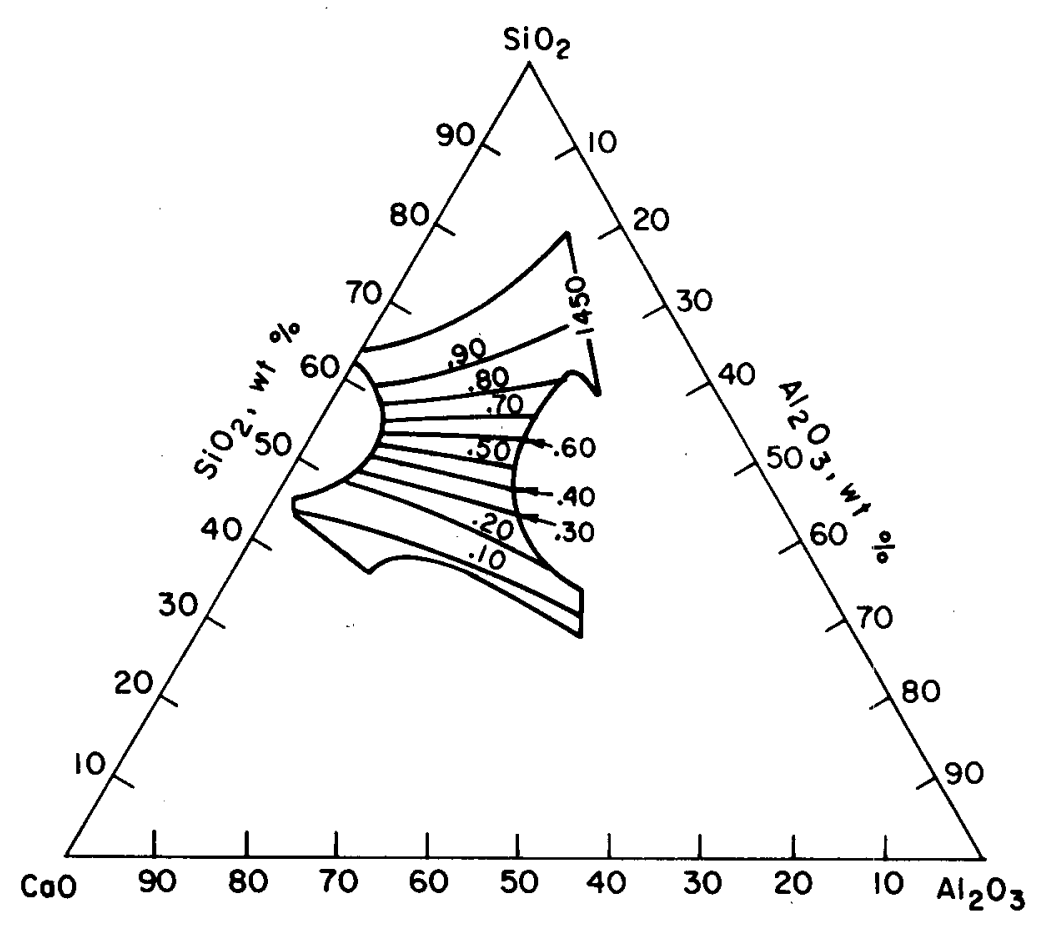

Fig. 35. Activities of $\mathrm{SiO}_{2}-\mathrm{Al}_{2} \mathrm{O}_{3}-\mathrm{CaO}$ Slags at $1450^{\circ} \mathrm{C}$ (from Ref. 48).

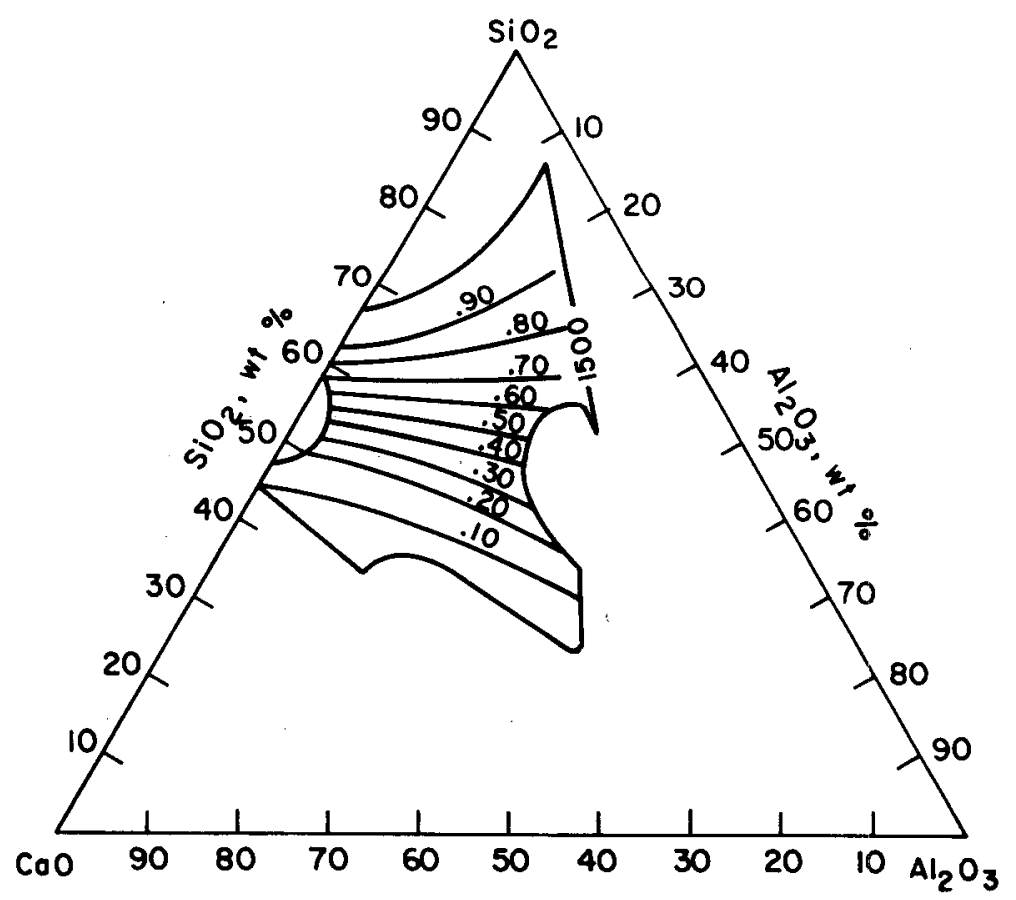

Fig. 36. Activities of $\mathrm{SiO}_{2}$ in $\mathrm{SiO}_{2}-\mathrm{Al}_{2} \mathrm{O}_{3}-\mathrm{CaO}$ Slags at $1500^{\circ} \mathrm{C}$ (from Ref. 48). 


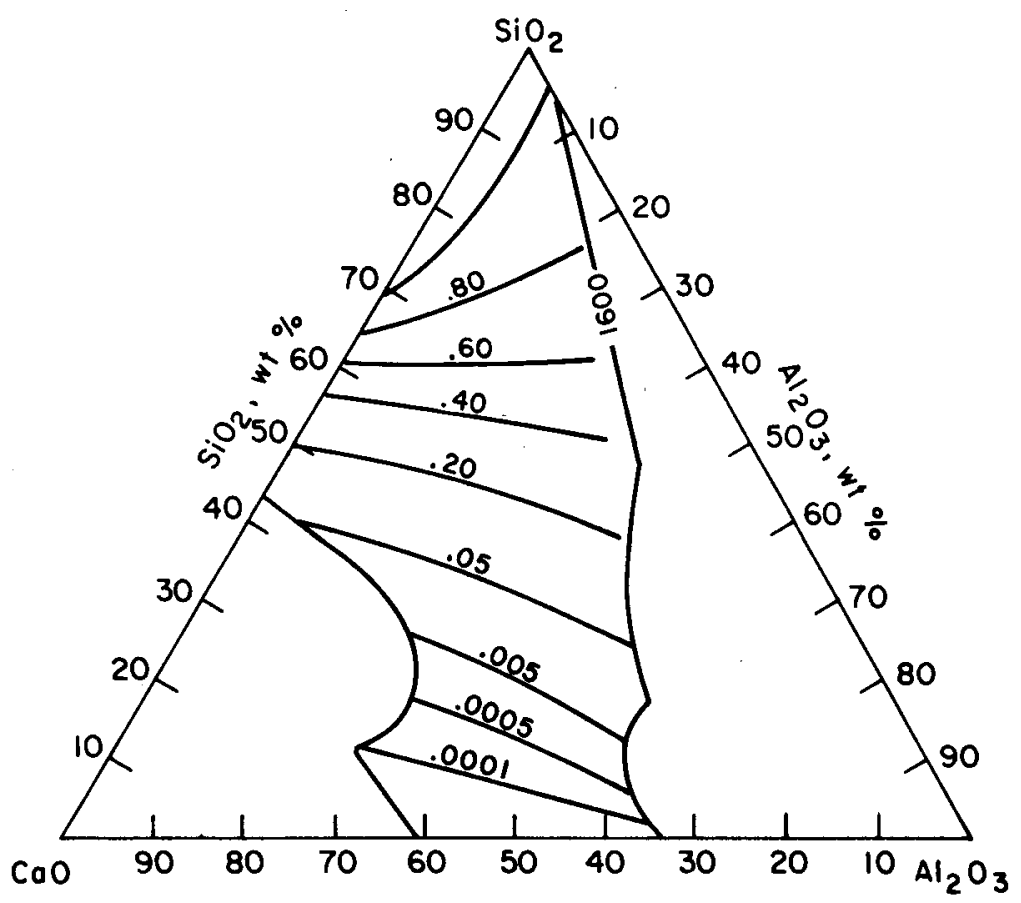

Fig. 37. Activities of $\mathrm{SiO}_{2}$ in $\mathrm{SiO}_{2}-\mathrm{Al}_{2} \mathrm{O}_{3}-\mathrm{CaO}$ Slags at $1600^{\circ} \mathrm{C}$ (from Ref. 48).

This optimization leads to the equation:

$$
\mathrm{W}=2079+883 \mathrm{y}_{\mathrm{SiO}_{2}}^{2}
$$

which led to agreement with the extrapolated activity data of Ref. 47 to with in $5 \%$ (which is less than the uncertainties in their values).

Recent measurements of the miscibility gap in this system 49 indicate an upper consolute temperature of $725^{\circ} \mathrm{C}$ at $28 \mathrm{~mol} \% \mathrm{Al}_{2} \mathrm{O}_{3}$. This result is more in consonance with our analysis than the earlier values at much higher temperatures exhibited in Figs. 30 and 32 . We did not attempt to incorporate this miscibility gap into our calculations, but could have readily done so by introducing temperature dependence for the terms in Eq. 63. However, until these results are confirmed, the uncertainties remain too large to incorporate this miscibility gap.

F. $\quad \mathrm{CaO}-\mathrm{AlO}_{1} \cdot 5^{-\mathrm{SiO}_{2}}$

We utilized data from three of the binaries discussed above, as well as ternary data, to analyze data on the ternary system $\mathrm{CaO}-\mathrm{AlO}_{1} .5-\mathrm{SiO}_{2}$.

\section{Activities}

The activities of silica measured by Rein and $\mathrm{Chipman} 47$ at $1600^{\circ} \mathrm{C}$ are exhibited in Fig. 33. The authors noted that values at 10 $\mathrm{SiO}_{2}$ concentrations are relatively imprecise. Results of a Gibbs-Duhem integration of the data in Fig. 33 led to the values of ${ }^{a} \mathrm{CaO}$ and $\mathrm{a}_{\mathrm{AlO}}{ }_{1.5}$ exhibited in Fig. 34 . 
Kay and Taylor 48 measured $\mathrm{aSiO}_{2}$ at 1450,1500 , and $1550^{\circ} \mathrm{C}$. Measured values at 1450 and $1500^{\circ} \mathrm{C}$ are exhibited in Figs. 35 and 36 , respectively, and values extrapolated to $1600^{\circ} \mathrm{C}$ are exhibited in Fig. 37. The curves for the three lowest values of ${ }^{\mathrm{S}_{\mathrm{SiO}}} \mathrm{P}_{2}$ plotted in this figure were obtained by extrapolation. Kalyanram et al.50 measured the activities of $\mathrm{CaO}$ at $1500^{\circ} \mathrm{C}$ (Fig. 38.)

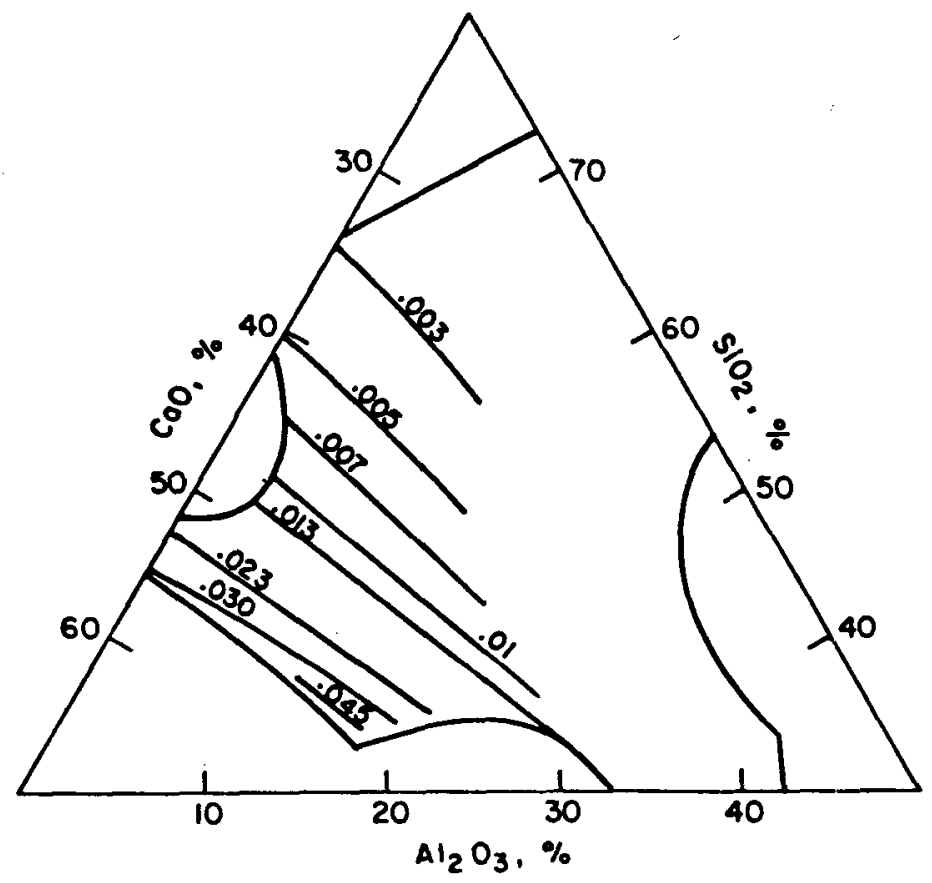

Fig. 38. Activities of $\mathrm{CaO}$ in $\mathrm{SiO}_{2}-\mathrm{Al}_{2} \mathrm{O}_{3}-\mathrm{CaO}$ Slags at $1500^{\circ} \mathrm{C}$ (from Ref. 50).

\section{Free Energies of Formation of Ternary Compounds}

a. $\mathrm{CaAl}_{2} \mathrm{Si}_{2} \mathrm{O}_{8}$ (anorthite)

The melting point of $\mathrm{CaAl}_{2} \mathrm{Si}_{2} \mathrm{O}_{8}$ given by Robie et al. 25

is $1830 \mathrm{~K}$. The free energies of formation of Robie et al. were extrapolated from $1800 \mathrm{~K}$ to $1830 \mathrm{~K}$ and combined with free energies of fusion of the constituent oxides to give $\Delta G_{m}$ at $1830 \mathrm{~K}$ of $-10,112 \mathrm{cal}$ for the reaction

$$
1 / 5 \mathrm{CaO}(l)+2 / 5 \mathrm{AlO}_{1.5}(l)+2 / 5 \mathrm{SiO}_{2}(l)+\text { solution }
$$

b. $\mathrm{Ca}_{2} \mathrm{Al}_{2} \mathrm{SiO}_{7}$ (gehlenite)

A melting point of $1863 \mathrm{~K}$ for $\mathrm{Ca}_{2} \mathrm{Al}_{2} \mathrm{SiO}_{7}$ is given by Robie et al.25 Their data were extrapolated from $1800 \mathrm{~K}$ to $1863 \mathrm{~K}$ and combined with 
free energies of fusion of the constituent oxides to give a value for $\Delta G_{m}$ of $-14016 \mathrm{cal}$ at $1863 \mathrm{~K}$ for the reaction

$$
2 / 5 \mathrm{CaO}(\ell)+2 / 5 \mathrm{AlO}_{1.5}(\ell)+1 / 5 \mathrm{SiO}_{2}(\ell) \rightarrow \text { solution. }
$$

\section{Results}

The input parameters for the calculations are the expressions for $\mathrm{W}$ obtained earlier for the $\mathrm{CaO}-\mathrm{SiO}_{2}, \mathrm{CaO}-\mathrm{Al}_{2} \mathrm{O}_{3}$, and $\mathrm{AlO}_{1} .5-\mathrm{SiO}_{2}$ systems, a value of $Z=2$, and the values of the parameters $a, b$, and $c$ used for the binary systems. Of the three binaries, the input for the $\mathrm{AlO}_{1.5}-\mathrm{SiO}_{2}$ binary has, by far, the weakest experimental basis.

In order to perform the calculation, we require values of the three energy parameters $W_{12}, W_{13}$, and $W_{23}$ at all compositions in the ternary. We have discussed earlier a symmetric and an asymmetric interpolation of the values in the three binaries, which are given in Eqs. 37 and 39, respectively.

Both methods led to good representations of the ternary data when a ternary correction term was added. We will discuss only the results of the symmetric method, which were slightly better overall than those obtained by the as ymmetric method.

Using the symmetric approximation (Eq. 37), we obtained good representations of the data if we added a ternary term to the total molar excess free energies of mixing of the system. This term is given by the expression

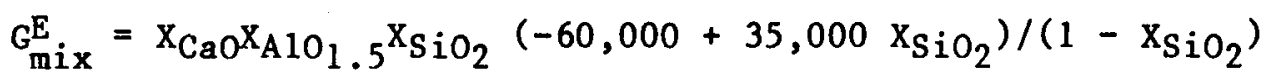

The results led to calculated free energies of mixing of the liquid at the melting points of the two ternary compounds in consonance with the measured data, as shown below.

$\Delta G_{\operatorname{mix}}$, cal

$\Delta G_{\operatorname{mix}}$, cal

Compound

anorthite $\left(\mathrm{CaAl}_{2} \mathrm{Si}_{2} \mathrm{O}_{8}\right)$

gehlenite $\left(\mathrm{Ca}_{2} \mathrm{Al}_{2} \mathrm{SiO}_{7}\right)$
$\mathrm{T}, \mathrm{K}$

1830

1863
Meas.

Calc.

$-10,112$

$-14,016$

$-10,108$

$-13,364$ 
The representation of the measurements of $\mathrm{aSiO}_{2}$ by Kay and Taylor 48 and Rein and $\mathrm{Ch}$ ipman 47 is very good, with the correspondence to the measurements of Kay and Taylor being the better. (In Figs. 39-41, we exhibit comparisons with the results of Kay and Taylor and Rein and Chipman at 1600 and $1500^{\circ} \mathrm{C}$.) The representation in Figs. 40 and 41 would have been even better had we fitted the $\mathrm{CaO}-\mathrm{SiO}_{2}$ and $\mathrm{AlO}_{1} .5-\mathrm{SiO}_{2}$ binaries to reproduce accurately the measurements of Kay and Taylor rather than those of Rein and Chipman.

The comparisons of calculated activities of $\mathrm{AlO}_{1.5}$ and $\mathrm{CaO}$ with those of Rein and Chipman are given in Figs. 42 and 43. The measurements are reasonably well represented with the representation of $\mathrm{a}_{\mathrm{AlO}} \mathrm{O}_{1}$ being good and that of acao being fair. It should be emphasized that these two activities are calculated from $\mathrm{a}_{\mathrm{SiO}_{2}}$ by a Gibbs-Duhem integration which depends strongly on the concentration dependence of $\mathrm{aSiO}_{2}$ (i.e., on a derivative) which is different in the measurements of Rein and Chipman 47 and Kay and Taylor. 48 As is we 11 known, this leads to significant uncertainties in these activities; these uncertainties are probably larger than the deviations of our calculations from the reported values.

The measurements of Kalyanram et al.50 are not well represented in Fig. 44, largely because their data for the binary differ from the binary data of Rein and Chipman used to determine our binary. If adjusted by multiplying the activities by a constant factor, their measurements would correspond reasonably well with our calculations. This kind of uncertainty in the measurements was implied by Kalyanram et al., who did not plot activities but rather a quantity $A$ which is proportional to activity.

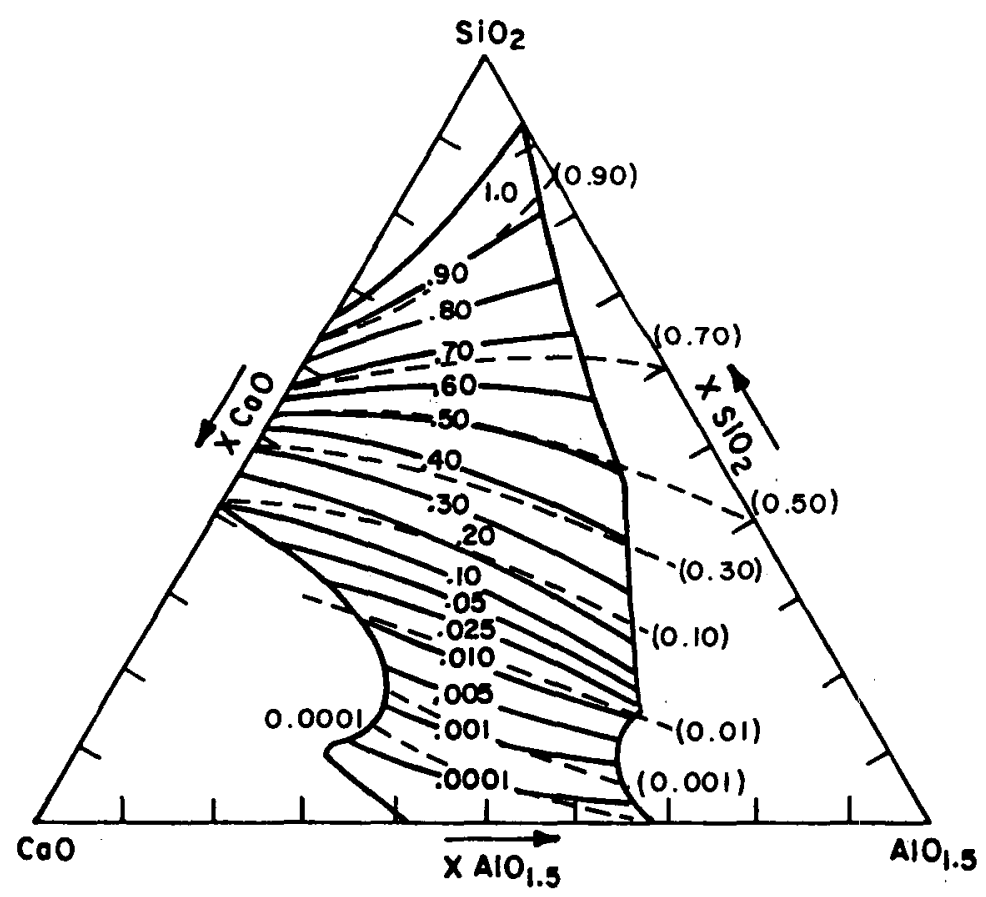

Fig. 39. Calculated Values of Activities in $\mathrm{SiO}_{2}-\mathrm{Al}_{2} \mathrm{O}_{3}-\mathrm{CaO}$ slags at $1600^{\circ} \mathrm{C}$ (dashed lines), with $\mathrm{a}_{\mathrm{SiO}_{2}}$ Superimposed on Fig. 33 . 


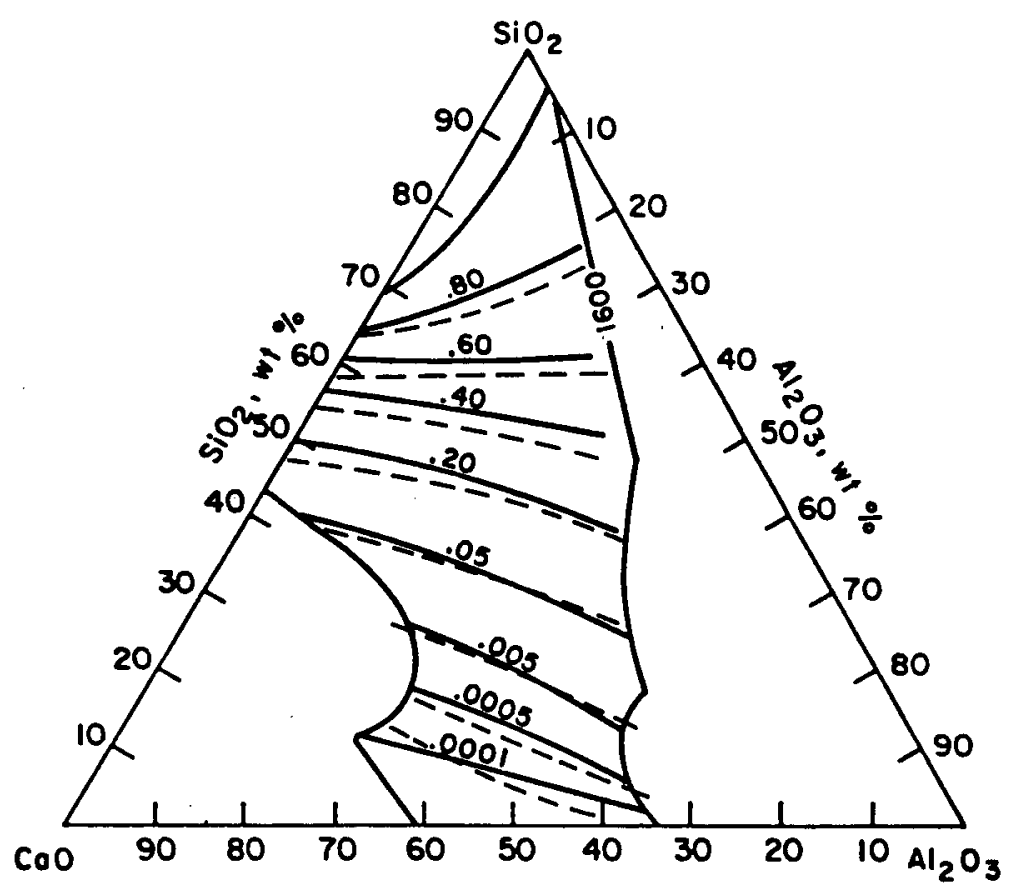

Fig. 40. Calculated Values of Activities in $\mathrm{SiO}_{2}-\mathrm{Al}_{2} \mathrm{O}_{3}-\mathrm{CaO}$ slags at $1600^{\circ} \mathrm{C}$ (dashed lines), with $\mathrm{aSiO}_{2}$ Superimposed on Fig. 37 .

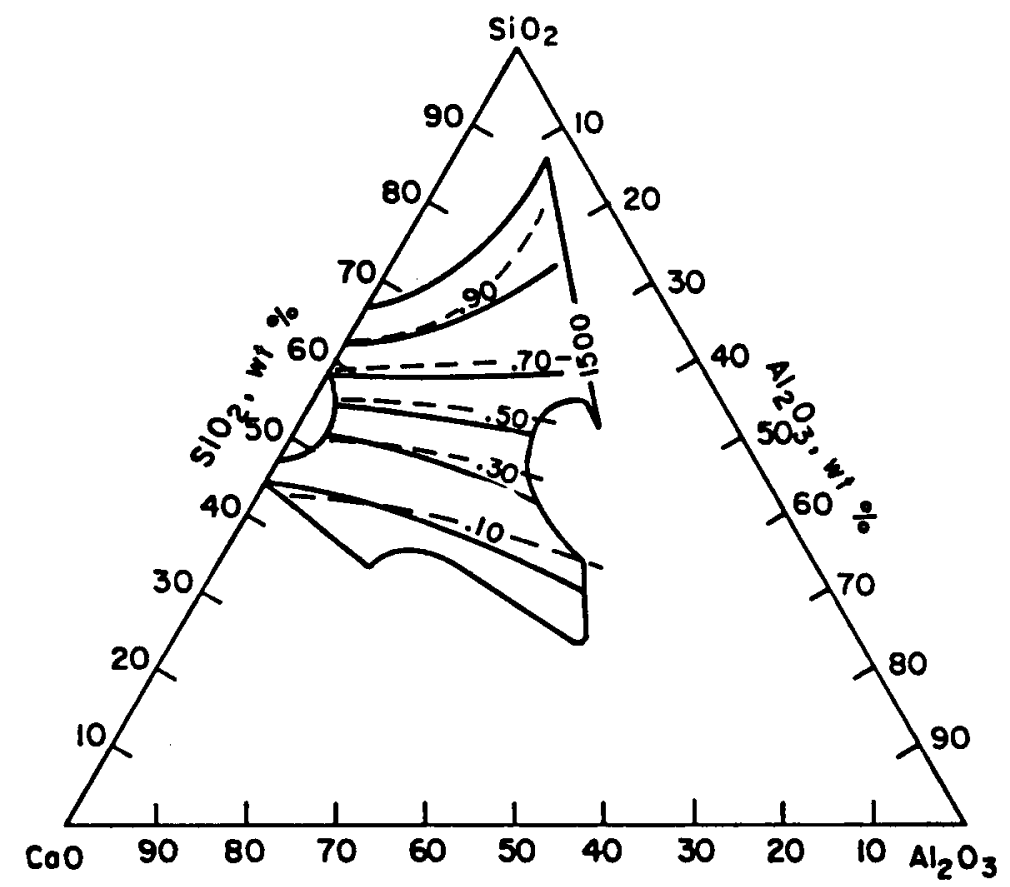

Fig. 41. Calculated Values of Activities in $\mathrm{SiO}_{2}-\mathrm{Al}_{2} \mathrm{O}_{3}-\mathrm{CaO}$ Slags at $1500^{\circ} \mathrm{C}$ (dashed lines), with ${ }^{S_{\mathrm{SiO}}} \mathrm{Super}_{2}$ imposed on Fig. 36. 


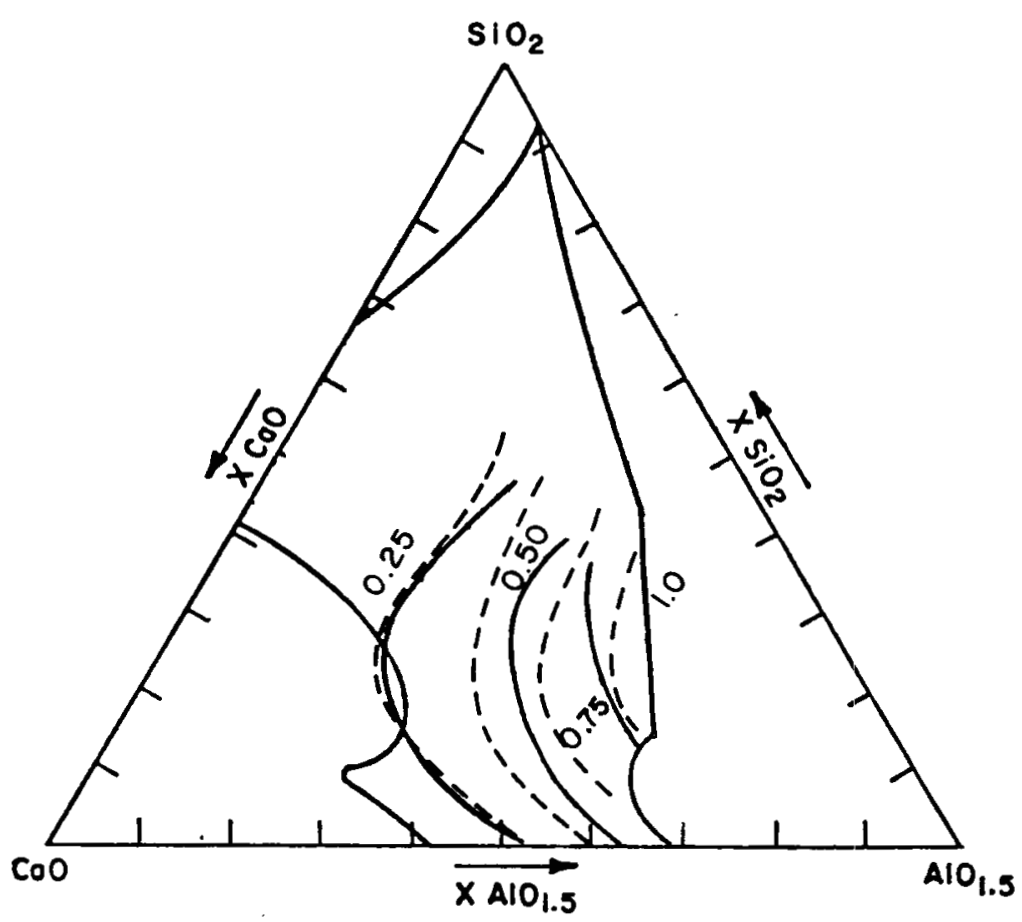

Fig. 42. Calculated Values of Activities in $\mathrm{SiO}_{2}-\mathrm{Al}_{2} \mathrm{O}_{3}-\mathrm{CaO}$ slags at $1600^{\circ} \mathrm{C}$ (dashed 1ines), with $\mathrm{a}_{\mathrm{A} 10_{1.5}}$ Superimposed on the Results of Ref. 47.

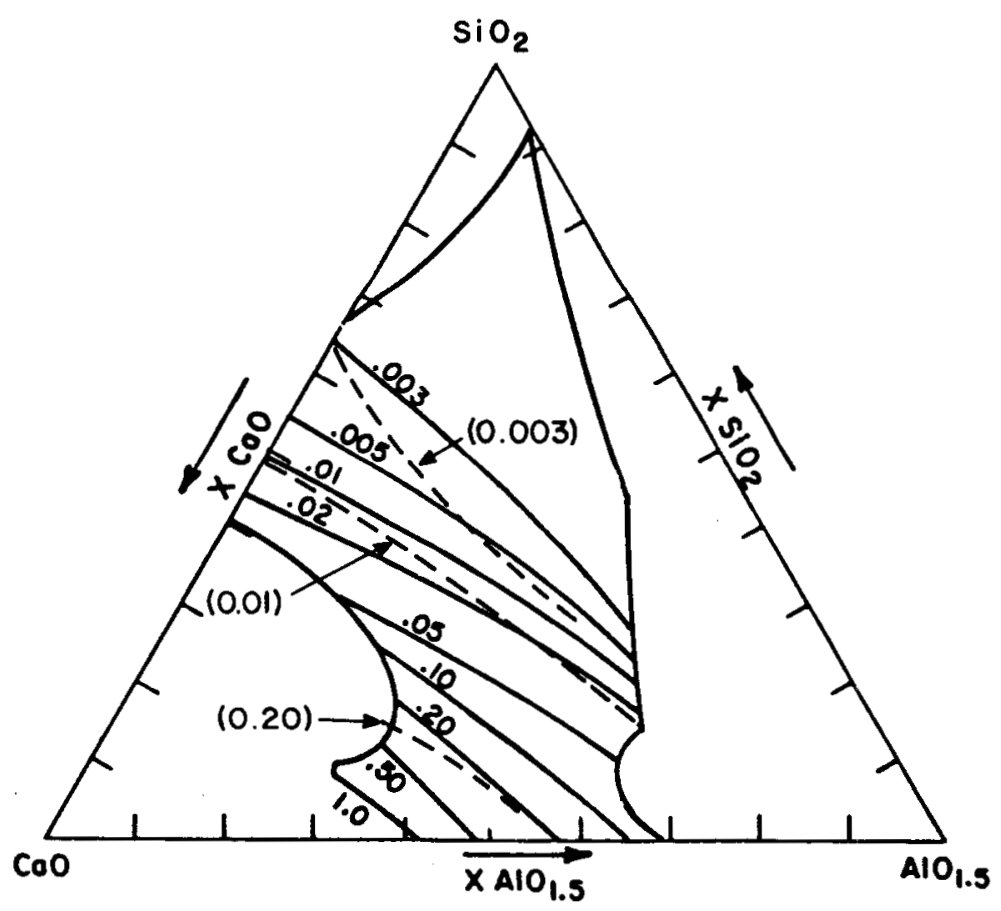

Fig. 43. Calculated Values of Activities in $\mathrm{SiO}_{2}-\mathrm{Al}_{2} \mathrm{O}_{3}-\mathrm{CaO}$ slags at $1600^{\circ} \mathrm{C}$ (dashed 1 ines), with a $\mathrm{CaO}$ Superimposed on Fig. 34. 


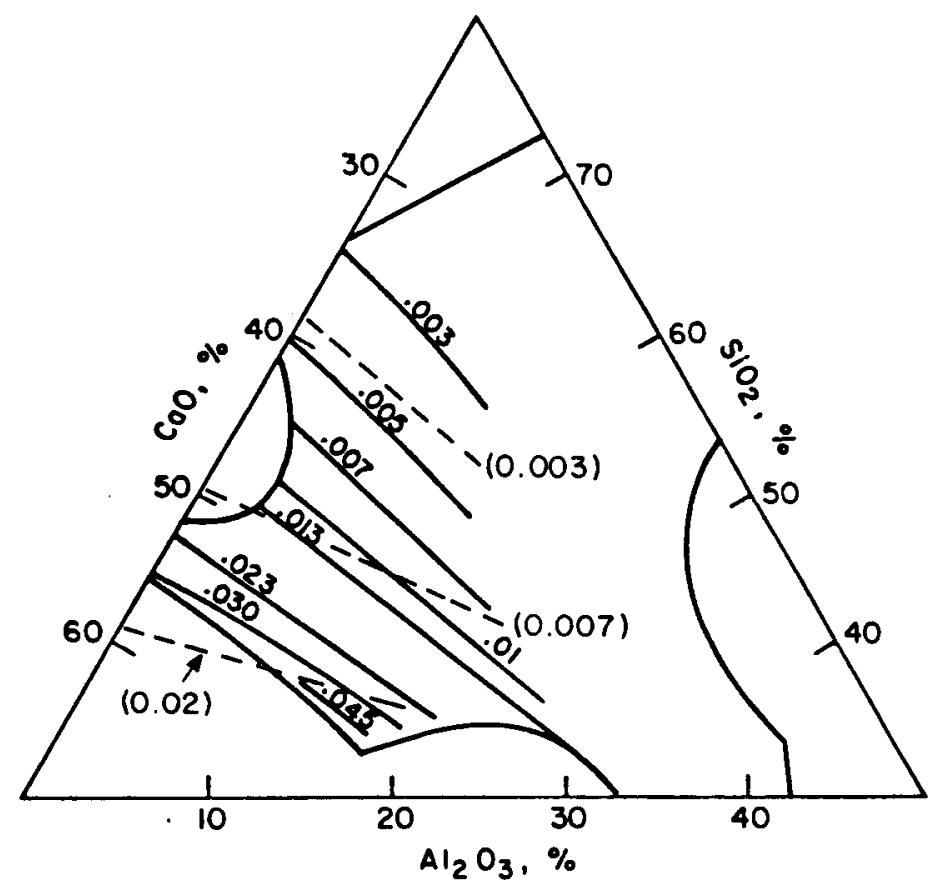

Fig. 44. Calculated Values of Activities in $\mathrm{SiO}_{2}-\mathrm{Al}_{2} \mathrm{O}_{3}-\mathrm{CaO}$ Slags at $1500^{\circ} \mathrm{C}$ (dashed lines), with a $\mathrm{CaO}$ Superimposed on Fig. 38 (solid lines).

In any case, the differences between the measurements of asio, of Rein and Chipman and of Kay and Taylor are considerably larger than the differences between our calculated results and the measurements of Kay and Taylor. We conclude that we have achieved a fit in this ternary system by using a total of 12 parameters ( 10 for the three binaries and two for the ternary excess term), which represent all the data well within the uncertainties in the measurements.

G. $\quad \mathrm{NaO}_{0.5}-\mathrm{CaO}-\mathrm{SiO}_{2}$

We utilized two kinds of data in our calculations for $\mathrm{NaO}_{0} .5-\mathrm{CaO}-\mathrm{SiO}_{2}$. The first is the silica liquidus measured by Shahid and Glasser 52 down to $1000^{\circ} \mathrm{C}$. The second source of data is the measurements of $\mathrm{aNaO}_{\mathrm{N}}$ by Neudorf and Eliliott at $1323 \mathrm{~K} .37$ Both data sets combined provide a good $\cdot 5$ representation of the concentration dependence of thermodynamic properties at high silica concentrations.

The only input parameters are the coefficients of the expressions for $\mathrm{W}$ for the $\mathrm{CaO}-\mathrm{SiO}_{2}$ and $\mathrm{NaO}_{0} .5^{-\mathrm{SiO}_{2}}$ systems. No data exist on the $\mathrm{NaO}_{0.5}-\mathrm{CaO}$ binary system, which will be assumed to be ideal, i.e., $W=0$. (Analogous molten salt systems usually have only relatively small negative deviations from ideal solution behavior.) The asymetric model (Eq. 39 with $\mathrm{SiO}_{2}$ as the odd component 1) was used to combine these expressions for $W$ to calculate the thermodynamic properties for the ternary system. The results were close 
enough to the measurements so that no ternary term had to be added. In Fig. 45 are plotted the measured and calculated silica liquidus temperatures. These two sets of curves agree within the experimental uncertainties except at $1600^{\circ} \mathrm{C}$ near the $\mathrm{Na}_{2} \mathrm{O}-\mathrm{SiO}_{2}$ binary where the calculated binary liquidus at high temperatures did not correspond to the measurements of $\mathrm{Kracek} .35$ (This point will be discussed later.)

In Fig. 46, we plot our calculated values, as well as the measured 37 values of $\log \mathrm{a}_{\mathrm{Na}_{2} \mathrm{O}}$ (which is twice $\log \mathrm{a}_{\mathrm{NaO}_{0.5}}$ ) at $-10,-9.5,-9.0$, and -8.5 . The first three of these calculated curves are in excellent correspondence with the measurements. The calculated curve of $\log a_{\mathrm{Na}_{2} \mathrm{O}}=-8.5$ deviates from the measurements by about 0.2 ( 0 r about 0.1 for $\log a_{\mathrm{NaO}}{ }_{5}$ ), which may be larger than the experimental precision. However, it should be noted that Neudorf and Elliott 37 found that the measurements in the ternary (which contained $\mathrm{CaO}$ ) "were less stable, less reproducible, and took longer times to come to steady values than was the case with the binary melts."

The correspondence between our calculations and the measurements in this ternary system is very good and appears to be accurate enough to serve as baseline information for a calculation of the quaternary system.

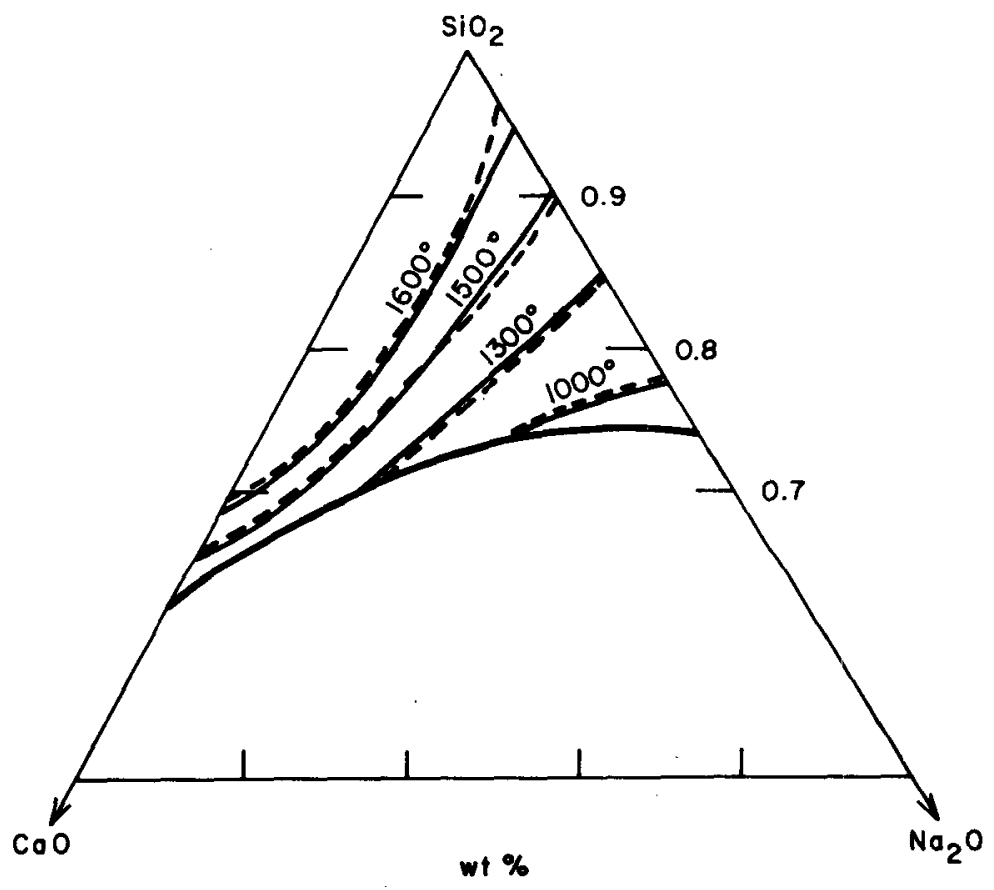

Fig. 45. Silica Liquidus Temperatures in the $\mathrm{CaO}-\mathrm{Na}_{2} \mathrm{O}-\mathrm{SiO}_{2}$ System. Solid lines represent measured values, and the dashed lines represent values calculated from our model. 


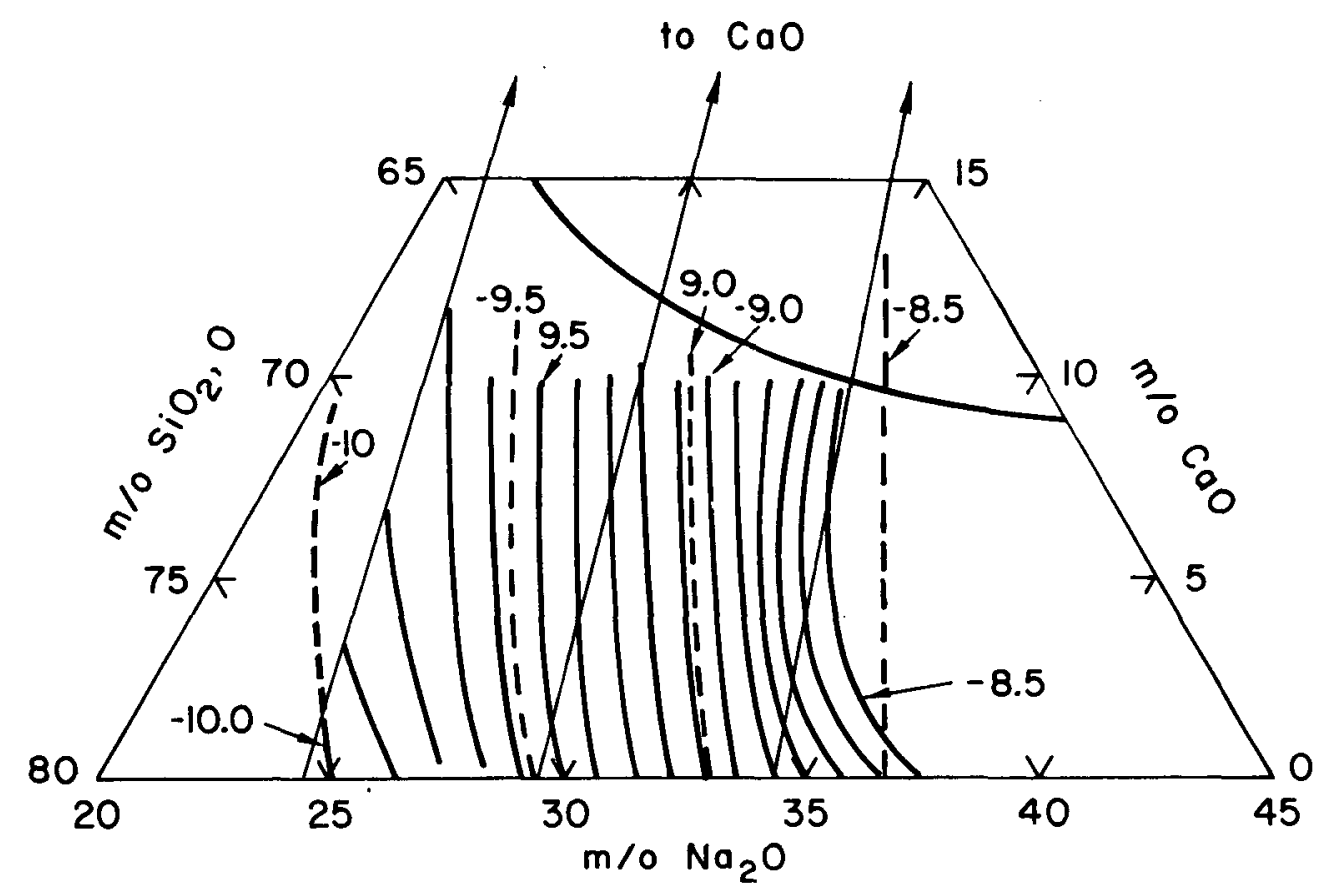

Fig. 46. Values of $\log _{10} \mathrm{a}_{\mathrm{Na}_{2} \mathrm{O}}$ as a Function of Composition in the $\mathrm{Na}_{2} \mathrm{O}-\mathrm{CaO}-\mathrm{SiO}_{2}$ Systern. Solid lines are values measured by Neudorf and Elliott, 37 dashed lines are calculated from the model.

H. $\quad \mathrm{NaO}_{0} .5^{-\mathrm{AlO}} 1.5-\mathrm{SiO}_{2}$

The data used for this system consist of recent and as-yet unpublished data on activities of $\mathrm{Na}_{2} \mathrm{O}, 53$ exhibited in Fig. 47 , the phase diagram, 20 and the free energy of formation of analbite 25 ( $\left.\mathrm{NaAlSi}_{3} \mathrm{O}_{8}\right)$. Using the data of Robie et al.25 at the melting point (1391K) and the enthalpies of fusion of the oxides, we obtain a standard free energy change for the reaction

$$
1 / 5 \mathrm{NaO}_{0.5}(\ell)+1 / 5 \mathrm{AlO}_{1.5}(\ell)+3 / 5 \mathrm{siO}_{2}(\ell)+\operatorname{analbite}(\ell)
$$

equal to $-10.6 \mathrm{kcal}$. The uncertainty in this value is probably about $\pm 1 \mathrm{kcal}$.

We performed calculations based on the symmetric (Eq. 37) and asymmetric (Eq. 39) interpolation techniques, with $\mathrm{SiO}_{2}$ as the asymmetric component. In both equations, with no ternary terms, we obtained good fits to the activity data, but $\Delta G^{\circ}$ for reaction 65 was only $-7.6 \mathrm{kcal}$. Consequently, we need to add negative ternary terms. 
Using the asymmetric approximation and adding the following expression to the total excess free energy of mixing

$$
\delta G^{E}=-70 \mathrm{X}_{\mathrm{NaO}_{0} .5} \mathrm{X}_{\mathrm{AlO}_{1.5}} \mathrm{X}_{\mathrm{SiO}_{2}}\left[1-\frac{1}{7\left(1-\mathrm{X}_{\mathrm{SiO}_{2}}\right)}\right]
$$

led to a value of $\Delta G^{\circ}$ for reaction 65 of $-9.9 \mathrm{kcal}$ and to values of the activities of $\mathrm{Na}_{2} \mathrm{O}$ plotted in Fig. 47. These are comparable to the values interpolated from the measurements of Young and Elliott.53 In addition, calculated values of the activities of $\mathrm{SiO}_{2}$ and $\mathrm{Al}_{2} \mathrm{O}_{3}$ are compared with estimated values of Young and Elliott in Figs. 48 and 49.

The absolute values of the activities of $\mathrm{Na}_{2} \mathrm{O}$ are consistent with the measurements, essentially within the experimental uncertainties. However, the concentration dependence of these activities could be better represented. We plan to refine calculations for this system. In any case, because of the relatively low $\mathrm{Al}_{2} \mathrm{O}_{3}$ contents of most slags, such a refinement would not have a very large effect on calculations of the volatilization of sodium since the absolute values of the activities of $\mathrm{Na}_{2} \mathrm{O}$ are reasonably well represented. The estimated activities of $\mathrm{SiO}_{2}$ and $\mathrm{Al}_{2} \mathrm{O}_{3}$ given by Young and Elliot are reasonably represented by our calculations within their relatively large uncertainties. 
A Albite $\quad \mathrm{Na}_{2} \mathrm{O} \cdot \mathrm{Al}_{2} \mathrm{O}_{3} \cdot 6 \mathrm{SiO}_{2}$ $\left.\begin{array}{l}\mathrm{N} \text { Nepheline } \\ \mathrm{C} \text { Carnegieite }\end{array}\right\} \mathrm{Na}_{2} \mathrm{O} \cdot \mathrm{Al}_{2} \mathrm{O}_{3} \cdot 2 \mathrm{SiO}_{2}$ H+1+t Solid Solution

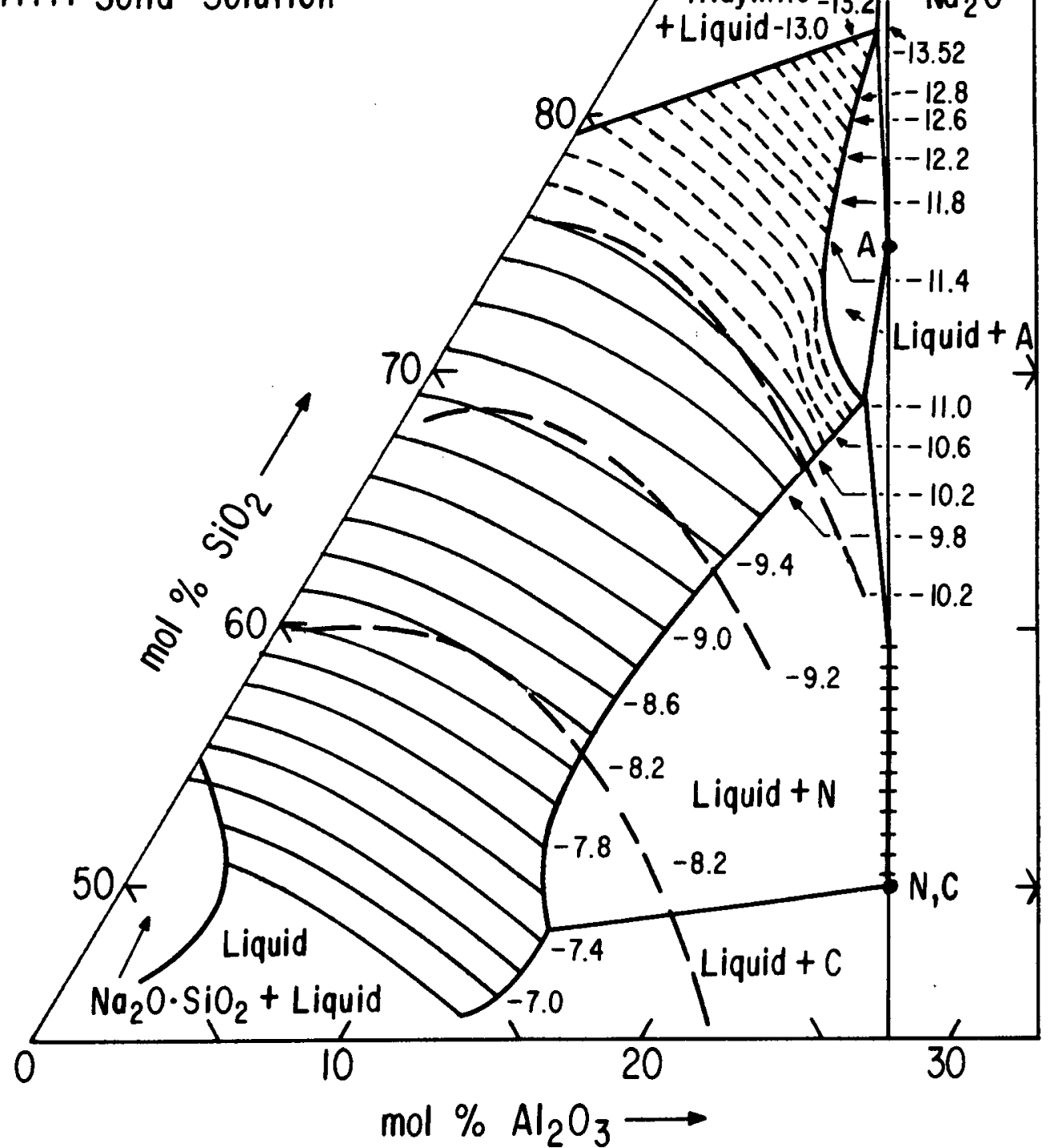

Fig. 47. Measured Values of $\log _{10} a_{\mathrm{Na}_{2} \mathrm{O}}$ (solid lines) in the $\mathrm{Na}_{2} \mathrm{O}-\mathrm{Al}_{2} \mathrm{O}_{3}-\mathrm{SiO}_{2}$ System. Short dashed lines are extrapolated from measurements of Young and Elliott, 53 and long dashed lines are calculated from the model. 


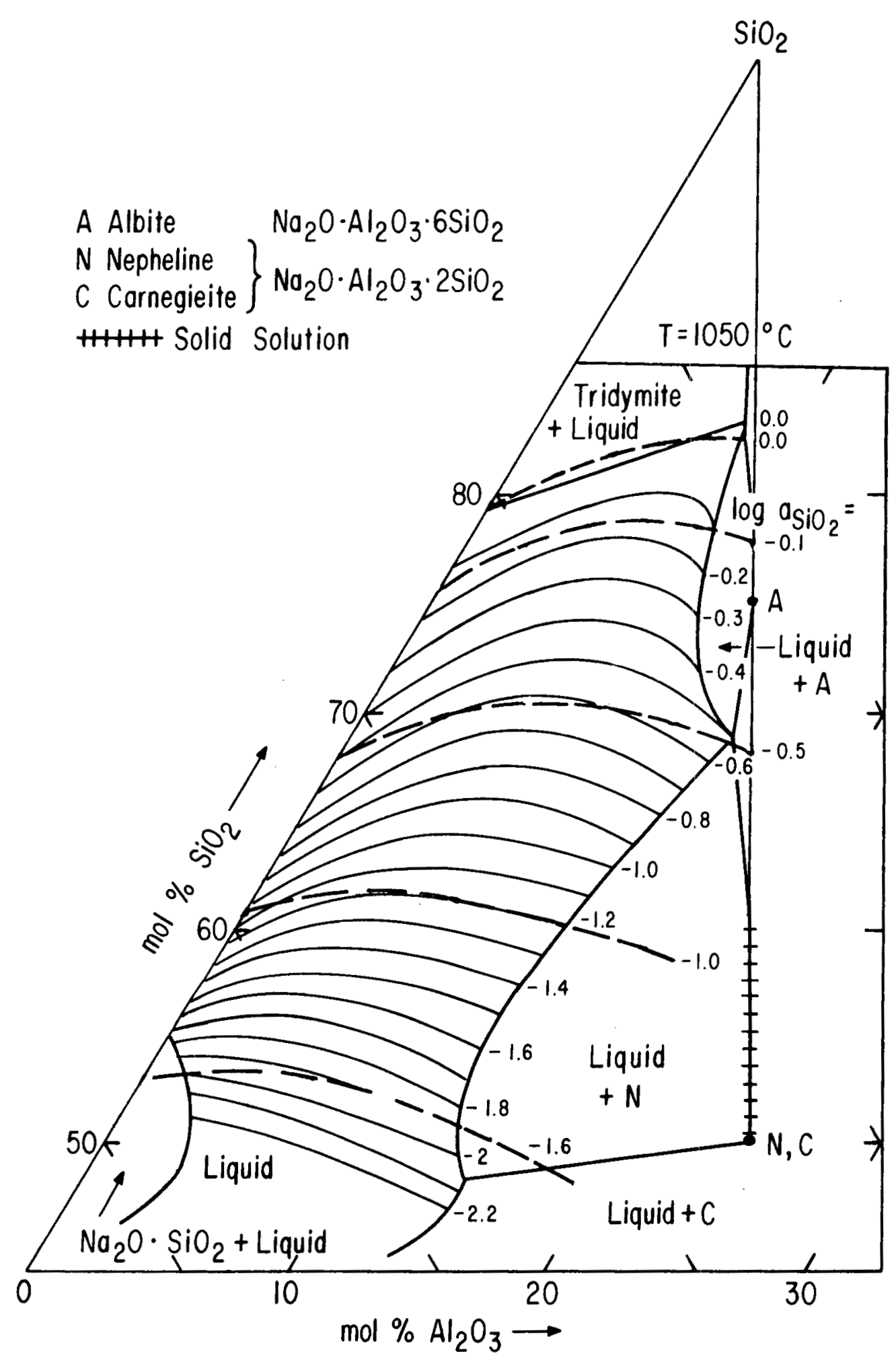

Fig. 48. Calculated Values of $\log _{10} \mathrm{a}_{\mathrm{SiO}}$ in the $\mathrm{Na}_{2} \mathrm{O}-\mathrm{Al}_{2} \mathrm{O}_{3}-\mathrm{SiO}_{2}$ System. Solid lines are calculated from the Measurements of Young and Elliott 53 using the Gibbs-Duhem equation; dashed lines are calculated from our model. 


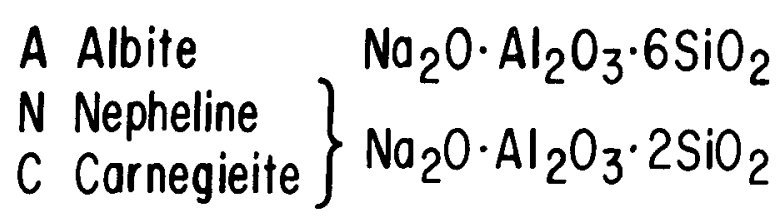
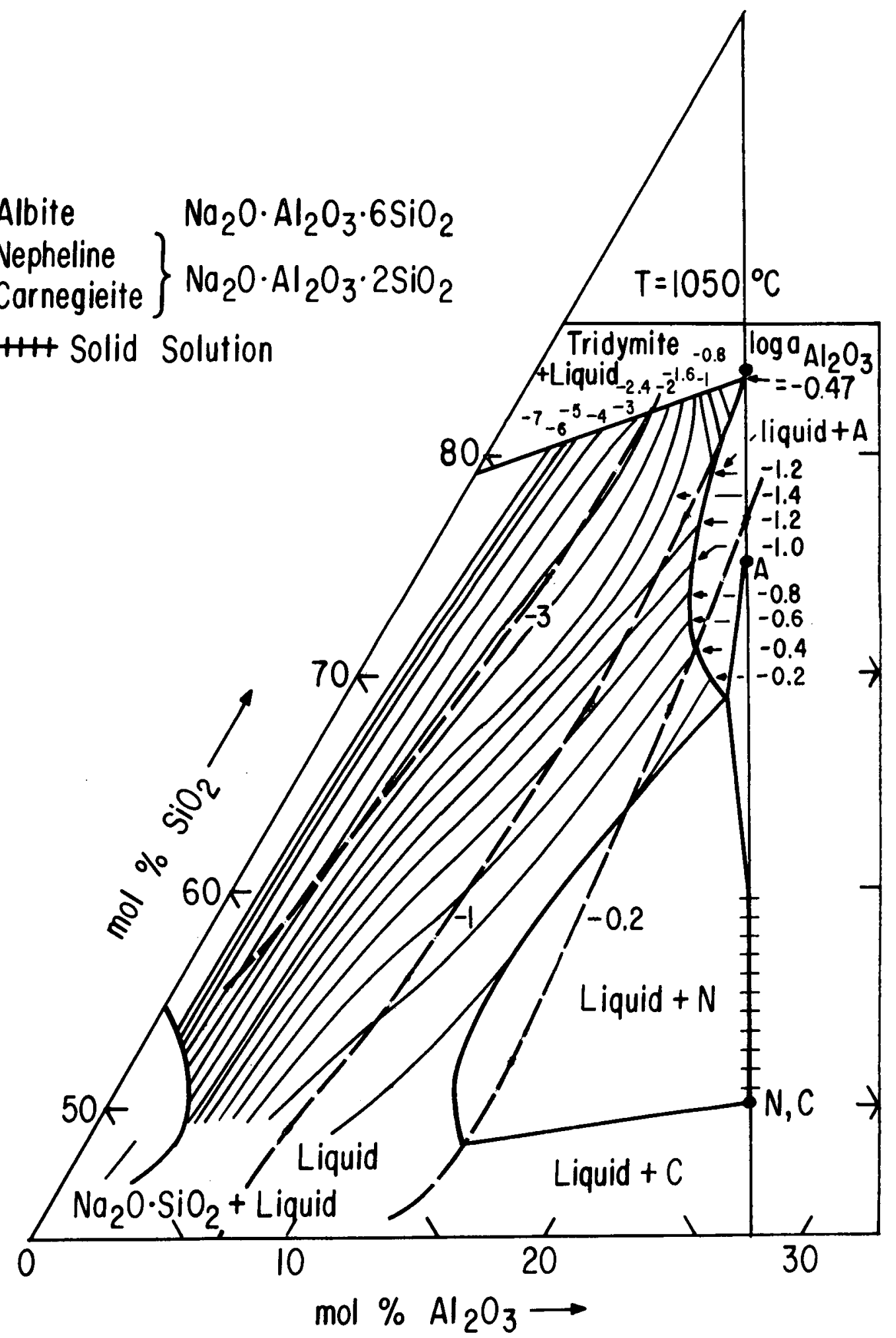

Fig. 49. Calculated Values of $\log _{10} \mathrm{a}_{\mathrm{Al}_{2} \mathrm{O}_{3}}$ in the $\mathrm{Na}_{2} \mathrm{O}-\mathrm{Al}_{2} \mathrm{O}_{3}-\mathrm{SiO}_{2}$ system. Solid lines are calculated from the Measurements of Young and Elliott 53 using the Gibbs-Duhem equation; dashed lines are calculated from our model. 


\section{THE QUATERNARY SYSTEM $\left(\mathrm{Na}_{2} \mathrm{O}-\mathrm{CaO}-\mathrm{Al}_{2} \mathrm{O}_{3}-\mathrm{SiO}_{2}\right)$}

Ten equations are to be solved in a quaternary system--six with the form of Eq. 36, and four with the form of Eq. 35 with $i$ and/or $j$ having the values $1,2,3$, and 4 . Since there is no exact solution, a complex iterative numerical procedure was used to solve the equations.

In addition, we need a method to approximate the parameters $W_{i j}$ and $S_{i j}$ in the quaternary. In the composition diagram for the ternary systems, the symmetric approximation defines lines of constant values of $y_{j} /\left(y_{i}+y_{j}\right)$, which define compositions where $W_{i j}$ and $S_{i j}$ are constant; in the asymmetric approximation, one component is chosen to be "different" (component 1) and the values of $W_{12}, s_{12}, W_{13}$, and $s_{13}$ are defined at constant $y_{1}$, while $W_{23}$ and $s_{23}$ are defined to be constant at constant $y_{3} /\left(y_{2}+y_{3}\right)$. In the three-dimensional composition diagram for the quaternary system, the plane in which $w_{i j}$ and $s_{i j}$ are constant is defined by the two intersecting 1 ines defining constant $W_{i j}$ and $S_{i j}$ in the two subsidiary ternary systems which contain the components $i$ and $j$.

We also have to define a self-consistent means for incorporating the ternary interaction terms into the calculation for the quaternary. For example, we had ternary terms of the form $\mathrm{AX}_{1} \mathrm{X}_{2} \mathrm{X}_{3}$ and $\mathrm{BX}_{1} \mathrm{X}_{2} \mathrm{X}_{3} /\left(1-\mathrm{X}_{1}\right)$. In going into the quaternary system, the term $\mathrm{AX}_{1} \mathrm{X}_{2} \mathrm{X}_{3}$ can be used in the same form, remembering that this term is also equal to $A\left[x_{1} X_{2} X_{3} /\left(x_{1}+x_{2}+x_{3}\right)^{3}\right]\left(1-x_{4}\right)^{3}$, which, for fixed $x_{1} / x_{2} / x_{3}$ ratios, decreases with an increase in $x_{4}$. similarly, the term $B X_{1} X_{2} X_{3} /\left(1-X_{1}\right)$ can be written as $B\left[X_{1} X_{2} X_{3} /\left(X_{1}+X_{2}+x_{3}\right) 3 /\left(1-\left(x_{1} /\right.\right.\right.$ $\left.\left.\left(x_{1}+X_{2}+X_{3}\right)\right)\right]\left[1-X_{4}\right]^{3}$ or more succinctly as $B\left[X_{1} X_{2} X_{3}\left(1-x_{4}\right) /\left(X_{2}+X_{3}\right)\right]$. Consequently, the total free energy of mixing of the quaternary is given by:

$$
\begin{aligned}
& \Delta G_{m}=R T \sum\left(x_{i} \ln x_{i}+\frac{A_{i} Z}{2} \ln \frac{x_{i i}}{y_{i}^{2}}\right)-35 x_{S i} x_{A 1} x_{C a}-70 x_{N a} x_{A 1} x_{C a} \\
& -25 \frac{\mathrm{X}_{\mathrm{Si}} \mathrm{X}_{\mathrm{Al}} \mathrm{X}_{\mathrm{Ca}}\left(1-\mathrm{X}_{\mathrm{Na}}\right)}{\mathrm{X}_{\mathrm{A} 1}+\mathrm{X}_{\mathrm{Ca}}}-10 \frac{\mathrm{X}_{\mathrm{Si}} \mathrm{X}_{\mathrm{Al}} \mathrm{X}_{\mathrm{Na}}\left(1-\mathrm{X}_{\mathrm{Ca}}\right)}{\mathrm{X}_{\mathrm{A} 1}+\mathrm{X}_{\mathrm{Na}}}
\end{aligned}
$$

where the parameters $A_{i}$ are the same as the parameters $a, b .$. defined earlier. The partial molar free energies of solution of any component are obtained by differentiating. The resultant equations are rather long expressions. To illustrate our results, we calculated $\log _{10}{ }^{a_{\mathrm{Na}} \mathrm{O}}$ ( 1 iquid as standard state) at various compositions and $1600^{\circ} \mathrm{C}$. These are exhrbited in Figs. 50 and 51 . Our equations permit us to perform such calculations in any other regime of temperature and composition and can be displayed in any reasonable format. In Fig. 50, we plot $\log _{10} a_{\mathrm{Na}_{2} \mathrm{O}}$ ( 1 iquid as standard state) vs. $\mathrm{X}_{\mathrm{Na}}$ at $1600^{\circ} \mathrm{C}$ for a ratio $\mathrm{X}_{\mathrm{Ca}} / \mathrm{x}_{\mathrm{Al}}=1$ and for six values of $\mathrm{X}_{\mathrm{Si}} /\left(1-\mathrm{X}_{\mathrm{Na}}\right)$. In $\mathrm{Fig}$. 51, we plot $\log _{10} a_{\mathrm{Na}_{2} \mathrm{O}}$ (liquid as standard state) vs $\mathrm{X}_{\mathrm{Ca}} /\left(\mathrm{X}_{\mathrm{A} 1}+\mathrm{X}_{\mathrm{Ca}}\right)$ at $1600^{\circ} \mathrm{C}$ for $X_{\mathrm{Na}}=0.02$ for four values of $\mathrm{X}_{\mathrm{Si}} /\left(1-\mathrm{X}_{\mathrm{Na}}\right)$. We define $\mathrm{X}_{i}$ as the cation fraction of the i'th cation. 


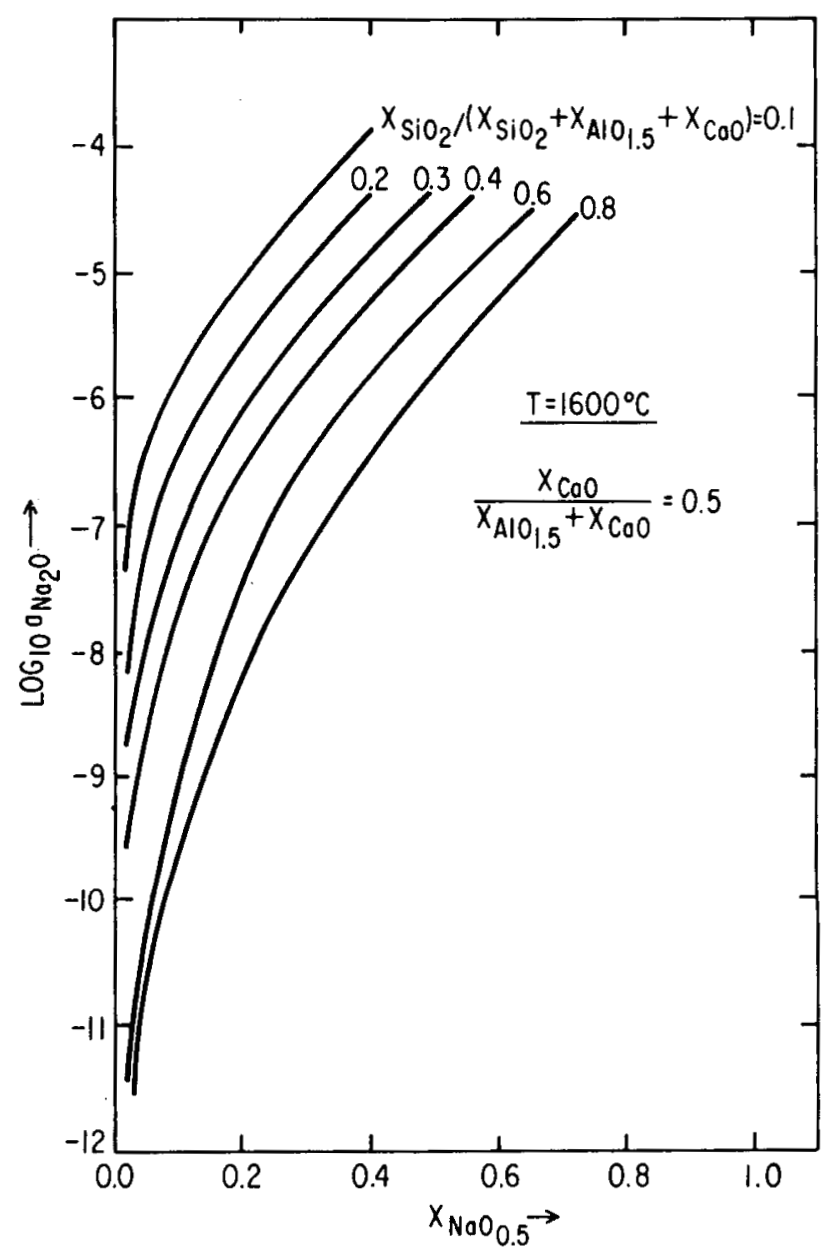

Fig. 50. Values of $\log _{10} a_{\mathrm{Na}_{2} \mathrm{O}}$ Calculated from the Model and Plotted as a Function of $\mathrm{X}_{\mathrm{NaO}} 0.5$ for $\left(\mathrm{X}_{\mathrm{CaO}}\right.$ ) $\left.\mathrm{x}_{\mathrm{AlO}}{ }_{1.5}\right)=1$ at Several values of $\mathrm{x}_{\mathrm{SiO}_{2}} \mathrm{i}\left(\mathrm{x}_{\mathrm{SiO}_{2}}+\mathrm{x}_{\mathrm{AlO}_{1.5}}+\mathrm{x}_{\mathrm{CaO}}\right)$ in the Quaternary System, $\mathrm{Na}_{2} \mathrm{O}-\mathrm{CaO}-$ $\mathrm{Al}_{2} \mathrm{O}_{3}-\mathrm{SiO}_{2}$. No quaternary data were used in the calculation, as would be necessary for reliability.

These results are based solely on data on the subsidiary binary and ternary systems. Because of the general lack of accurate data (especially on the activities of $\mathrm{Na}_{2} \mathrm{O}$ ) in the quaternary system (i.e., data which is consistent with the data we used), we cannot refine this analysis by the incorporation of a quaternary interaction term. If a few data points in the quaternary become available, we can readily refine our results and better define their reliability. For example, if measurements are obtained of activities of $\mathrm{Na}_{2} \mathrm{O}$ as a function of temperature at a fixed mole fraction of $\mathrm{X}_{\mathrm{Na}}=0.03$ for about five well-spaced compositions of the other three components, this should be adequate to define the quaternary interaction term. 


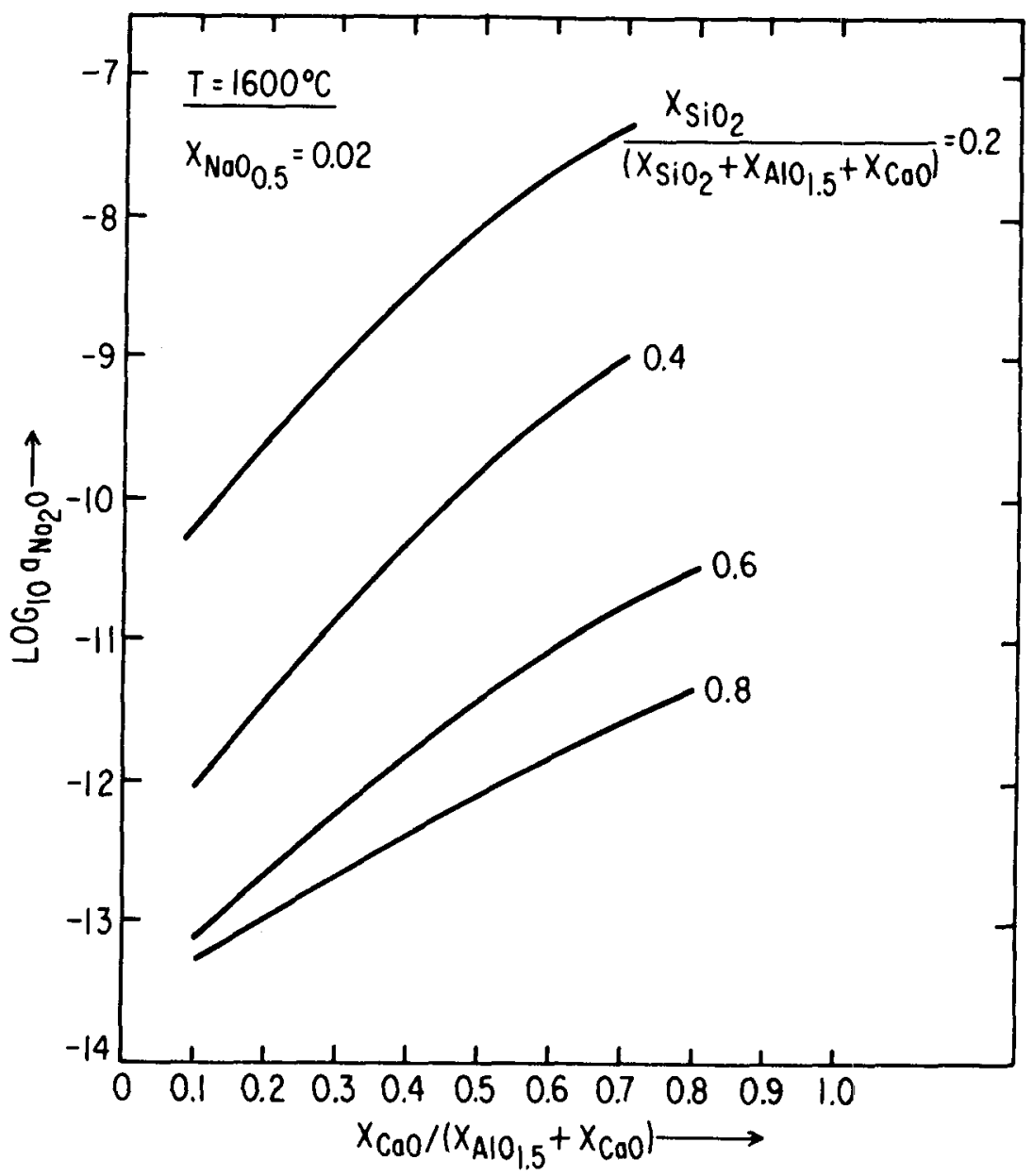

Fig. 51. Values of $\log _{10} a_{\mathrm{Na}_{2} \mathrm{O} \text { Calculated }}$ from the Model and Plotted as a Function of $\mathrm{X}_{\mathrm{CaO}} /\left(\mathrm{X}_{\mathrm{AlO}_{1.5}}+\mathrm{X}_{\mathrm{CaO}}\right)$ for $\mathrm{x}_{\mathrm{NaO}} \mathrm{O}_{5}=0.02$ at Several Values of $\mathrm{x}_{\mathrm{SiO}_{2}} /\left(\mathrm{x}_{\mathrm{SiO}_{2}}+\mathrm{x}_{\mathrm{AlO}_{1.5}}+\mathrm{x}_{\mathrm{CaO}}\right)$ in the Quaternary System, $\mathrm{Na}_{2} \mathrm{O}-\mathrm{CaO}-$ $\mathrm{Al}_{2} \mathrm{O}_{3}-\mathrm{SiO}_{2}$. No quaternary data were used in the calculation, as would be necessary for reliability. 
Our results represent a unique accomplishment. (1) We have been able to accurately represent a large amount of data on ordered binary systems at different compositions and temperatures in a self-consistent manner. This representation used a small number of parameters, and for systems such as $\mathrm{CaO}-\mathrm{SiO}_{2}$ and $\mathrm{CaO}-\mathrm{Al}_{2} \mathrm{O}_{3}$, it is good enough for quite accurate interpolations and extrapolations outside the range of data. (2) We have been able to obtain good representations of available data on the ternary systems $\mathrm{CaO}-\mathrm{Al}_{2} \mathrm{O}_{3}-\mathrm{SiO}_{2}$, $\mathrm{Na}_{2} \mathrm{O}-\mathrm{CaO}-\mathrm{SiO}_{2}$ and $\mathrm{Na}_{2} \mathrm{O}-\mathrm{Al}_{2} \mathrm{O}_{3}-\mathrm{SiO}_{2}$. (3) We have been able to set up the complex computer program necessary to perform calculations in quaternary systems and to utilize it to deduce properties of the quaternary system, $\mathrm{Na}_{2} \mathrm{O}-\mathrm{CaO}-\mathrm{Al}_{2} \mathrm{O}_{3}-\mathrm{SiO}_{2}$. The reliability and usefulness of the results will be considerably improved after a few key measurements in the quaternary system are made which will enable one to refine the calculations.

Data for some of the binaries $\left(\mathrm{Na}_{2} \mathrm{O}-\mathrm{Al}_{2} \mathrm{O}_{3}, \mathrm{Na}_{2} \mathrm{O}-\mathrm{SiO}_{2}\right.$ and $\left.\mathrm{Al}_{2} \mathrm{O}_{3}-\mathrm{SiO}_{2}\right)$ are either incomplete or not self-consistent. However, uncertainties in the data on $\mathrm{Na}_{2} \mathrm{O}-\mathrm{Al}_{2} \mathrm{O}_{3}$ and $\mathrm{Al}_{2} \mathrm{O}_{3}-\mathrm{SiO}_{2}$ may not have a very large influence for typical slags encountered in coal. The lack of a complete set of selfconsistent data is the single most important weakness in our calculation. Since we are most interested in the $\mathrm{Na}_{2} \mathrm{O}$ constituent, a reliable set of data on the activities of $\mathrm{Na}_{2} \mathrm{O}$ in all of the binaries, ternaries, and the quaternary from a single reliable laboratory would probably make an important contribution to the understanding of alkali volatilities.

A subtle problem which has not previously been considered arises in any analysis of binary systems such as $\mathrm{NaO}_{0}, 5^{-\mathrm{SiO}_{2}}$. According to models for silicates, the addition of $\mathrm{Na}_{2} \mathrm{O}$ to $\mathrm{SiO}_{2}$ breaks a Si-O-Si bond to form a doubly charged [ $\mathrm{Si}-0 \cdots \mathrm{O}^{-\mathrm{Si}}$ ] configuration (represented by $\mathrm{C}^{2-}$ ) by the addition of oxide ion to a silicon. The double negative charge of this configuration attracts the $\mathrm{Na}^{+}$ions, which equilibrate according to the reactions

$$
\begin{aligned}
& \mathrm{Na}^{+}+\mathrm{C}^{2-}+\mathrm{NaC}^{-} \\
& \mathrm{Na}^{+}+\mathrm{NaC}^{-}+\mathrm{Na}_{2} \mathrm{C}
\end{aligned}
$$

Thus, in extremely dilute solutions of $\mathrm{Na}_{2} \mathrm{O}$, each molecule produces three independent entities, $2 \mathrm{Na}^{+}+\mathrm{C}^{2-}$. (This is analogous to, but quite different from a solution of $\mathrm{H}_{2} \mathrm{SO}_{4}$ in water producing three independent particles.) With an increase in concentration (albeit, still dilute), these independent solute species associate and the number of independent particles decreases perhaps to as few as one. In our calculations, the ideal term we employ implicitly assumes that there are two independent particles at high dilution. Thus, if there is considerable association so that the effective number of particles is less than 2, one would expect the real system to have higher silica activities and liquidus temperatures in dilute solutions than had been calculated. This is consistent with the discrepancy in this binary system we discussed in section III.C for the liquidus temperature of silica above $1470^{\circ} \mathrm{C}$. A similar problem is possible for $\mathrm{CaO}^{-\mathrm{SiO}_{2}}$ mixtures. However, in this case, the as sociation between $\mathrm{Ca}^{2+}$ and $\mathrm{C}^{2-}$ is between two divalent entities 
and is consequently much stronger. Thus, there will be a strong tendency to have only one entity, $\mathrm{CaC}$, even in dilute solution. For the $\mathrm{CaO}-\mathrm{SiO}_{2}$ system, the ideal term implicitly assumes one entity per CaO molecule and is thus intrinsically capable of fitting the data.

If this speculation is correct, one result is that the concentration dependence of activities upon composition will have more curvature than would otherwise be expected. The curvature is in a direction which should enhance the possibility of miscibility gaps. Consequently, this effect is a possible fundamental reason for the appearance of miscibility gaps (or of incipient miscibility gaps) in many silicate systems. We plan a deeper study of this problem.

We have been behind schedule, largely because of difficulties arising from the lack of reliable data, but we hope to complete the analyses of at least two more quaternary systems in FY 1983.

In any case, we have made a unique accomplishment in our analyses of silicate systems and have produced a set of equations and parameters which can be used to calculate the activities of components in the quaternary system, $\mathrm{Na}_{2} \mathrm{O}-\mathrm{CaO}-\mathrm{Al}_{2} \mathrm{O}_{3}-\mathrm{SiO}_{2}$. The reliability of these equations for three of the subsidiary ternaries $\left(\mathrm{Na}_{2} \mathrm{O}-\mathrm{Al}_{2} \mathrm{O}_{3}-\mathrm{SiO}_{2}, \mathrm{Na}_{2} \mathrm{O}-\mathrm{CaO}-\mathrm{SiO}_{2}\right.$, and $\mathrm{CaO}-\mathrm{Al}_{2} \mathrm{O}_{3}-\mathrm{SiO}_{2}$ ) appears to be reasonably good, and with only a small amount of data, a reliable representation of the quaternary is possible. Our techniques and results should prove to be technologically useful for deducing the temperature- and concentration-dependence of activities and volatilities of components such as $\mathrm{Na}_{2} \mathrm{O}$ in complex slag mixtures.

\section{ACKNOWLEDGMENTS}

The authors acknowledge the support of the U.S. Department of Energy, Morgantown Energy Technology Center, and the continued encouragement of Dr. V. Kothari of METC. 


\section{RE FERENCES}

1. P. L. Lin and A. D. Pelton, Metall. Trans. 10B, 667-676 (1979).

2. C. R. Masson, I. B. Smith, and S. G. Whiteway, Can. J. Chem. 48, 14561464 (1977); Proc. 11th International Congress on Glass, J. Gotz, Ed., Vo 1. 1, pp.3-41, Prague (1977).

3. D. R. Gaske11, Metal1. Trans. 8B, 131-145 (1977).

4. C. J. B. Fincham and F. D. Richardson, Proc. Roy. Soc. 223, 40 (1954).

5. G. W. Toop and C. S. Samis, Trans. TMS-AIME 224, 878-887 (1962).

6. M. Blander, Thermodynamic Properties of Molten Salt Solutions, Molten Salt Chemistry, M. Blander, Ed., Interscience, N.Y., p. 135 (1964).

7. M. Temkin, Acta Physicochim., URSS 20, 411 (1945).

8. H. Flood and W. J., Knapp, J. Am. Ceram. Soc. 46, 61 (1963).

9. M.-L. Saboungi and M. Blander, J. Chem. Phys. 63, 212-220 (1975).

10. I. Eliezer, N. Eliezer, R. A. Howald, and M. C. Verwolf, CALPHAD $\underline{3}$, $1-8$ (1979).

11. E. A. Guggenheim, Mixtures, Oxford Univ. Press, London (1952).

12. J. H. Hildebrand and R. L. Scott, The Solubility of Non-Electrolytes, Reinhold, N.Y. (1950).

13. M. Blander, Thermodynamic Properties of Molten Salt Solutions, Molten Salt Chemistry, M. Blander, Ed., Interscience, N.Y., pp. 150-151 (1964).

14. M.-L. Saboungi and M. Blander, J. Am. Ceram. Soc. 58, 1-7 (1975).

15. M. Blander and M.-L. Saboungi, Metal1. Trans. 10B, 613-622 (1979).

16. P. L. Lin, A. D. Pelton, and C. W. Bale, CALPHAD 44, 47-60 (1980).

17. P. L. Lin, A. D. Pelton, and C. W. Bale, J. Am. Ceram. Soc. 62, 414-422 (1979).

18. I. Barin and 0 . Knacke, Thermochemical Properties of Substances, Springer-Verlag, Berlin (1973); I. Barin, 0. Knacke, and O. Kubaschewski, Thermochemical Properties of Substances--Supplement, Springer-Verlag, Berlin (1977).

19. D. R. Stull and H. Prophet, JANAF Thermochemical Tables, 2nd Ed., NSRDS-NBS37, Supt. of Documents, Washington, D. C. (1971) and Supplements. 
20. E. M. Levin, C. R. Robbins, and H. F. McMurdie, Phase Diagrams for Ceramists, Am. Ceram. Soc., Columbus, Ohio (1964); Supplement, (1969); E. M. Levin and H. F. McMurdie, Supplement (1975).

21. J. F. Elliott and M. Gleiser, Thermochemistry for Steelmaking, AddisonWesley Publishing Co., Inc., Reading, Mass. (1960).

22. B. Phillips and A. Muan, J. Am. Ceram. Soc. 42, 414 (1959).

23. W. Gutt, Manufacture of Portland Cement from Phosphate Raw Materials, Paper CP90/68, p. 5 (1968), Publications Officer, Building Research Station, Bucknalls Lane, Garston, Watford, Herts., England.

24. Ya. I. O1'shanskii, Dokl. Akad. Nauk. SSR 76, 94 (1951).

25. R. A. Robie, B. S. Hemingway, and J. R. Fisher, Thermodynamic Properties of Minerals and Related Substances at $298.15 \mathrm{~K}$ and $\mathrm{I}$ Bar Pressure and at Higher Temperatures, Geologic Survey Bulletin 1452, U. S. Govt. Printing Office, Washington, D.C. (1978).

26. C. E. Wicks and F. E. Block, Thermodynamic Properties of 65 Elements. Their Oxides, Halides, Carbides, and Nitrides, U. S. Bureau of Mines Bull. 605 , U. S. Govt. Printing of fice, Washington, D. C. (1963).

27. T. Chart, High Temp. High Pressures 5, 241 (1973); Metal Sci. 8 , 344 $(1974) ; \underline{9}, 504$ (1975).

28. J. D. Tewhey and P. C. Hess, Phys. Chem. Glasses 20, 41-53 (1979).

29. R. A. Sharma and F. D. Richardson, J. Iron Steel Inst. 200, 373 (1962); 198,308 (1961).

30. R. H. Rein and J. Chipman, Trans. AIME 233, 415-425 (1965).

31. P. J. Spencer, The Thermodynamic Properties of Silicates, National Physical Laboratory Report Chem. 21 (1973).

32. R. W. Nurse, J. H. Welch, and A. J. Majumdar, Trans. Br. Ceram. Soc. 64, 409-418 (1965).

33. M. Allibert, C. Chatillon, K. T. Jacob, and R. Lourtau, J. Am. Ceram. Soc. 64, 307-314 (1981).

34. A. K. Charterjee and G. I. Zhmoidin, J. Mater. Sci. 7, 93 (1972).

35. F. C. Kracek, J. Phys. Chem. 34, 1588 (1930); J. Am. Chem. Soc. 61, 2869 (1939); J. Am. Chem. Soc. 52, 1436 (1930).

36. J. Williamson and F. P. Glasser, Science 148, 1589 (1965).

37. D. A. Neudorf and J. F. E1liott, Metall. Trans. 11B, 607 (1980). 
38. M. Rolin and P. H. Thanh, Rev. Int. Hautes Temp. Refract. $\underline{2}, 178$ (1965).

39. R. C. DeVries and W. L. Roth, J. Am. Ceram. Soc. 52, 367 (1969).

40. Y. Le Cars, J. Théry, and R. Collongues, "Domaine D'Existence et Stabilité des Alumines $B$ and $\mathrm{B}^{\prime \prime}$ dans le système $\mathrm{Al}_{2} \mathrm{O}_{3}-\mathrm{Na}_{2} \mathrm{O}$.

Étude par Rayons X et Microscopie Electronique," Rev. Int. Hautes

Temp. Refract. 9, 153-160, Masson S. A., Paris (1972).

41. A. Dubreuil, M. Malenfant, and A. D. Pelton, J. Electrochem. Soc. 128, 2006 (1981).

42. A. Staronka, H. Pham, and M. Rolin, "Étude du Système Silice-Alumine par la Méthode des Courbes de Refroidissement," Rev. Int. Hautes Temp. Refract. 5, 112, Masson S. A., Paris (1968).

43. S. Aramaki and R. Roy, J. Am. Ceram. Soc. 42, 644 (1959); 45, 239 (1962).

44. J. W. We $1 \mathrm{ch}$, Nature 186, 546 (1960).

45. T. Horibe and S. Kuwabara, Bul1. Chem. Soc. Japan 40, 980 (1967).

46. J. F. MacDowe 11 and G. H. Beall, J. Am. Ceram. Soc. 52, 24 (1969).

47. R. H. Rein and J. Chipman, Trans. AIME 227, 1193 (1963); see also Ref. 30.

48. D. A. R. Kay and J. Taylor, Trans. Faraday Soc. 56, 1372 (1960).

49. C. M. Jantzen, D. Schwahn, J. Schelten, and H. Herman, Phys. Chem. Glasses 22 , $122(1981)$.

50. M. R. Kalyanram, T. G. MacFarlane, and H. Be1l, J. Iron Steel Inst. $\underline{58}$, 195 (1960).

51. I. A. Aksay and J. A. Pask, J. Am. Ceram. Soc. 58, 507 (1975).

52. K. A. Shahid and F. P. Glasser, Phys. Chem. Glasses 2, 50 (1971).

53. D. Young and J. F. E1liott, Massachusetts Institute of Technology, private communication to A. G. Pelton and M. Blander (1982). 